\title{
MIXED SURFACTANT SYSTEMS FOR ENHANCED OIL RECOVERY
}

\author{
Topical Report \\ By \\ F. M. Llave \\ B. L. Gall \\ L. A. Noll
}

December 1990

Work Performed Under Cooperative Agreement No. DE-FC22-83FE60149

\author{
Prepared for \\ U.S. Department of Energy \\ Assistant Secretary for Fossil Energy \\ Jerry Casteel, Project Manager \\ Bartlesville Project Office \\ P.O. Box 1398 \\ Bartlesville, OK 74005
}

Prepared by

IIT Research Institute

National Institute for Petroleum and Energy Research

P.O. Box 2128

Bartlesville, OK 74005 


\section{TABLE OF CONTENTS}

Page

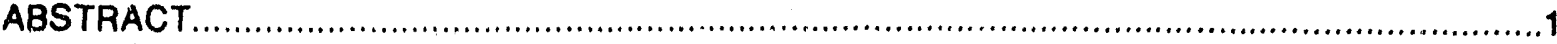

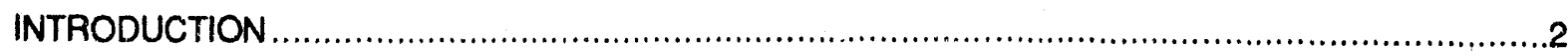

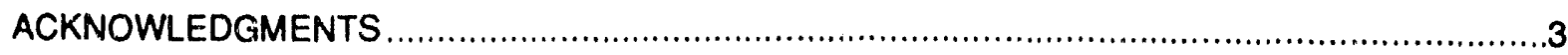

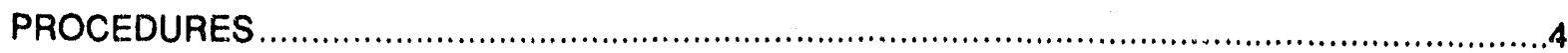

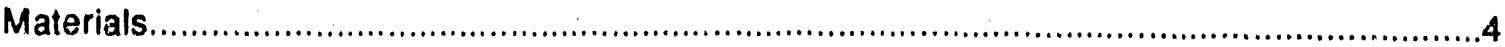

Phase Behavior and IFT Measurements of Mixed Surfactants ............................................4

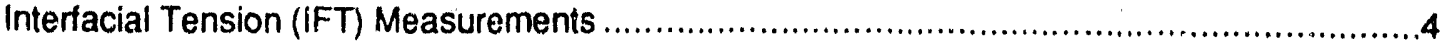

Phase Behavior Measurements .........................................................................

Phase Volume Measurements and Salinity Scans .........................................5

Phase Inversion Temperature Measurements....................................................5

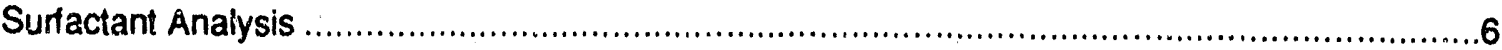

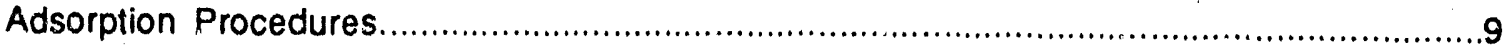

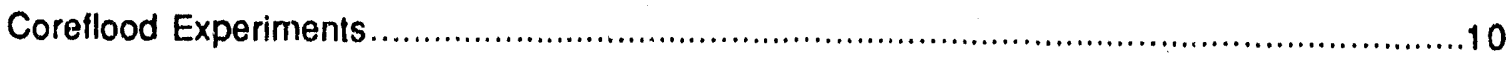

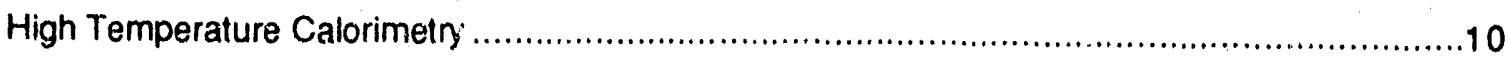

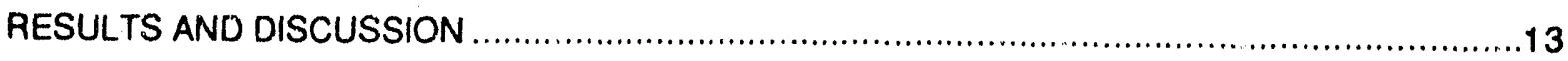

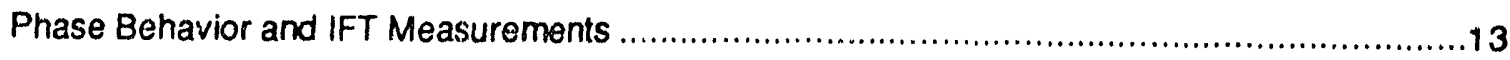

Alkyl Aryl Sulfonates and CME Surfactants .....................................................13

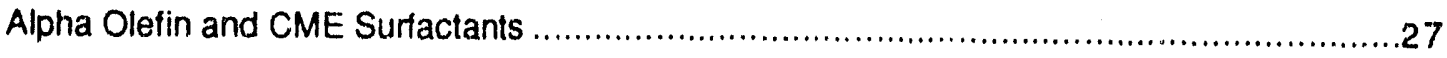

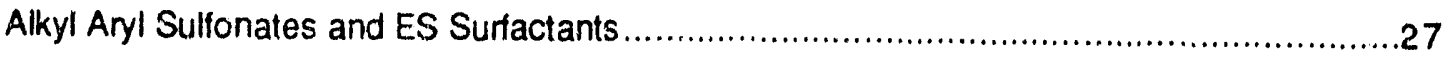

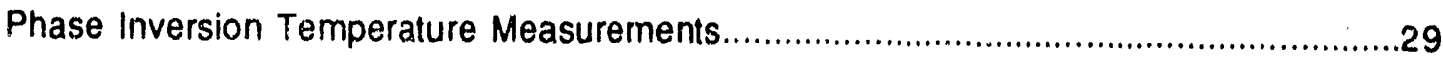

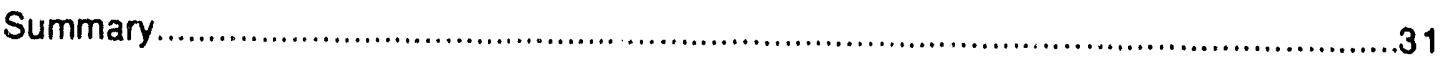

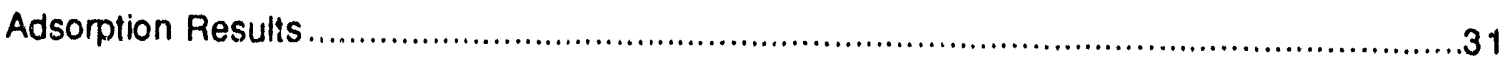

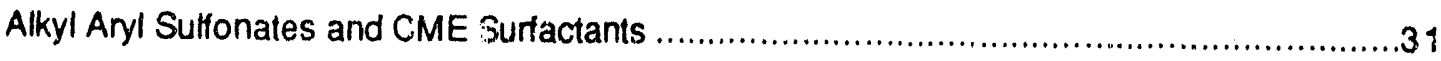

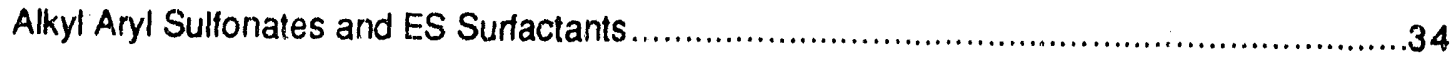

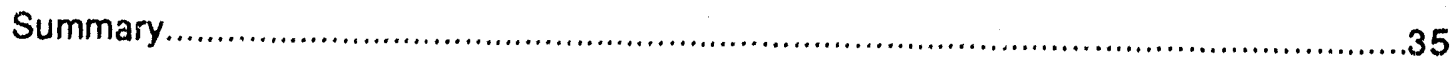

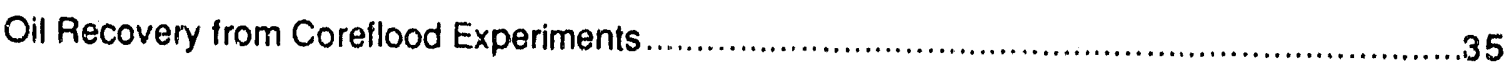

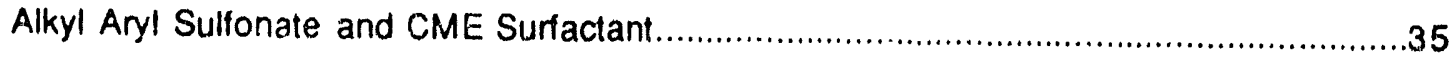

Other Mixed Surfactant Systems........................................................................41

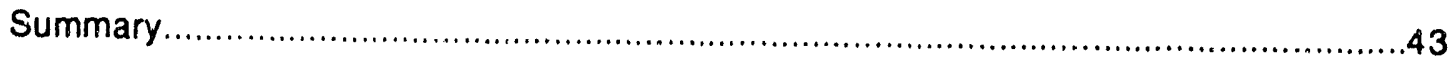

Solution Properties of Mixed Surfactant Systems as a Function of Temperature ......................43

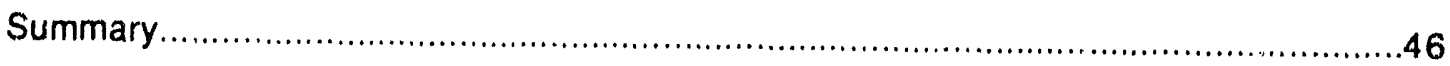


SUMMARY and CONCLUSIONS .47

REFERENCES. .58

APPENDIX 1 .52

TABLES

1. Commercial surfactants for adsorption and chromatographic separation studies....................4

2. Coreflood parameters using 'mixed surfactant systems..............................................10

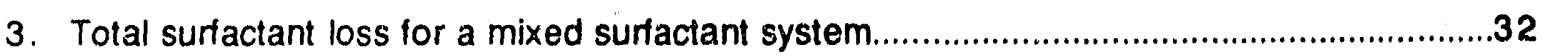

4. Surfactant loss of a mixed surfactant system on crushed Berea sandstone at ambient temperature.

5. Berea sandstone core parameters for oil recovery experiments using the surfactant mixture LXS-1314/MA-18/CES 6.5 at $50^{\circ} \mathrm{C}$.

6. Injection parameters for oil recovery experiments using the surfactant mixture LXS-1314/MA-18/CES 6.5 at $50^{\circ} \mathrm{C}$.

7. Berea sandstone core parameters for oil recovery experiments at $50^{\circ} \mathrm{C}$ using several different surfactant mixtures.

8. Injection parameters for oil recovery experiments at $50^{\circ} \mathrm{C}$ using several different surfactant mixtures. .42

A1. Enthalpies of dilution of Enordet LXS-1314 in water at $25^{\circ} \mathrm{C}$ .52

A2. Enthalpies of dilution of Enordet LXS-1314 in water at $50^{\circ} \mathrm{C}$ .53

A3. Enthalpies of dilution of Enordet LXS-1314 in water at $90^{\circ} \mathrm{C}$ .54

A4. Enthalpies of dilution of Enordet LXS-1314 in brine at $25^{\circ} \mathrm{C}$ .55

A5. Enthalpies of dilution of Enordet LXS-1314 in brine at $50^{\circ} \mathrm{C}$ .56

A6. Enthalpies of dilution of Enordet LXS-1314 in brine at $90^{\circ} \mathrm{C}$ .57

A7. Enthalpies of dilution of LXS,-13i4/RS-16 nixture in brine at $25^{\circ} \mathrm{C}$. .58

A3. Enthalpies of dilution of LXS-1314/RS-16 mixture in brine at $50^{\circ} \mathrm{C}$ .59

A9. Ethalpies of dilution of LXS-1314/RS-16 mixture in brine at $90^{\circ} \mathrm{C}$. 60

A10. Knot positions from the isothermal fits of Enordet LXS-1314 in water. .60

A11. Knot positions for the isothermal fits of Enordet LXS-1314 in brine. .61

A12. Knot positions for the isothermal fits of LXS-1314/RS-16 mixture in brine. .61

A13. Results of cubic spline fit: $L_{\phi}$ data for Enordet $L X S-1314$ in water. 62

A14. Results of cubic spline fit: $L_{\phi}$ data for Enordet LXS-1314 in brine.. .64

A15. Resists of cubiz spline fit: $L_{\phi}$ data for LXS-1314/RS-16 mixture in brine. .65

A16. Density of Shell Enordet LXS-1314 in water at $25^{\circ} \mathrm{C}$. .66 
A17. Density of Shell Enordet LXS.1314 in brire at $25^{\circ} \mathrm{C}$

A18. Density of LXS $-1314 / \mathrm{RS}-16$ mixture in brine at $25^{\circ} \mathrm{C}$.

\section{ILI_USTRATIONS}

1. UV spectra of LXS-1314.

2. UV spectra of $\mathrm{CO}-436$.

3. HPLC chromatogram of the mixture I.XS-1314, MA-18, and CES 6.5 surfactants showing the peaks attributed to anicnic and nonionic surfaciants.

4. HPLC chromatogram for the surfactant mixture LXS-13»4 and CO-436.....

5. HPLC chromatogram showing interference adsorption from componenis of the oil in the surfactant after coreflood experiments.

6. Chromatographic peak areas for various combinations of LXS-13 14 and CO-436 concentrations.

7. Interfacial tensions measured for a system containing LX:S-1314, RS-16 and $n$-decane at $50^{\circ} \mathrm{C}$ .14

8. Interfacial tensions measured for systems containing RS-16 and hydrocarbon...... 15

9. Estimated optimal salinity vs. secondary surfactant concentration. .15

10. Effect of hydrocarbon chain length and temperature of measured IFT's..........................16

11. Ternary phase diagrams for Winsor type phase behavior. .....................................17

12. Middle-phase composition as a function of salinity ..................................................18

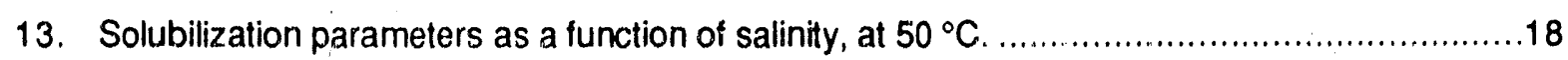

14. Interfacial tensions measured for system containing LXS-1314, MA-18, CES 6.5, and $n$-decane at $50^{\circ} \mathrm{C}$.

15. Interfacial tensions measured for system containing LXS-1314, MA-18, CES 6.5, and oil at $50^{\circ} \mathrm{C}$. 20

16. Calculated middle-phase composition as a function of salinity.

17. Solubilization parameters as a function of salinity for system of

LXS-1314, MA-18, and CES 6.5 with n-decane at $50^{\circ} \mathrm{C}$. .

18. Interfacial tensions measured for system containing LXS-1314, RS-16, and NBU crude oil at $50^{\circ} \mathrm{C}$......

19. Interfaciai tensions measured for system containing LXS-1112, RS-16, and NBU crude oil at $50^{\circ} \mathrm{C}$.

20. Interfacial tensions measured for system containing LXS-810, RS-16, and NBU crude oil at $50^{\circ} \mathrm{C}$. 
21. Interfacial tensions measured for system containing B-120, MA-18, CES 6.5, and NBU crude oil at $50^{\circ} \mathrm{C}$

22. Solubilization parameters as a function of salinity for system of B-120, MA-18,

CES 6.5 , and n-decane and NBU crude oil at $50^{\circ} \mathrm{C}$.

23. Interfacial tensions measured for system containing A-168, MA-18, CES 6.5, and

NBU crude oil at $50^{\circ} \mathrm{C}$

24. Interfacial tensions measured for system containing LXS-1314, CO-436, and

n-decane and NBU crude oil at $50^{\circ} \mathrm{C}$

25. Interfacial tensions measured for system containing LXS-1314, CO-436, and

n-decane and NBU crude oil at $50^{\circ} \mathrm{C}$

26. Electrical conductivity measured for system containing LXS-810 and RS-16

with NBU crude oil.

27. Relative surfactant concentration as a function of volume through a crushed Berea sandstone column for the surfactani system, LXS-1314/MA-18/CES 6.5, in NBU brine

28. Relative surfactant concentration as a function of volume through a crushed Berea sandstone column for the surfactant system, LXS-1314/MA-18/CES 6.5, in NBU brine.

29. Oil production for corefloods LMC/CF-2 and LMC/CF-3 using the surfactant mixture $1.5 \%$ LXS-1314/0.75\% MA-18/0.75\% CES 6.5 in Berea sandstone cores.

30. Effect of salinity gradient on production of NBU oil from Berea sandstone cores using the surfactant mixture LXS-1314/MA-18/CES 6.5.

31. Oil production during coreflood LMC/CF-5 during continuous injection of surfactant mixture, LXS-1314/MA-18/CES 6.5

32. Cumulative oil production for all corefloods using the surfactant

mixture LXS-1314/MA-18/CES 6.5

33. Comparison of cumulative oil production for iwo mixed surfactant systems.

34. Apparent molar volumes of LXS-1314 in water, in brine, and LXS-1314/RS-18 mixture in brine at $25^{\circ} \mathrm{C}$

35 Relative apparent molar enthalpies of LXS-1314 in water at $25^{\circ}, 50^{\circ}$, and $90^{\circ} \mathrm{C}$ 44

36. Relative apparent molar enthalpies of LXS- 1314 in brine at $25^{\circ}, 50^{\circ}$, and $90^{\circ} \mathrm{C}$. 45

37. Relative apparent molar enthalpies of the LXS-1314/FS-16 mixture in brine at $25^{\circ}, 50^{\circ}$, and $90^{\circ} \mathrm{C}$ 


\title{
MIXED SURFACTANT SYSTEMS FOR ENHANCED OIL RECOVERY
}

by Feliciano M. Llave, Bonnie L. Gall, and Leo A. Noll

\begin{abstract}
The results of an evaluation of mixed surfactant systems for enhanced oil recovery are described. Several surfactant combinations have been studied. These include alkyl and alkyl aryl sulfonates as primary surfactants and carboxymethylated ethoxylated (CME) surfactants and ethoxylated sulfonates (ES) as secondary surfactants. The ethoxylated surfactants increase the salinity tolerance of the primary surfactants and, in theory, allow tailoring of the surfactant system to match selected reservoir conditions. The experiments conducted included interfacial tension (IFT) measurements, phase behavior measurements, adsorption and/or chromatographic separation of mixed surfactant systems, measurements of solution properties such as the critical micelle concentration (CMC) of surfactant mixtures, and crude oil displacement experiments. The effects of temperature, surfactant concentration, salinity, presence of divalent ions, hydrocarbon type, and component proportions in the mixed surfactant combinations, and injection strategies on the performance potential of the targeted surfactant/hydrocarbon systems were studied.

Mixtures that were emphasized in this study were alkylxylene sulfonates (LXS) and CME surfactants. The CME surfactant improved solubility of the LXS surfactants in brine. Adsorption decreased significantly at salinities great enough to cause L.XS phase separation without CME in solution. No significant chromatographic separation of the surfactant mixtures could be detected in dynamic adsorption tests. However, no ultralow IFT values were determined for the chosen mixtures. Solubilization parameters were also low. As a result, oil production from Berea sandstone cores using these mixtures was only approximately $10 \%$ of residual oil after waterflood. Injection strategies such as the use of bicarbonate preflush or a salinity gradient had minimal effect on oil production. Preliminary results using a mixture of alkylxylene sulfonate and an ethoxylated sulfate indicated better oil recovery potential, although IFT values and oil solubilization for this mixture with one oil were only moderately favorable.

Dilution experiments at different temperatures indicated that the CMC of one LXS surfactant in water occurred at a concentration less than $0.1 \%$ for temperatures less than $90^{\circ} \mathrm{C}$. The $\mathrm{CMC}$ of this surfactant in brine could not be detected. Instead, results were consistent with the dilution of a two phase system (either a solution + solid or a solution + surfactant-rich second phase). A mixture of LXS and CME surfactants in brine consisted of a single-phase solution. Dilution results, however, indicated that the CMC of this mixture occurred below the detection limits of the experiment $(<0.04 \%)$, indicating that the CME surfactant was very effective in altering the behavior of $L X S$ in brine.
\end{abstract}


Surfactant mixtures designed to improve the salinity tolerance of chemically enhanced oil recovery processes hold some potential for improved oil recovery. Additional study is required, however, to develop and optimize the methodology governing its successful application in the field.

\section{INTRODUCTION}

The application of mixed surfactant systems for enhanced oil recovery (EOR) was investigated. These surfactant systems include surfactant mixtures that may have combined properties that enhance the overall effectiveness of the surfactant system. The purpose of using mixed surfactants is to allow flexibility in design of surfactant systems that optimize oil production for specific reservoir oll, salinity, and temperature conditions and to determine if the combination of different surfactant types produces synergistic effects compared to the use of surfactant types that have been extensively studied in the past.

Most of the work that has been conducted on chemical flooding EOR was focused on sulfonate-type surfactants. The mide investigation of petroleum sulfonates has beer based on defined criteria of material cost, reservoir compatibility, and supporting results from laboratory experiments. Petroleum sulfonate-based chemical floods have also been implemented in the fleld with limited success, both technically and economically.

Sensitivity to salinity has often been an overriding factor affecting surfactant performance in the field. 1 Traditionally, cosurfactants or cosolvents consisting of short chain alcohols have been used to increase surfactant salinity tolerance. Unfortunately, mixtures of surfactart and alcohol are subject to preferential partitioning into the oil phase and also to chromatographic separation of the slug components by the reservoir rock. The success of one field project by Exxon using a salt-tolerant surfactant and the lack of success using salinity gradients prompted Lowry ef al. ${ }^{1}$ to recommend that the Department of Energy support further development of the use of salt-tolerant surfactants.

Salt-tolerant surfactants for EOR applications have been investigated to a limited extent. These include ethoxylated nonionic surfactants, ${ }^{2-3}$ ethoxylated sulfonates, ${ }^{4-6}$ and ethoxylated carboxylates. ${ }^{7-12}$ The addition of the ethoxy groups enhances solubility of the surfactant and reduces sensitivity to high concentration salt. Norionic surfactants have better salt tolerance, but suffer from greater adsorption onto reservoir rocks and the tendency to form separate phases at temperatures above their cloud pointc. The ethoxylated anionic surtactants have been synthesized to incorporate the benefits of nonionic surfactants directly into the surfactant structure, thereby simplifying surfactant composition and lessening the possibility of chromatographic separation of the surfactant slug componenis. These studies emphasized phase behavior and IFT measurements rathor than oil recovery results, however. 
Previous research conducted at NIPER initiated the investigation of surfactants for use in high salinity/high temperature EOR applications. The study has focused on carboxymethylated ethoxylated surfactants (CME). These studies determined that only moderately low IFT values were obtained for these surfactants. ${ }^{13}$ In addition, phase separation and surfactant loss for this surfactant type were significant for conditions where lowest IFT values have been measured. ${ }^{14}$ Application of this surfactant type as the only surfactant in a chemical flood application appears to be limited.

The focus of this year's work was to develop more effective surfactant flooding systems that have broader tolerance to variations in salinity through the use of mixed surfactant systems. The emphasis of this study was to combine types of surfactants like the CME or other sirnilar ethoxylated surfactants with less expensive surfactants which have good oil recovery characteristics but only tolerate low salinity conditions. The combination of different surfactant types may yleld an overall system with improved salinity tolerance and resistance to the chromatographic separation which plagues systems that contain alcohol and surfactant.

Several surfactant combinations have been studied in the course of this work. These include alkyl and alkyl aryl sulfonates as primary surfactants and carboxymethylated ethoxylated surfactants and ethoxylated sulfonates as secondary surfactants. The experiments conducted included interfacial tension (IFT) measurements, phase behavior measurements, adsorption and/or chromatographic separation of mixed surfactant systems, measurements of solution properties such as the critical micelle concentration of surfactant mixtures, and crude oil displacement experiments. Studies onthe effects of temperature, surfactant concentration, salinity, presence of divalent ions, hydrocarbon type, and component proportions in the mixed surfactant combinations, and injection strategies on the performance potential of the targeted surfactant/hydrocarbon systerns were determined.

This report describes the results of these experiments and indicates a direction for further work on mixed surfactant systemis.

\section{ACKNOWLEDGMENTS}

This work was sponsored by the U.S. Department of Energy urider cooperative agreement FC22-83FE60149. The authors wish to thank Sharon A. Munden, Troy R. French, Clarence J. Raible, Ronald L. Masias, Mike E. Crocker, and Charles B. Josephson of NIPER, as well as Deanna B. Evans, Associated Western University (AWU) summer siudent, for their contribution and assistance in performing the experiments. 


\section{PROCEDURES}

\section{Matarlais}

The surfactants listed in table 1 were used without further purification. Solutions were prepared using reagent grade salts. Concentrations are reported as weight reagent to weight of solution.

\section{Phase Behavlor and IFI Measurements of Mixed Surfactants}

\section{Interfaclal Tension (IFT) Measurements}

IFT measurements were performed using a Model 300 spinning drop interfacial tensiometer manufactured at University of Texas at Austin. These measurements were conducted on different mixed surfactant systems and various hydrocarbons, under several conditions of temperature and salinity. Oil and surfactant solutions were not pre-equilibrated. Measurements were usually taken after a minimum time of about 1 hour at the desired temperature. Additional measurements were taken until a stable IFT measurement was obtained for the surfactant system/hydrocarbon combination ( $\pm 10 \%$ deviation). Only the average values are presented in the graphs and in the tables. The solution densities and refractive indices us?d in the IFT calculations were measured using a Mettler/Paar DMA 45 calculating digital density meter and a Bausch \& Lomb refractometer.

TABLE 1. - Commercial surfactants for adsorption and chromatographic separation studies

\begin{tabular}{cccccc}
\hline Trade Name & Company & Activity, \% & Hydrophobe & Hydrophile & Average EO's \\
\hline LXS-810 & Shell & 100 & $C_{8-10}$ xylene & $-\mathrm{SO}_{3}^{-}$ & 0 \\
LXS-1112 & Shell & 100 & $\mathrm{C}_{11-12}$ xylene & $-\mathrm{SO}_{3}^{-}$ & 0 \\
LXS-1314 & Shell & 100 & $\mathrm{C}_{13-14}$ xylene & $-\mathrm{SO}_{3}^{-}$ & 0 \\
B120 & Stepan & 40 & alkyl aryl & $-\mathrm{SO}_{3}^{-}$ & 0 \\
AOS-1416 & Shell & 100 & $\mathrm{C}_{14-16}$ & $-\mathrm{SO}_{3}^{-}$ & 0 \\
AOS-1618 & Shell & 100 & $\mathrm{C}_{16-18}$ & $-\mathrm{SO}_{3}^{-}$ & 0 \\
A-168 & Alcolac & 30 & $\mathrm{C}_{16-18}$ & $-\mathrm{SO}_{3}^{-}$ & 0 \\
CO-436 & GAF & 58 & nonylphenol & $-\mathrm{SO}_{4}^{-}$ & 3 \\
MA-18 & Sandoz & 90 & n-nonylphenol & $-\mathrm{COO}^{-}$ & 9 \\
RS-16 & Sandoz & 90 & $C_{16}-\mathrm{C}_{18}$ & $-\mathrm{COO}^{-}$ & 8 \\
JA-6 & Sandoz & 90 & $C_{13}$ & $-\mathrm{COO}^{-}$ & 3 \\
CES 6.5 & Hüls & 90 & i-nonylphenol & $-\mathrm{COO}^{-}$ & 6.5 \\
\hline
\end{tabular}




\section{Phase Behavlor Measurements}

\section{Phase Volume Measurements and Sallnity Scans}

The phase behavior measurements were conducted under a variety of conditions. Of interest in these studies were the effects of parameters such as: temperature, surfactant concentration, salinity, presence of divalent ions, hydrocarbon type, and mixed surfactant combinations on the phase behavior of these surfactant/hydrocarbon systems. These tests were conducted using solutions that were made up at a constant water-oil ratio (WOR $=1$ ) in 10-mL glass pipets that were sealed and incubated in ovens at the desired temperature condition. Phase volumes were read at set time intervals until constant readings were obtained. Using these constant phase volume readings, the solubilization parameters of the hydrocarbon $\left(\sigma_{0}=V_{0} / V_{s}\right)$ and the brine $\left(\sigma_{W}=V_{W} / V_{s}\right)$ in the microemulsion phase were calculated, as defined by equation 1.15

$$
\sigma_{0}\left(\sigma_{w}\right)=\left(\frac{\text { original volume of oil or water - volume of excess oil or water }}{\text { volume of surfactant }}\right)
$$

where the volume of the surfactant is calculated from the weight of active material divided by the density of the product as used. Observations regarding limiting phase behavior, i.e. formation of gels, liquid crystalline phases, and precipitates were also recorded.

\section{Phase Inversion Temperature Measurement}

The phase inversion temperatures (PIT) of the surfac:ant systems studied were measured using an apparatus designed and constructed at NIPER. ${ }^{16}$ The PIT is the temperature condition at which a waterin-oil emulsion changes into an oil-in-water emulsion or vice versa. The transition can be detected by measuring the electrical conductivity of a well-stirred mixture as a function of the temperature. At low temperature conditions, an oil-in-water emulsion of high solution conductivity is present. As the operating temperature is increased, the electrical conductivity of the mixture slowly increases, due in part to the increase in electrical conductivity of the solution with temperature. As heating continues, the surfactant inolecules become sufficiently dehydrated for the emulsion to invert and the electrical conductivity of the solution decreases, often abruptly, and often over several orders of magnitude. The rate of decrease is dependent upon the stability and structure of the emulsion which is dependent on the surfactant molecular structure and concentration, the composition of the oil, the salinity of the aqueous phase, and the mobility of oil-water interface. Beyond this transition temperature, the mixture is a relatively nonconducting water-in-oll emulsion.

The PIT is characteristic of the mixture, and the phase inversion is often a reversible transformation. The PIT experiment is routinely associated with measurement of phase transition for nonionic surfactants, and the technique has been used extensiveiy by Shinoda to investigate surfactant-oil interaction. 17-18 
The determination of the phase inversion temperature (PIT) of surfactants at reservoir salinity with crudes provides an important means of evaluating the applicability of a surfactant for a specific reservoir. The PIT measurements as well as phase behavior studies (salinity scan) are design aids for establishing salinity tolerance and solubilization parameters of the selected surfactant systems.

\section{Surfactant Analysis}

All surfactants used in this study had UV adsorption maxima in the region of 260 to $290 \mathrm{~nm}$. Examples of UV adsorption spectra of two surfactants used in this study, as determined using a Beckman $D^{\circledR}-64$ spectrophotometer, are shown in figures 1 and 2.

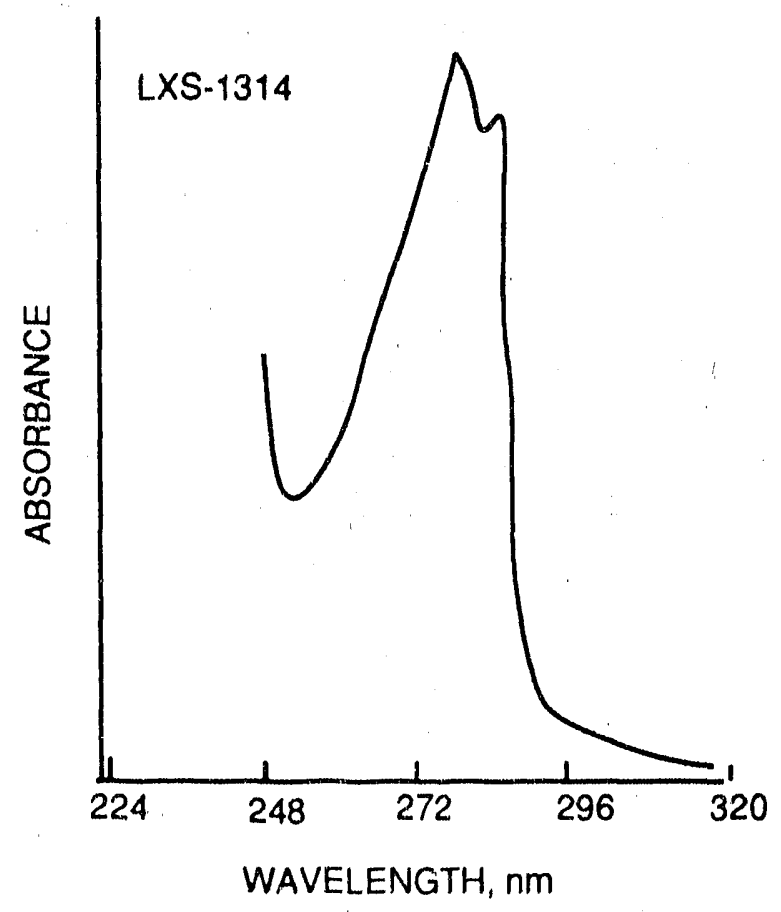

FIGURE 1. - UV spectra of LXS-1314.

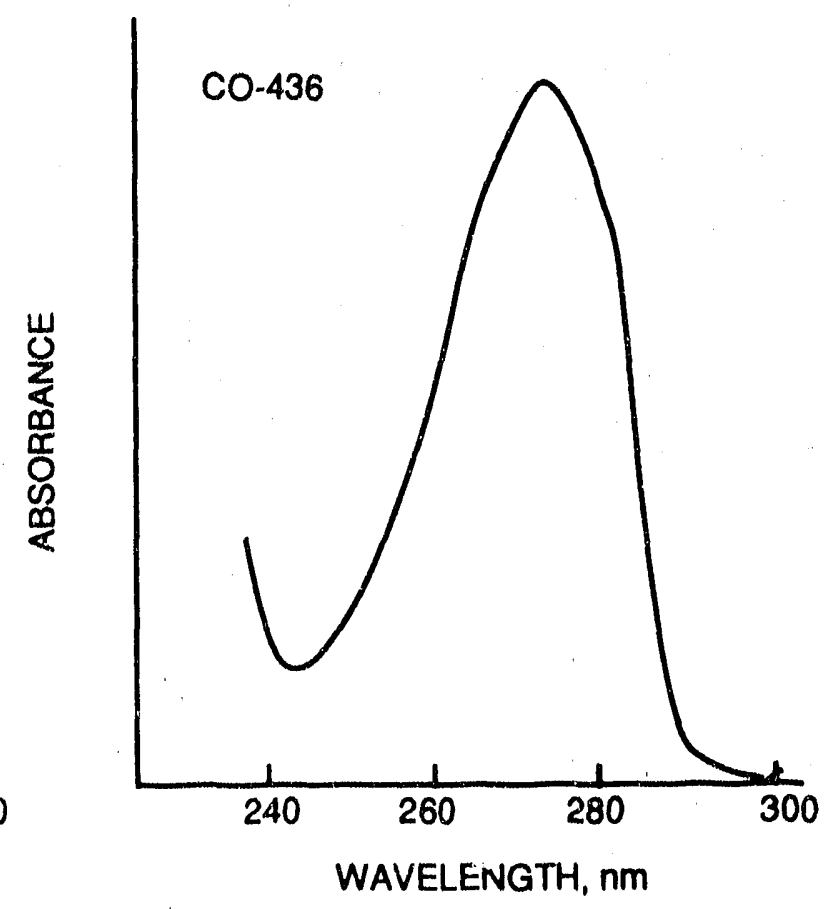

FIGURE 2. - UV spectra of CO-436.

Surfactant mixtures were analyzed using a high-pressure liquid chromatography (HPLC) apparatus from Waters Associates. The HPLC system used a reverse phase $C_{8}$ column, Zorbax ${ }^{8 X}$ from Du Pont, for surfactant separation. The mobile-phase solvent varied from a $45 \% / 17 \% / 38 \%$ mixture of $\mathrm{H}_{2} \mathrm{O} / \mathrm{CH}_{3} \mathrm{OH} / \mathrm{CH}_{3} \mathrm{CN}$ to $100 \% \mathrm{CH}_{3} \mathrm{CN}$. This solvent gradient would separate nonionic surfactant components from anionic surfactant components. The anionic surfactant (the major portion of the surfactants) peaks, however, overlapped significantly. This indicates that the hydrophobic ends of these surfactants have similar affinities for the reverse-phase column and that the hydrophilic ends have similar affinities for the mobile-phase solvent. Such similarity should favor simultaneous movement of surfactant mixtures through the reservoir and minimize chromatographic separation problems during a surfactant oil recovery project. 
Figures 3 and 4 show typical HPLC chromatograms for surfactant mixtures used in the adsorption studies. Surfactants were detected using their UV adsorption at $272 \mathrm{~nm}$.

In each case, the LXS-1314 surfactant appeared to move through the chromatographic column along with the surfactant with which it was mixed. Elution from the column occurred in less time and required a less hydrophobic mobile phase solvent when the LXS-1314 was mixed with the ethoxylated sulfate (CO-436) than with the ethoxylated carboxylates (MA-18 and CES 6.5).

Effluent samples from the coreflood experiments required additional analytical preparation before surfacte.t analysis could be performed. Solubilized oil components in samples that contairied surfactant produced intertering UV absorption that masked the detection of the surfactants. Compcinents of the effluent brine were adsorbed on Waters Sep-Pak $\mathrm{C}_{18}$ cartridges, washed with water containing no UV adsorbing components, and desorbed using methanol. The anionic surfactants could then be determined without interference from other components in the effluent samples. Interference was observed, however, at higher retention times (>12 minutes) which hindered detection of nonionic components of the surfactants. Figure 5 shows a typical chromatogram of effluent samples containing surfactant and solubilized oil after this analytical treatment.

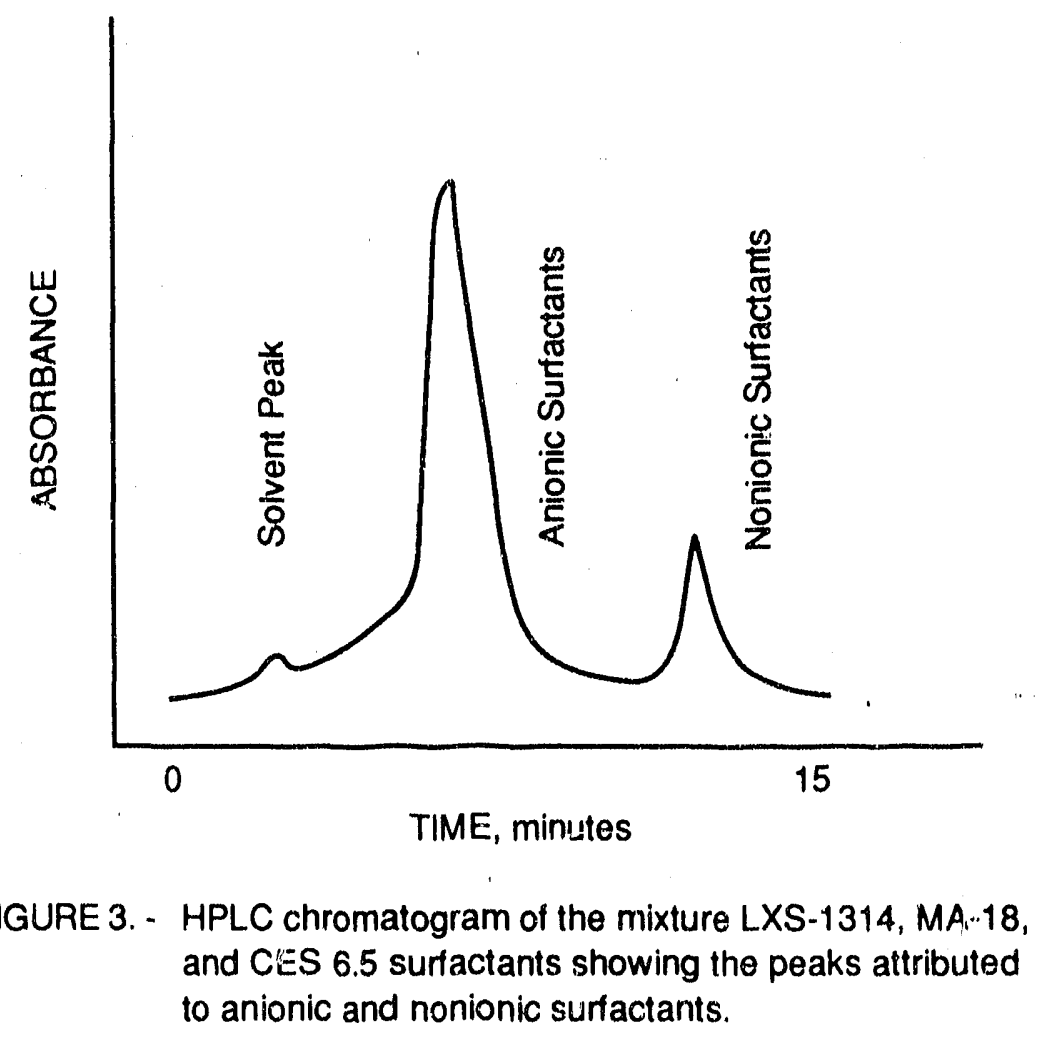




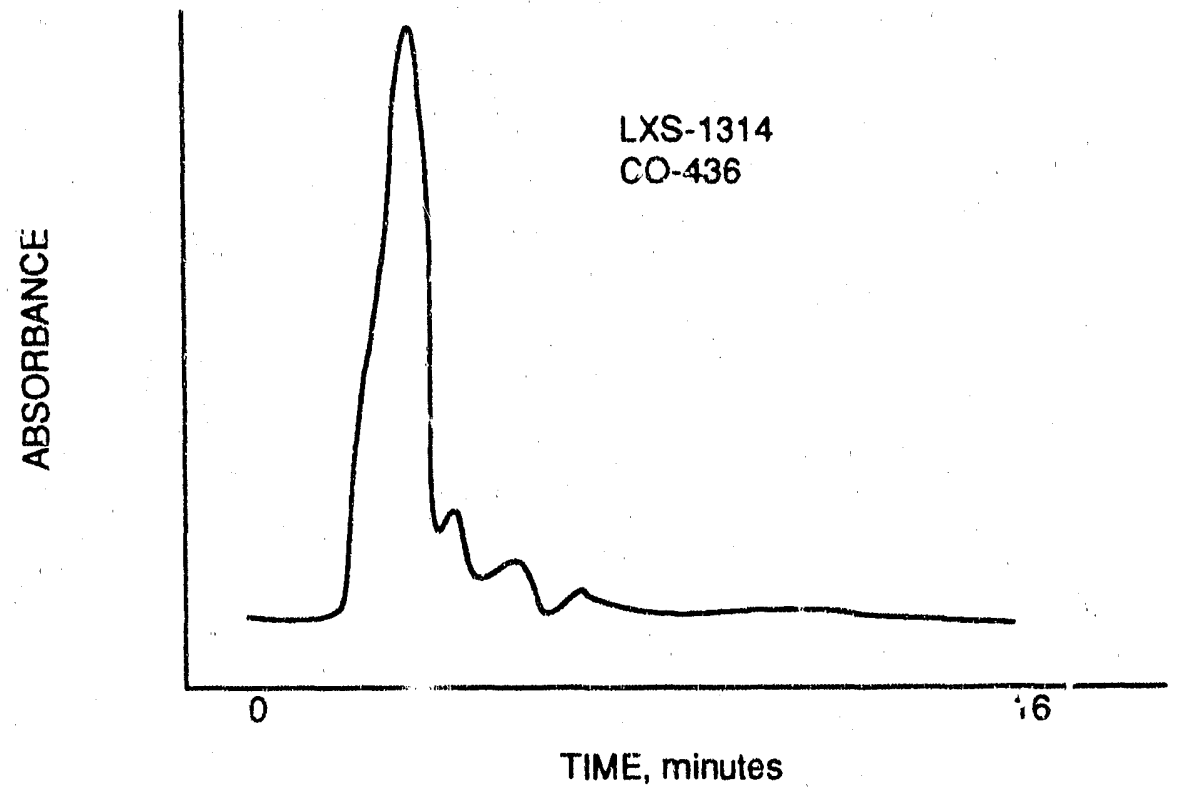

FIGURE 4. - HPLC chroma" Jgram for the surfactant mixture LXS-1314 and CO-436.

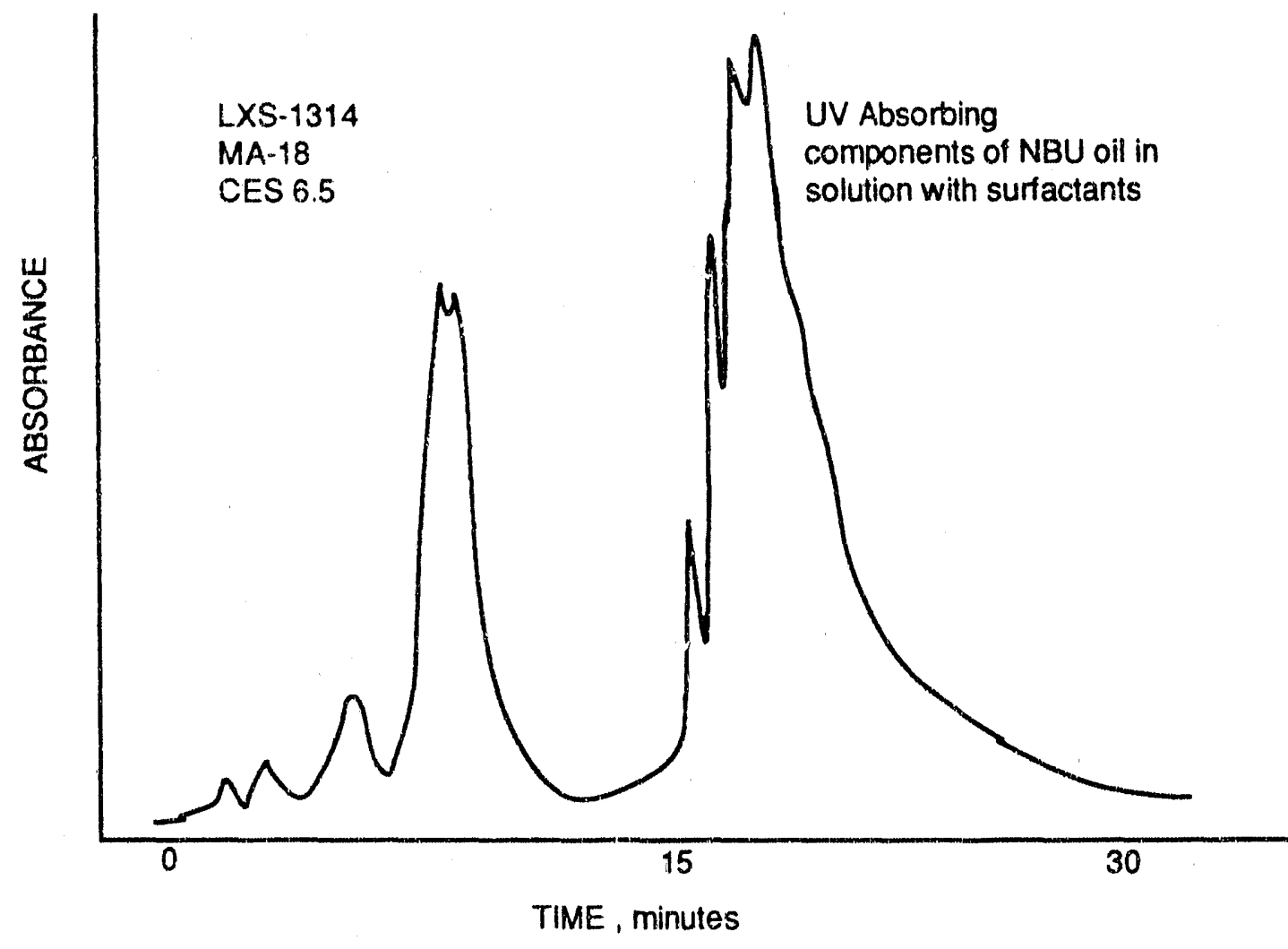

FIGURE 5. - HPLC chromatogram showing interference adsorption from components of the oil in the surfactant after coreflood experiments. 


\section{Adsorption Procedures}

Batch adsorption tests were conducted at ambient temperature to determine the amount of total surfactant loss on crushed Berea sandstone for the surfactant mixtures used in this study. Two surfactant mixtures were tested. The salinity of the first mixed surfactant (LXS-1314 and CO-436) was $3 \% \mathrm{NaCl}$. For the second surfactant system (LXC,-1314, M-18, and CES 6.5), the brine was composed of $6.65 \% \mathrm{NaCl}$, $1.5 \% \mathrm{CaCl}_{2}$, and $0.24 \% \mathrm{MgCl}_{2}$. All HPLC solvents (water, acetonitrile, and methanol) were UV grade. The crushed sandstone was a sievsu fraction of the total sample (180 to 212 mesh) and had a surface area of $0.64 \mathrm{~m}^{2} / \mathrm{g}$. Surfactant analysis used the HPLC methods described above. Areas under the chromatographic peaks were used to determine surfactant concentrations in the mixtures. Peak areas were also measured for several concentration ratios for these two surfactante. Construction of a threedimensional surface for peak area as a function of the two concentrations indicated that the total peak areas are additive, as shown in figure 6. Surfactant peaks of several components partially overlapped. Therefore, it was not possible to distinguish precisely if one component disappeared rather than the other. However, a change in the shape to the overlapping peaks could be used to suggest the disappearance of one component rather than another. For the static tests, no change in peak shape for overlapping HPLC curves could be observed. Adsorption from flowing solutions was also measured to determine both total adsorption and possible preferential adsorption of surfactant mixtures.

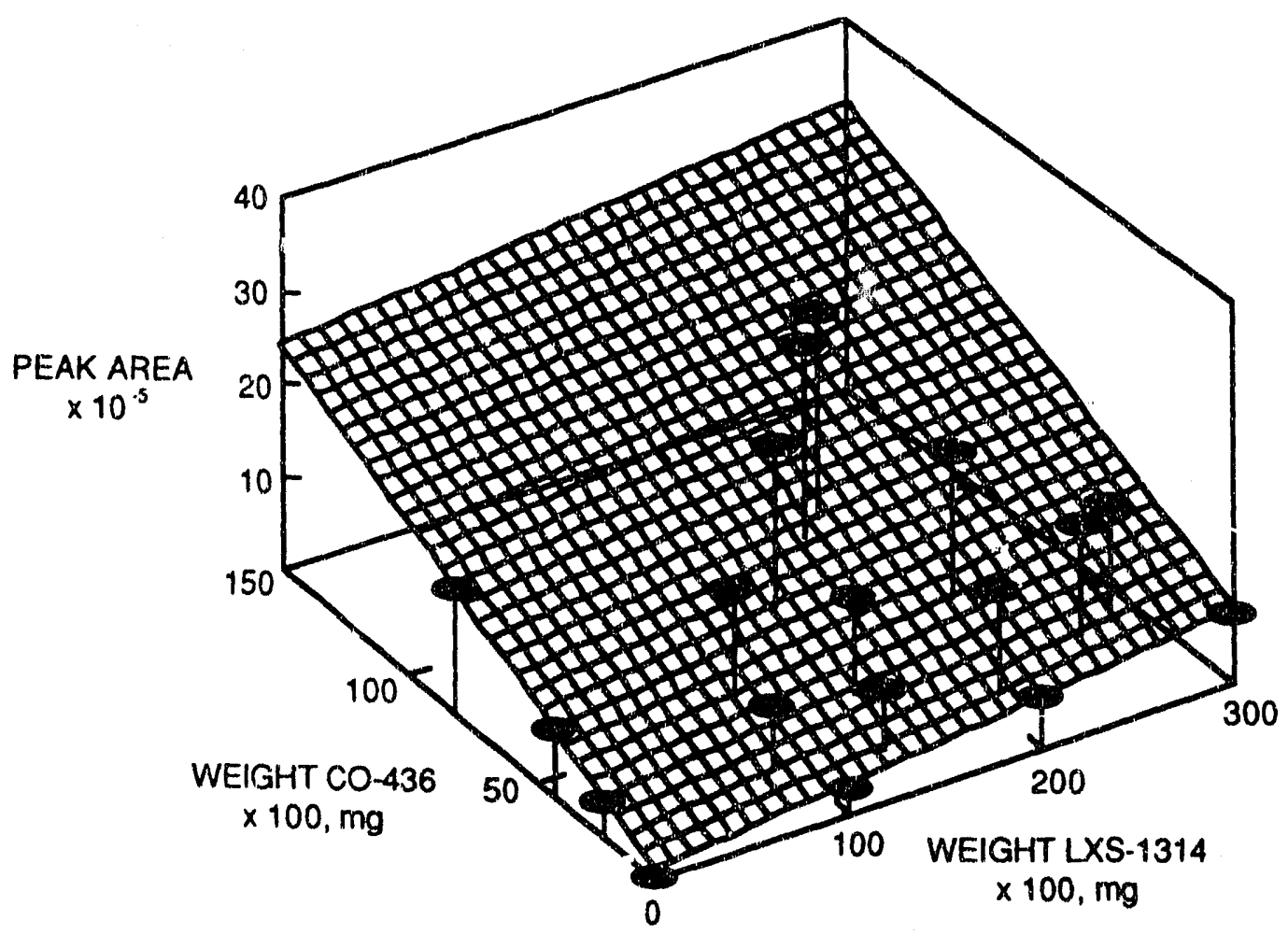

FIGURE 6 - Chromatographic peak areas for various combinations of L.XS-1314 and C. $0-436$ concentrations. 
Dynamic adsorption tests were conducted using 1- to 2-ft, 1/4-in.-diameter columns filled with crushed Berea sandstone. The apparatus has been described in a previous repont. ${ }^{14}$ Effluent samples were collected using the fraction collector and analyzed for the presence and amount of surfactant.

\section{Coreflood Experiments}

Coreflood experiments were conducted by replacing the crushed sandstone columns with Berea sandstone core plugs $3.8 \mathrm{~cm}$ in diameter and approximately $25 \mathrm{~cm}$ in length. General procedures for these experiments have been reported previously. ${ }^{14}$ In general, cores were first saturated with NBU brine, flushed to residual brine saturation with oil, and waterflooded to residual oil saturation with NEU brine. If corefloods were to be conducted using a brine other than NBU brine, the core would be flushed with approximately 1 brine PV of the new brine betore the start of the chemical flood. Table 2 shows typical coreflood parameters used during this study.

Core effluent was analyzed for surfactant concentration in the brine. Surfactant in the oil was not dete-mined because of the presence of UV adsorbing comironents in the oll which interfered with the surfactant analysis. Incremental oil production was measured.

\section{Hlah-Temperafure Calorimetry}

The effect of temperature on the micellization and solution behavior of commercial surfactants has been studied by the use of solution calorimetry. The technique used in this investigation is enthalpy of

TABLE 2. - Coreflood parameters using mixed surfactant systems

Temperature, ${ }^{\circ} \mathrm{C}$ 50

Confining stress, psi . .150 to 200

Core Berea sandstone:

Permeability to brine, and 200 to 600

Porosity, \% 18.2 to 23 Fluids:

Brine - $\mathrm{NaCl}, \%$. 5 to 12

or Brine $-\mathrm{NaClCaCl}_{2} / \mathrm{MgCl}_{2}$ (simulated North Burbank Unit brine) $6.65 / 1.53 / 0.24$

Total surfactant, \% (active weight) 1 to 3

Tracer - fluorescein, ppm .10 to 10.6

Oit - decane or North Burbank Unit crude oil

Production:

Fluid flow rate, $\mathrm{ft} / \mathrm{d}$ 1 to 3 
dilution measurements of aquentiz surfactant solutions. A series of papers from the National institute for Petroleum and Enargy Research (NIPER) ${ }^{20-27}$ has described the effects of temperature, chain length, alcohol, and electrolyte concentration on the critical micelle concentration (CMC) of pure surfactants. relative apparent partial molar enthalpies and heat capacities of aqueous surfactant solutions, and the behavior of commercial surfactants at ambient and high temperatures.

The high-temperature experiments were carried out by means of the Albert-Wood mass flow, temperature-rise calorimeter, while the ambient temperature experiments were run in an LKB System 2107 dilution calorimeter. References 20 through 27 describe the use of the high temperature calorimeter, while reference 28 describes the LKB calorimeter. The precision of replicate measurements of large enthalpies is generally better than $\pm 1 \%$.

The three surfactant systems chosen were LXS-1314 in distilled water, the same surfactant in brine, and a mixture of $80 \%$ LXS-1314 and 20\%, RS-16 in brine. The dilution experiments were conducted so that only the surfactant was diluted, not other components of the surfactant solutions such as the added salt. Bolsman 29 has shown a midpoint salinity of $0.5 \% \mathrm{NaCl}$ for LXS-1314 with paraffin oil at $67^{\circ} \mathrm{C}$. Using his correlation of midpoint salinity as a function of temperature, the midpoint salinity is $0.36 \%$ at $25^{\circ}$ and $0.59 \%$ at $90^{\circ} \mathrm{C}$. The selection of $0.5 \%$ brine concentration for the dilution experiments reflects this salinity window.

Since sodium chioride $(\mathrm{NaCl})$ brine at high temperatures is quite corrosive to the tubing of the dilution calorimeter, it was decided to use sodium sulfate $\left(\mathrm{Na}_{2} \mathrm{SO}_{4}\right)$ as the electrolyte for the brine soiutions. In a study of the effects on phase behavior of chloride vs. sulfate as the anion, Foulser et al. ${ }^{30}$ have shown that on a weight basis, chloride is about 1.7 times as effective as sulfate. Solutions of gqual osmosity have equal freezing points and equal osmotic pressures; the activity of water in such solutions is equal. The osmosity of a $0.933 \% \mathrm{Na}_{2} \mathrm{SO}_{4}$ solution is equal to that of a $0.5 \% \mathrm{NaCl}$ solution. 31 Thus the brine used for high-temperature dilution calorimetry was $0.933 \% \mathrm{Na}_{2} \mathrm{SO}_{4}$ solution as the equivalent to $0.5 \% \mathrm{NaCl}$ brine.

Subsequent comparison of a $2 \%$ solution of LXS. 1314 in $0.5 \% \mathrm{NaCl}$ with the same surfactant concentration in the $\mathrm{Na}_{2} \mathrm{SO}_{4}$ brine indicated some difference in surfactant solution propertles could be observed. The solution in the sulfate brine was cloudier than that in the chioride brine, and both showed signs of settling of turbid me arial after about an hour. Both solutions were optically active when held beiween crossed polars. Solutions of $0.2 \%$ surfactant were also prepared in the same brines. These were less cloudy than the $2 \%$ solutions, again with the sulfate being the nore cloudy of the two. When heated in boiling water, the $0.2 \%$ solution in chloride brine cleared up completely; that in the sulfate brine became much less cloudy, but didn't completely clear up. Both of the $2 \%$ solutions were a little less turbid 
at the temperature of boiling water than at room temperature. These observations suygest that the solubility of LXS-1314 is greater at $100^{\circ}$ than at $25^{\circ} \mathrm{C}$ and that the solution properties of the surfactant is similar but not quite equivalent for the two brines. However, because of equipment considerations, the sulfate brine was used for the dilution experiments. The mixture of LXS-1314 and RS-16 in brine was clear and transparent at all concentrations used. The presence of RS-16 in solution jesult?d in the elimination of solubility problems for the LXS-1314 in this brine. This suggests an association has occurred between the two surfactants.

Distilled deionized water was used to prepare the brine and as a solvent for the LXS-1314 in water. Dilution experiments were carried out at $25^{\circ}, 50^{\circ}$, and $90^{\circ} \mathrm{C}$. The dilution ratios of surfactant solution to solvent were $3 / 2,1 / 1$, and $2 / 3$. Eight solutions were made for each surfactant at total active concentrations of 0.1 to $4.0 \mathrm{wt} \%$. The experimentaily measured values of the enthalpies of dilution are given in appendix $A$, tables $A 1$ through $A 9$. In these tables, $P$ is the backpressure used to ensure that the contents of the calorimeter remained as a single liquid phase; $\sigma$ is the standard deviation of a point in the cubic spline fit; columns 1 and 2 list the initial and final surfactant molalities for each dilution, and column 3 gives the experimentally observed enthalpy change for that dilution. Column 4 lists the residual, which is the experimental enthalpy minus the fitted enthalpy, as explained below.

The enthalpies of dilution are the chords of a plot of relative apparent molal enthalpy $\left(L_{\phi}\right)$ as a function of surfactant molality concentration. The $L \phi$ curve is developed by fitting the experimental data by a cubic spline technique, ${ }^{20}$ which maintains continuous first and second derivatives. The routine generates a series of cubic polynomials joining a set of points referred to as "knots.". The values of the first derivative of $L_{\phi}$ versus concentration at low concentration are determined by the Debye-Hückel limiting law for a 1:1, electrolyte; the value of $L_{\phi}$ at zero concentration is constrained to be zero. The knots used for the cubic spline fit are shown in tables A10 through A12. All the dilution enthalpies were small, so all points were given a weight of 1 in the fitting routine. The least-squares fits to the experimental values are found in tables A13-A15.

For the ambient temperature dilution experiments, the mass flow rate of liquids was obtained by weighing the bottles and measuring the time of flow. These flow rates were measured to an accuracy of better than $\pm 0.01 \%$. For the high-temperature experiments, the volumetric flow rates of the solvent and of the sample stream were measured to a precision of better than $\pm 0.3 \%$. To calculate the mass flow rates of reagents, the densities of their solutions are required. These densities were measured at $298.2 \mathrm{~K}\left(25^{\circ}\right.$ C) and $1 \mathrm{~atm}$ with a Mettler vibrating tube densimeter, which is accurate to four decimal places. The densities at higher pressures were calculated by assuming that the compressibilities of the solutions were equal to that of pure water. Since the concentrations of solutes in solutivn were relatively small $(<0.08 \mathrm{~m})$, this was a reasonable approximation. 
The densities along with the linear least-squares fits to the density data are presented in appendix $A$, tables $A 1$ through $A 3$. Tables $A 1$ through $A 3$ also include the apparent molar volumes, $V_{\phi}$, which were calculated from 32

$$
V_{\phi}=\frac{M}{d}-\frac{1000\left(d-d^{0}\right)}{m d d^{0}}
$$

where $M$ is the molecular weight of solute, $d$ is the density of solution, $m$ is the molality of solution, and $d^{\circ}$ is the density of solvent. In oversimplified terms, the apparent molar volume is the volume occupied by a mole of solute. If the volume is relatively small, it suggests that the surfactant molecules are in a constrained environment, while a large value suggests a more loose structure.

\section{RESULTS AND DISCUSSION \\ Phase Behavior and IFT Muasurements}

\section{Alkyl Aryl Sulfonates and CME Surfactants}

Screening IFT measurements and salinity scans were conducted for a series of surfactant mixtures containing alky laryl sulfonate (AAS) as the primary surfactant and a carboxymethylated ethoxylated surfactant (CME) as the secondary surfactant, using n-decane, $n$-hexadecane and North Burbank Unit (NBU) crude oil as the hydrocarbon coinponent. These measurements were conducted as a function of salinity and wt \% CME in the surfactant formulation. The total surfactant concentration in these experiments was fixed at several concentration levels, in terms of wt \% of surfactant active component.

One of the series of surfactants testec' contained Shell's Enordet LXS-series of surfactants and several CME surfactants. L.XS-1314 was tested in combination with Sandoz Chemical's RS-16, using the different hydrocarbon components. For the system containing LXS-1314 and RS-16 with n-decane, the results are presented in figure 7. The plot of measured IFT versus salinity is shown for the different surfactant mixtures tested. Results show that the combination of the two surfactants yielded relatively low IFT values $\left(<10^{-2} \mathrm{mN} / \mathrm{m}\right.$ ) even at high salinities ( $w t \% \mathrm{NaCl}$ ). The results also indicate a broadening of the salt tolerance range, while maintaining relatively low IFT values $\left(10^{-3}-10^{-1} \mathrm{mN} / \mathrm{m}\right)$. This range of IFT values was considerably lower than the values of the measurements determined when using the AAS or the CME surfactant alone, under similar conditions. The :esults from the study also indicate a possible maximum in the concentration of the CME surfactant that can be added before the formation of liquid gels or crystals occurs. The upper limit for CME seems to be about $30 \%$ of the total surfactant concentration in the formulation. The upper bound of the salinity range appears to be at about $14 \mathrm{wt} \% \mathrm{NaCl}$ before any multiphase behavior was observed undes these conditions. Provious experimental results have shown that the CME surfactants alone had high salirity tolerance but yiondec rilatively higher IFT values $\left(>7 \times 10^{-1} \mathrm{mN} / \mathrm{m}\right)$, from 5 to $20 \mathrm{wt} \% \mathrm{NaCl}$ with n-decane. ${ }^{13}$ The IFr measurements using the CME surfactant alone are presented in figure 8 . These IFT values are lower than those previously observed for 
this surfactant with $n$-dodecane at salinities from 10 to $20 \mathrm{wt} \% \mathrm{NaCl}^{13}$ The IFT measurements using the CME surfactant alone were conducted to provide the base-case IFT values when the total surfactant concentration in the formulation was the CME surfactant. Under the conditions tested, using this surfactant alone will not result in favorable conditions for oil recovery.

Figure 9 shows a plot of the estimated optimal salinity as a function of CME surfactant concentration in the mixed surfactant system. The optimal salinity was estimated, based on the relative proximity of an IFT minimum. ${ }^{33}$ Figure 9 also shows a comparison of the estimated optimal salinity with a system containing a mixture of ethoxylated sulfonate (EOR-200) with a petroleum sulfonate (TRS 10-410 or Petrostep-465).34 This comparison was made to show the advantages of using mixed surfactants to enhance or "tailor-make" optimal conditions. The results show that a lesser amount of CME was necessary in order for the overall surfactarit to behave effectively in high-salinity conditions. Compared to the previous results using the ethoxylated sulfonate, 27 no regions of precipitation, phase separation, or birefringence were observed in the present study for salinities less than $14 \mathrm{wt} \% \mathrm{NaCl}$.

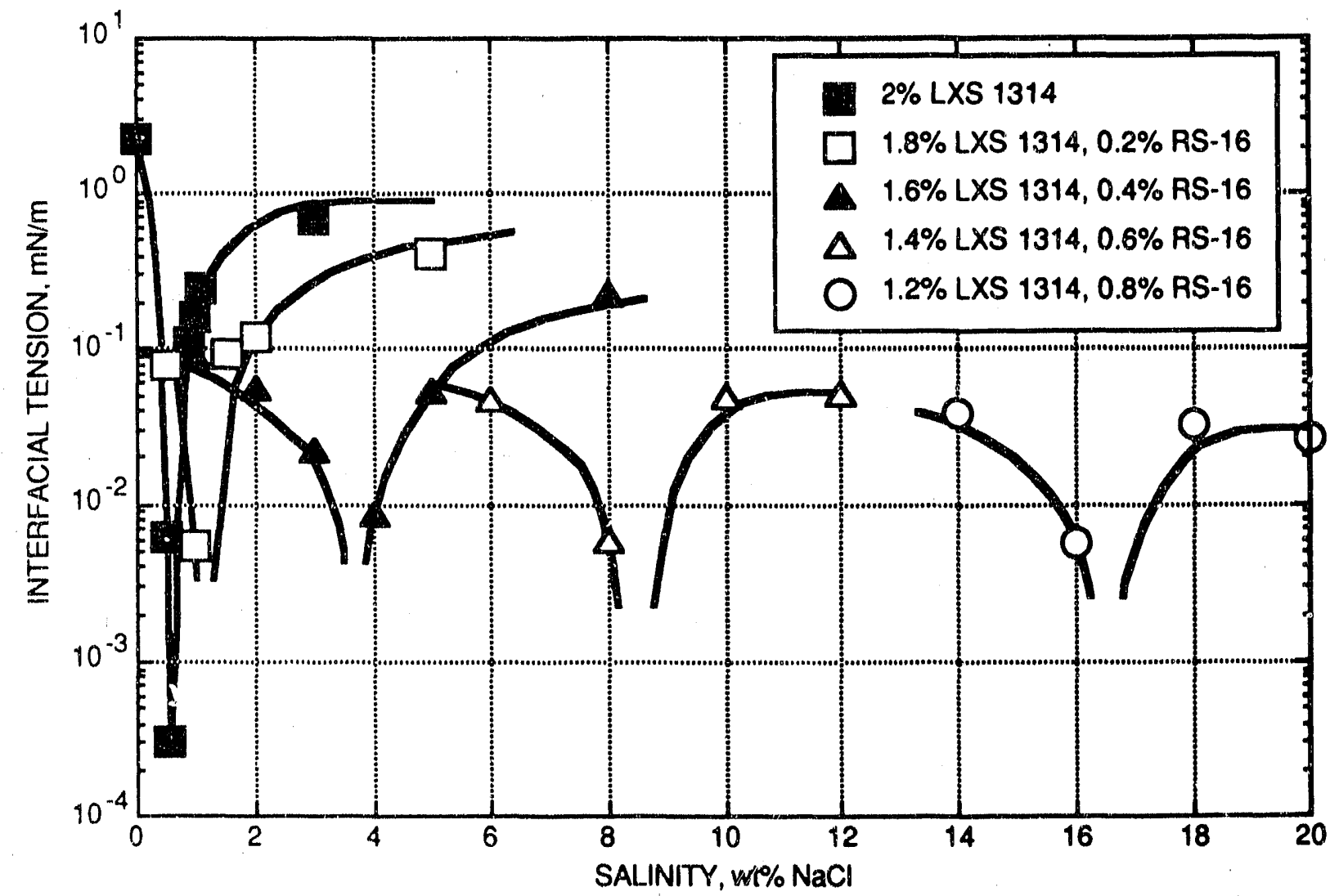

FIGURE 7. - Interfacial tensions measured for a system containing LXS-1314, RS-16 and n-decane at $50^{\circ} \mathrm{C}$. 


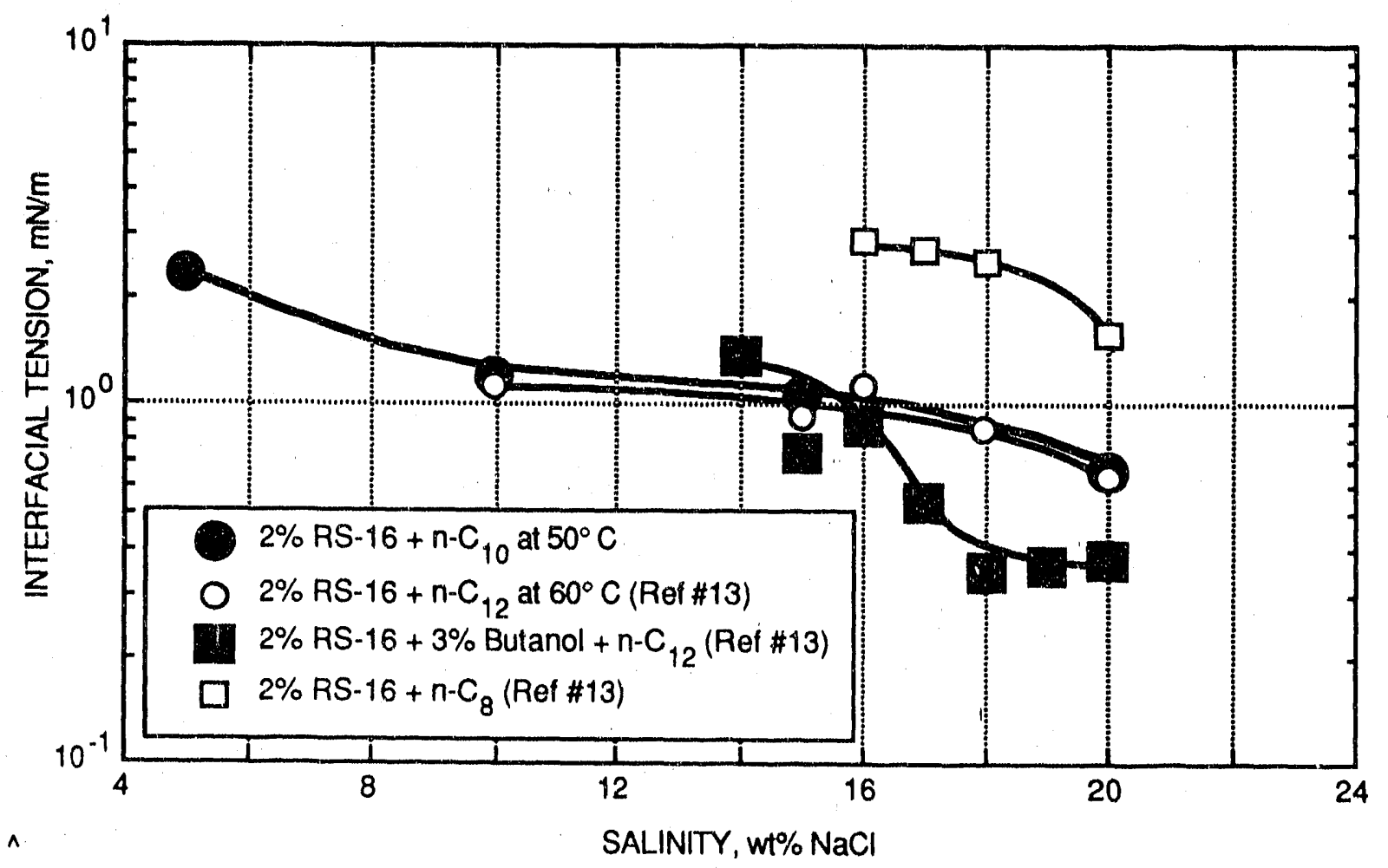

FIGURE 8. - Interfacial tensions measured for systems containing RS-16 and hydrocarbon.

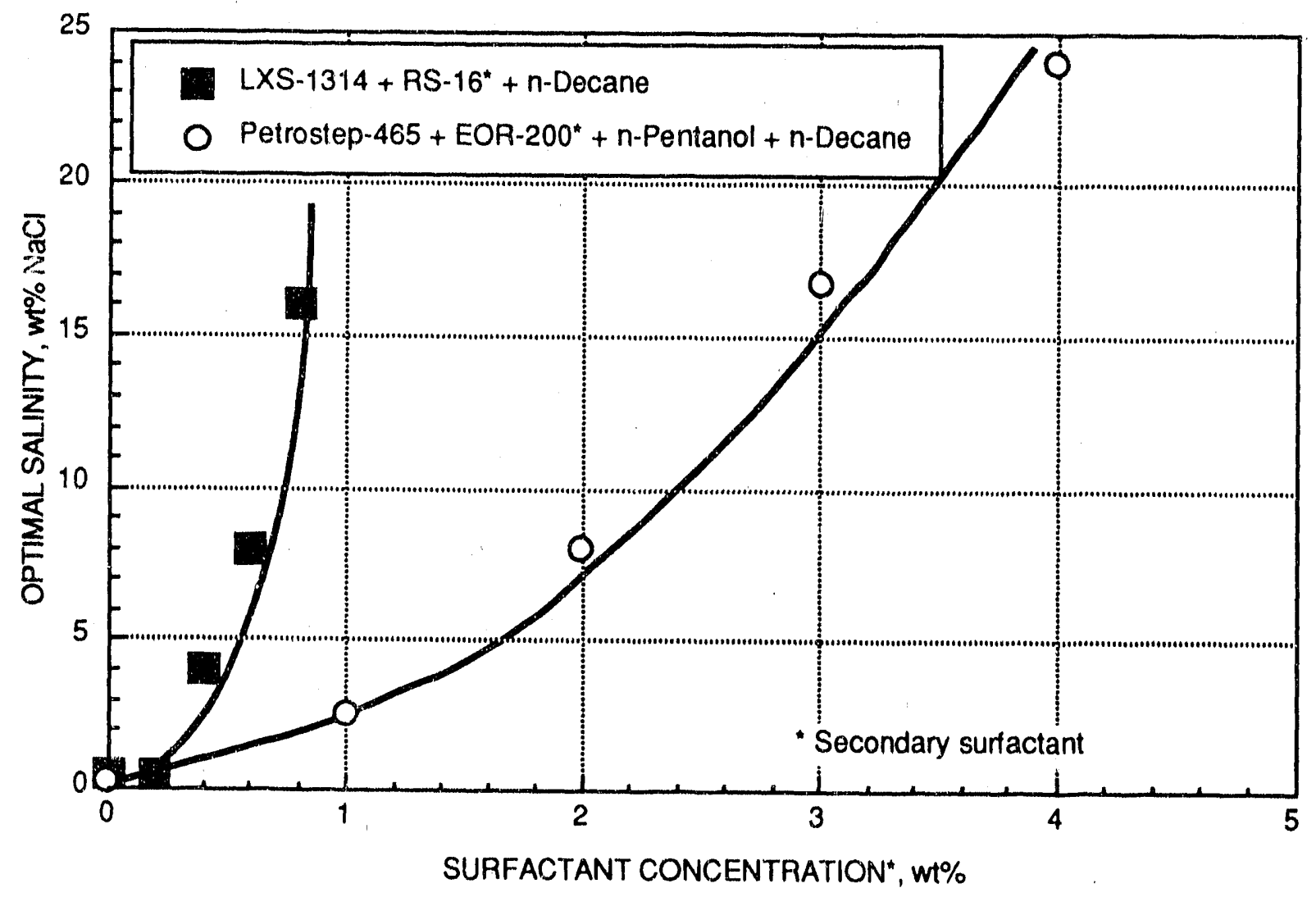

FIGURE 9. - Estimated optimal salinity vs. secondary surfactant concentration. 
The effect of changing the hydrorarbon chain length as well as temperature was investigated. Figure 10 shows a comparison of the IFT values and estimated optimal salinity as a function hydrocarbon chain length and temperature conditions. The results showed that for the binary mixtures at a fixed surfactant formulation and temperature, an increase in the hydrocarbon chain length resulted in an increase in the optimal salinity and a corresponding shight increase in the IFT values. The appropriate comparison ha: to be made at the optimal salinity of each of the mixtures tested. A similar observation has been made, ${ }^{33}$ that at a fixed salinity, the behavior of the surfactant-oil-brine system shifts from $1 \rightarrow m \rightarrow u$ (lower $\rightarrow$ middle $\rightarrow$ upper phase) microemuision by decreasing the oll or hydrocarbon chain length.

Phase behavior studies have been conducted for this AAS + CME system to determine the solubilization parameters and the width of the three-phase window. The results from the IFT screening studies were used as a guide for the salinity ranges to be considered in the phase behavior measurements. A salinity scan of the surfactant binary system was conducted to map out the extent of the Winsor type III behavior. ${ }^{35}$ For this purpose, phase tubes containing the surfactants and the hydrocarbon at different salinities were equilibrated at $50^{\circ} \mathrm{C}$, with water-oil ratio (WOR) fixed at 1:1. The results of the phase tube volume measurements were used to determine solubilization parameters as well as to determine the extent of the midpoint salinity with respect to total surfactant concentration. ${ }^{36}$

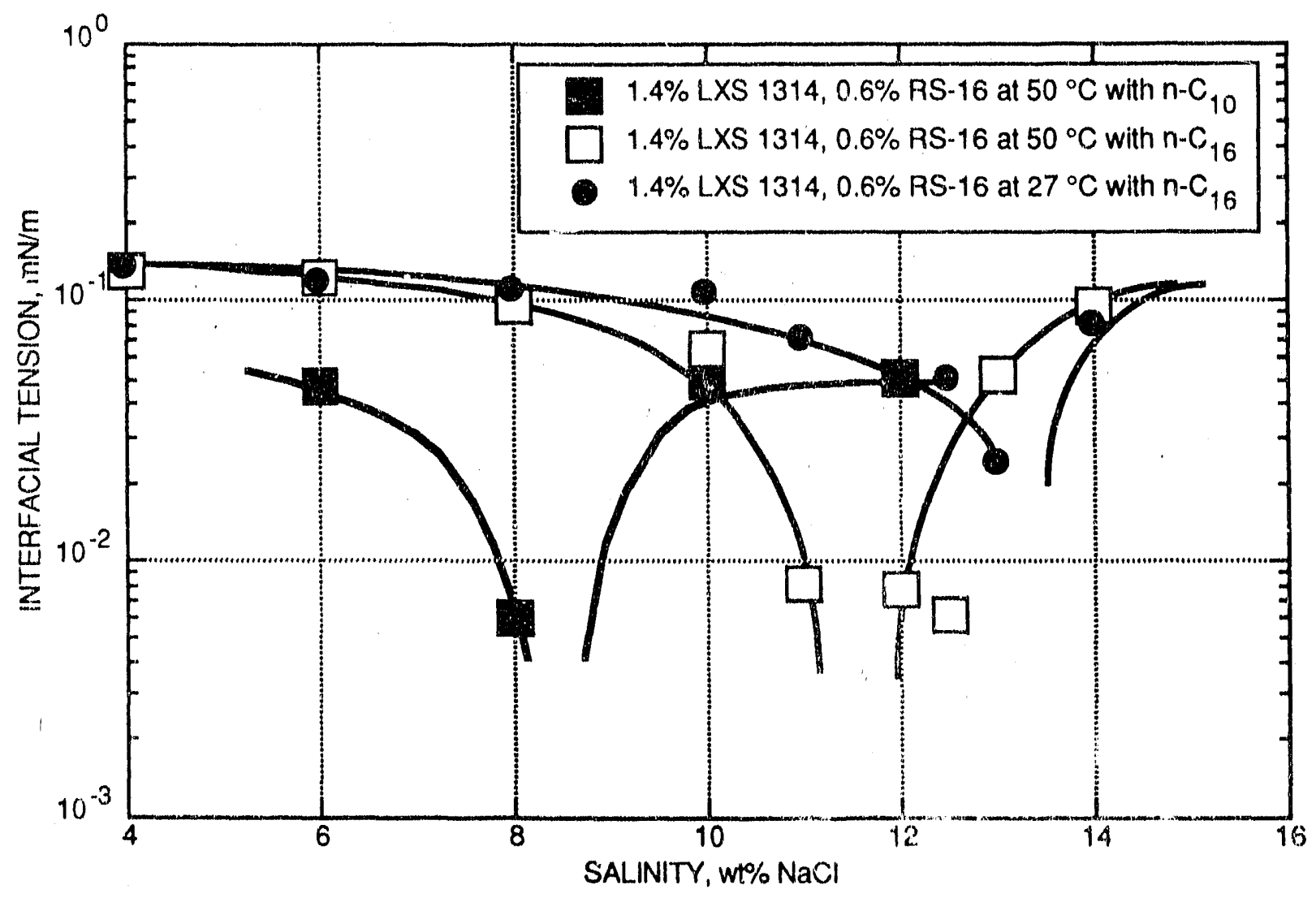

FIGURE 10. - Effect of hydrocarbon chain length and iemperature of measured IFTs. 
Figure 11 shows a representation of three types of phase diagram for a system containing surfactant, brine, and oil and their relationship with observed phase tube volume fractions. ${ }^{37}$ Using these phase volume relationships, the middle-phase region composition can be calculatr $\mathrm{i}$. Figure 12 shows a ternary plot of the component concentrations of the middle-phase region, based on the observed phase volume fractions. This plot represents a locus of invariant points (I) or middle-phase microemulsion as a function of the variation in salinity. The surfactant/hydrocarbon system would yield type $I(-)$ behavior at lower salinity ranges, while the system will exhibit a type $\|(+)$ behavior at higher salinity ranges. For this surfactant system, the combination of $1 . f \%$ LXS-1314 + $0.4 \%$ RS-16 yielded a middle-phase microemulsion from 3.0 to $5.0 \mathrm{wt} \% \mathrm{NaCl}$, while the solutions containing $1.4 \%$ LXS-1314 + 0.6\% RS-16 yielded a middle-phase microemulsion from 6.0 to $10 \mathrm{wt} \% \mathrm{NaCl}$.

The closer the invariant composition is to the brine/oil base line of the ternary diagram the more favorable are the interfacial tensions. Under such conditions, the midrile phase is more swollen with brine and oil, yielding lower interfacial tensions between the microemulsion/brine and microemulsion/oil. ${ }^{36}$ Figure 13 shows a plot of the oil and water solubilization parameters for the system. From this plot, the

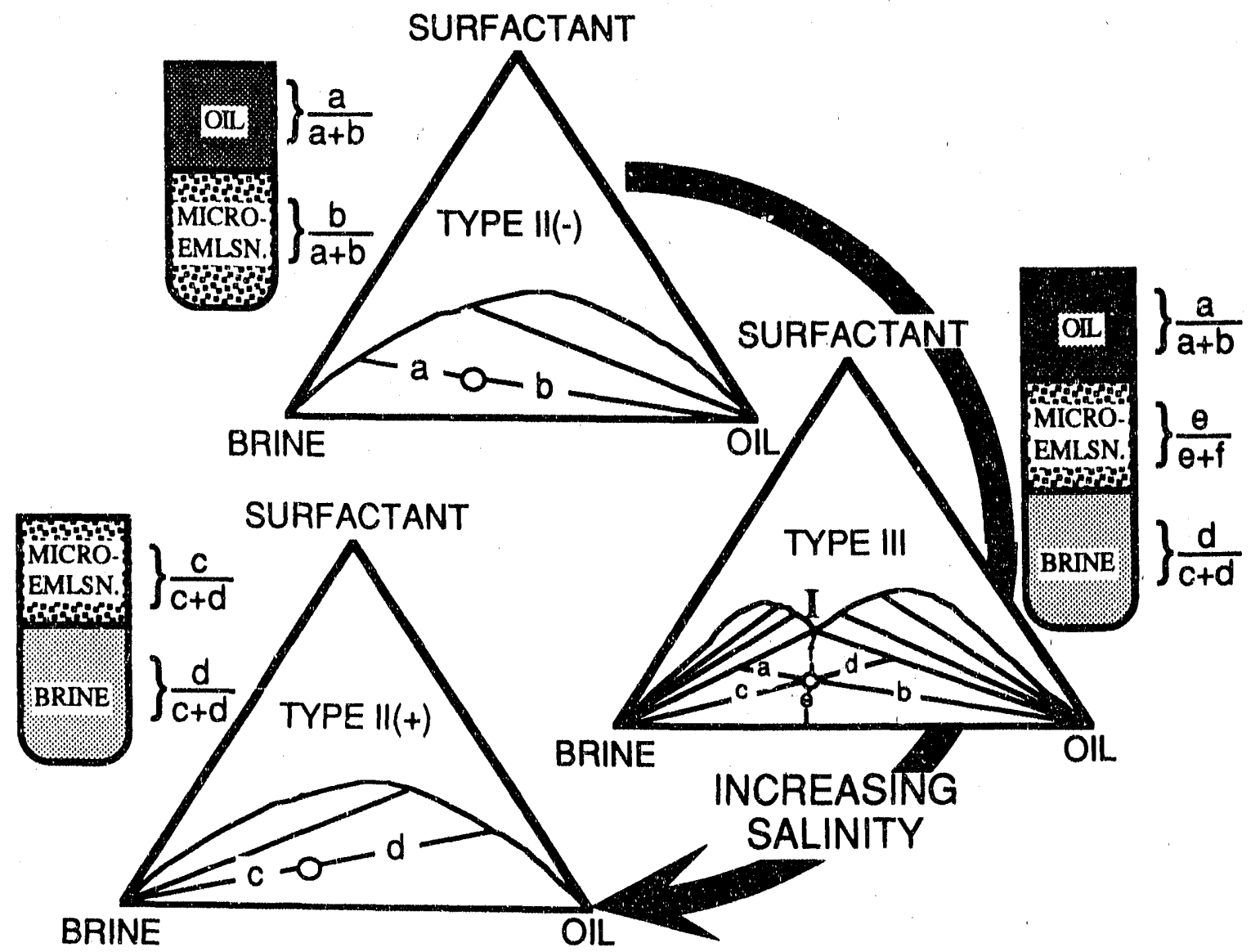

FIGURE 11. - Ternary phase diagrams for Winsor type phase behavior. 


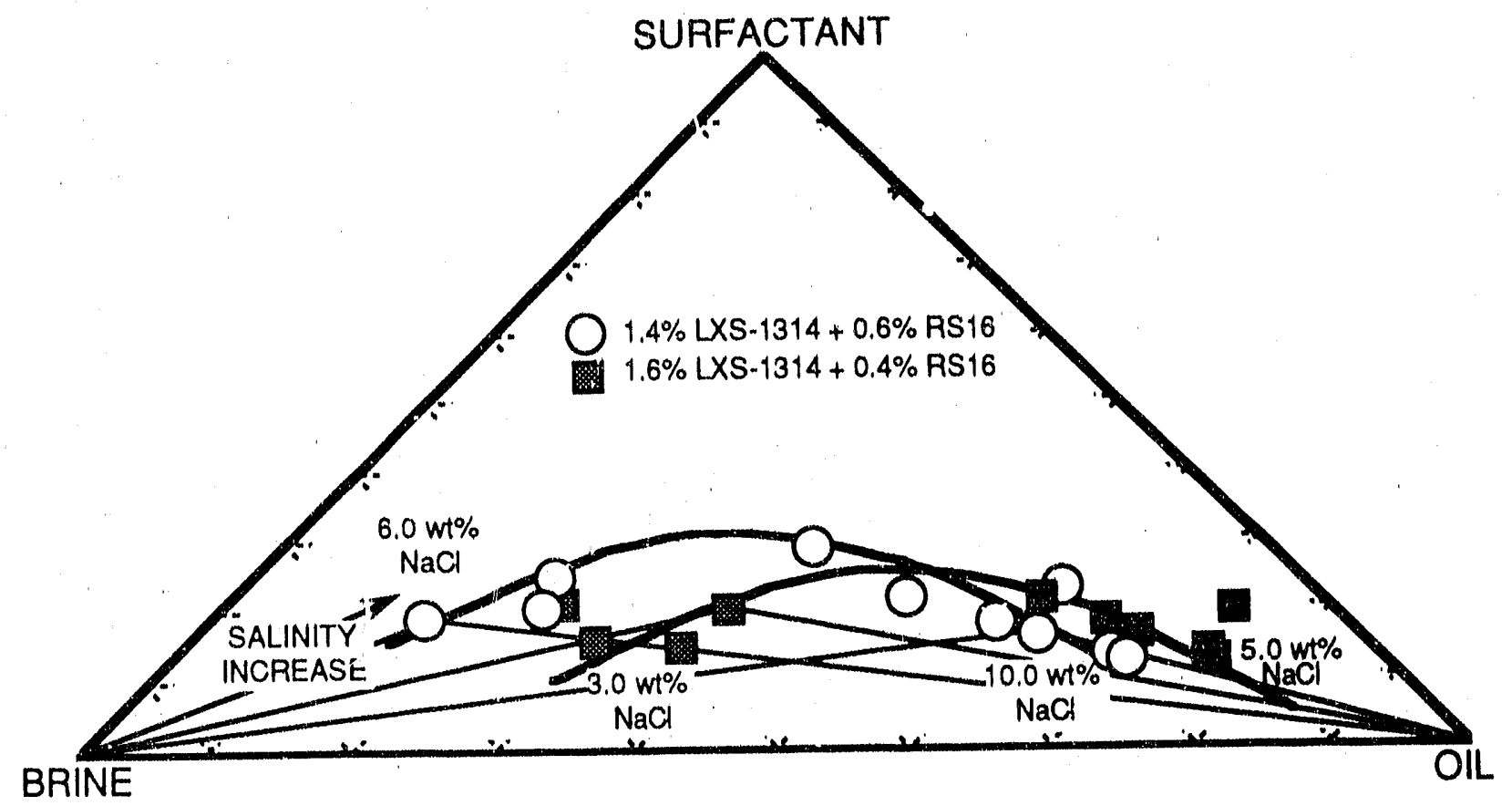

FIGURE 12. - Middle-phase composition as a function of salinity.

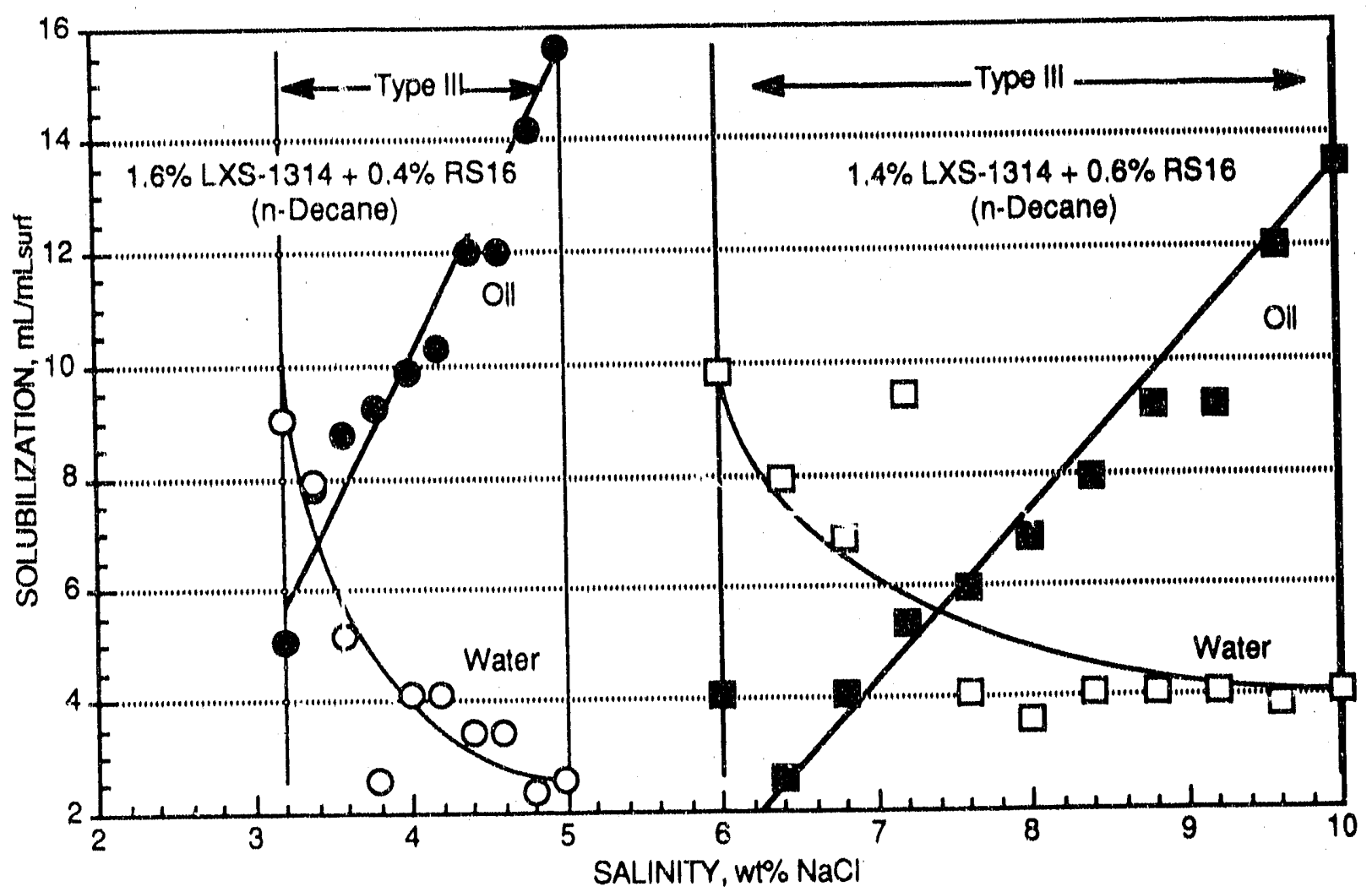

FIGURE 13. - Solubilization parameters as a function of sallinity, at $50^{\circ} \mathrm{C}$. 
estimated midpoint salinities for the two surfactant combinations are 3.6 and $7.5 w t \%$. The calculated solubilization parameters for this system were falrly low. Following the analogy that high solubilization results in ultralow IFT's, ${ }^{37}$ the values of calculated solubllization parameters should only yield moderate to low IFT values.

IFT measurements were also conducted for the binary mixture of LXS-1314, and a carboxymethylated ethoxylated surfactant, Sandoz Chemicals' JA-6, with n-decane. The relatively low, phase-separation temperature of $\mathrm{JA}-6\left(<24^{\circ} \mathrm{C}\right.$ at $0.5 \mathrm{wt} \% \mathrm{NaCl}$ salinity $\left.{ }^{14}\right)$ became a hindrance in the desired experimental measurements, even at low concentration of $0.1 \mathrm{wt} \% \mathrm{JA}-6$. These results were to be compared with the IFT values measured from the previous binary system containing LXS.1314 and RS-16 surfactants. The main difference between the two CME surfactants is in the primary $\left(R_{1}\right)$ hydrocarbon chain length and the degree of ethoxylation. For the RS-16 surfactant, the $R_{1}$ structura is a $C_{16}$ to $C_{18}$ group and the degree of ethoxylation is 8 , while the JA-6 surfactant has a structure of $C_{13}$ arid a degree of ethoxylation of 3. Prevlous results have shown that the JA-6 alone can exhibit relatively low IFT values with $n$-dodecane and $n$-decane at salinity ranges greater than $15 w t \%{ }^{13}$

Two other CME surfactants, Sandoz Chemlcals' MA-18 and Hüls's CES 6.5, were also used as secondary surfactanis in this study. Surfactant structures are given in table 1. These CME surfactants yielded relatively higher phase separation temperatures in previuus studies. ${ }^{14}$ For the IFT measurements, an equal ratio of the iwo surfactants (1:1) was added to the primary surfactant LXS-1314. Relatively low IFT values have been measured, less than $10^{-2} \mathrm{mN} / \mathrm{m}$ at a sailnity of about $3 \mathrm{wt} \% \mathrm{NaCl}$. These measurements were conducted using surfactant formulations containing only $10 \% \mathrm{CME}$ surfactants of the total surfactant concentration. No unfavorable phase behavior has been observed under these conditions. Additional IFT measurements were conducted for this surfactant system with $n$-decane at different salinities. The proportion of the AAS to CME surfactarits was varied to investlgate the extent of the improvement in salinity tolerance of the overall system. The IFT measurements yielded fairly uniform values of IFT (about $10^{-2} \mathrm{mN} / \mathrm{m}$ ) over a broad range of salinities $(0.5$ to $9 \mathrm{wt} \% \mathrm{NaCl}$ ) as a function of the different surfactant proportions tested. The results of these measurements are presented in figure 14. Similar IFT measurements were conducted using the North Burbank Unit (NBU) oll and the surfactant systems tested. Reasonable values of IFT were obtained for this system when using NBU oil. The results of the study are presented in figure 15. 


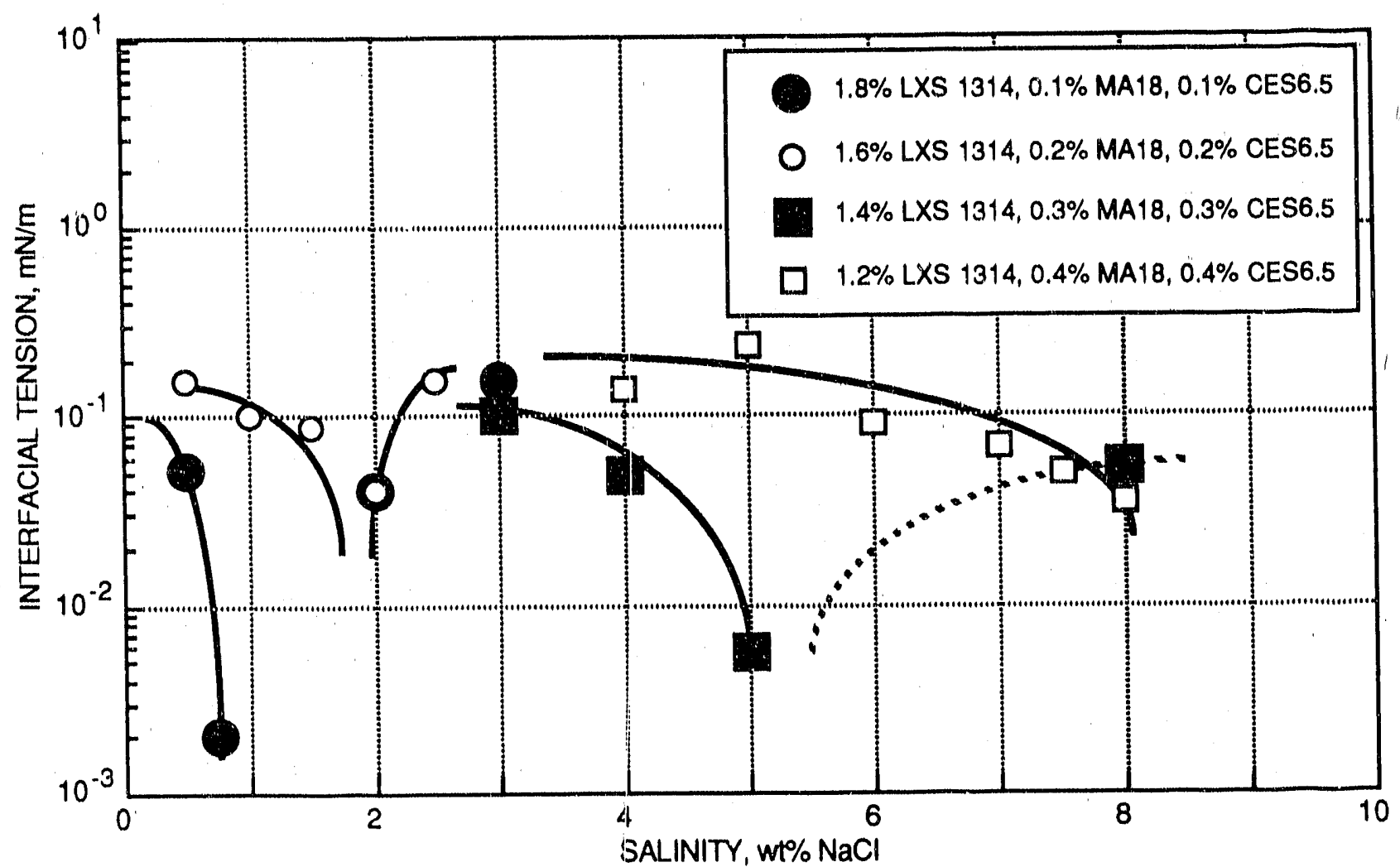

FIGURE 14. - Interfacial tensions measured for Sy'stem containing LXS-1314, MA-18, CES 6.5 , and n-decane at $50^{\circ} \mathrm{C}$.

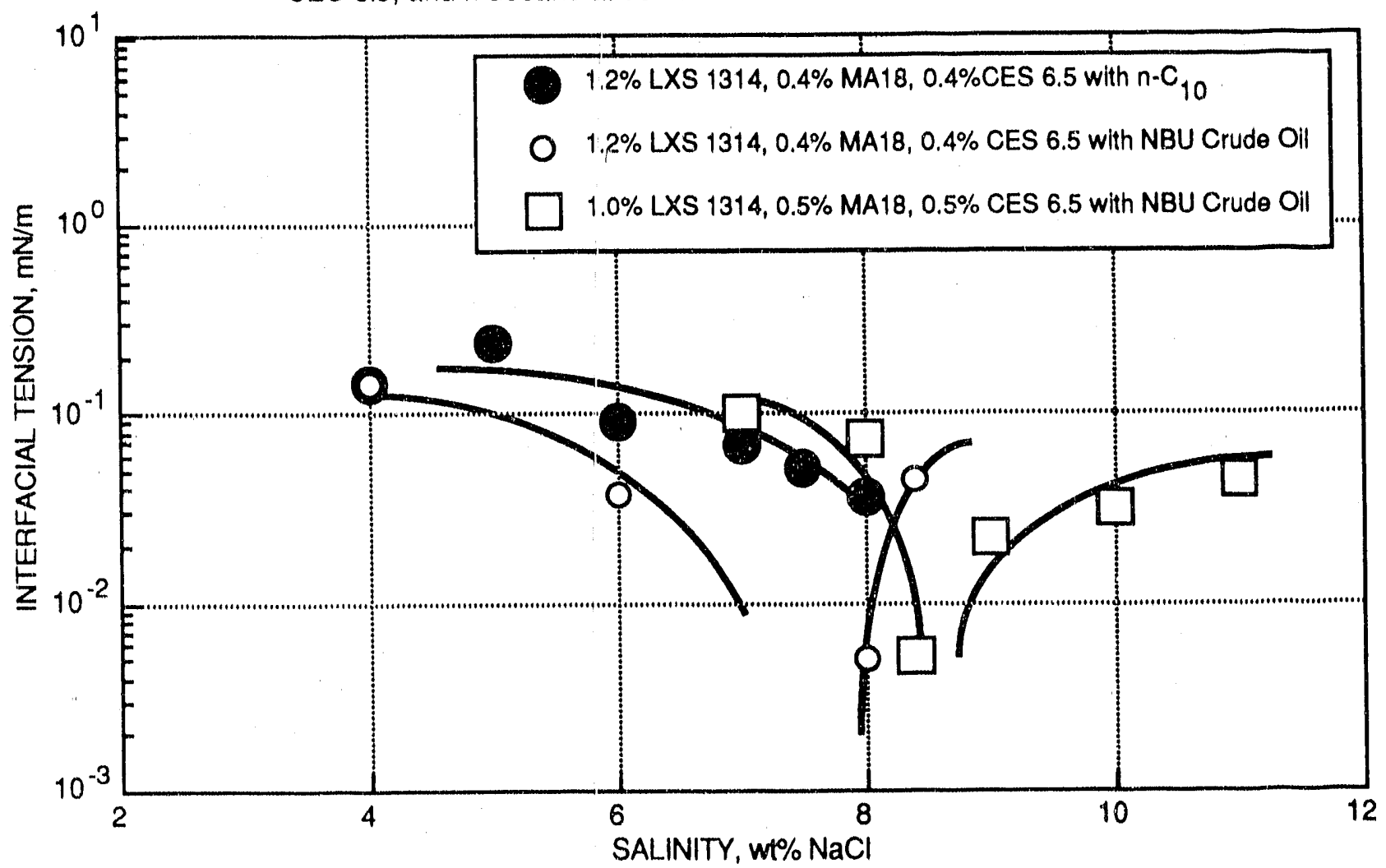

FIGURE 15. - Interfacial tensions measured for systern containing LXS-1314, MA-18, CES 6.5, and oil at $50^{\circ} \mathrm{C}$. 
Similar phase behavior measurernents have been conducted using a combination of the two CME surfactants, MA-18 and CES 6.5 , as secondary surfactants. The proportion of the different surfactants in the system were fixed, while the total surfactant concentration was varied from 0.5 to $4 \%$. The results are presented in figure 16. This figure shows a ternary plot of the calculated component concentrations of the middle-phase region. This plot shows a locus of the middle-phase microemulsion composition as a function of the variation in salinity. The total amount of surfactant did not seem to have a significant effect on the composition of the middle-phase. The solubilization parameters valculated for this system reflect similar range of midpoint salinities. These results are presented in figure 16 . The values for the calculated solubilization parameters are also fairly low, such that the effective IFT for the system would not be very favorable. As a base-case test, this system was used in a coreflood experiment to be discussed in a later section.

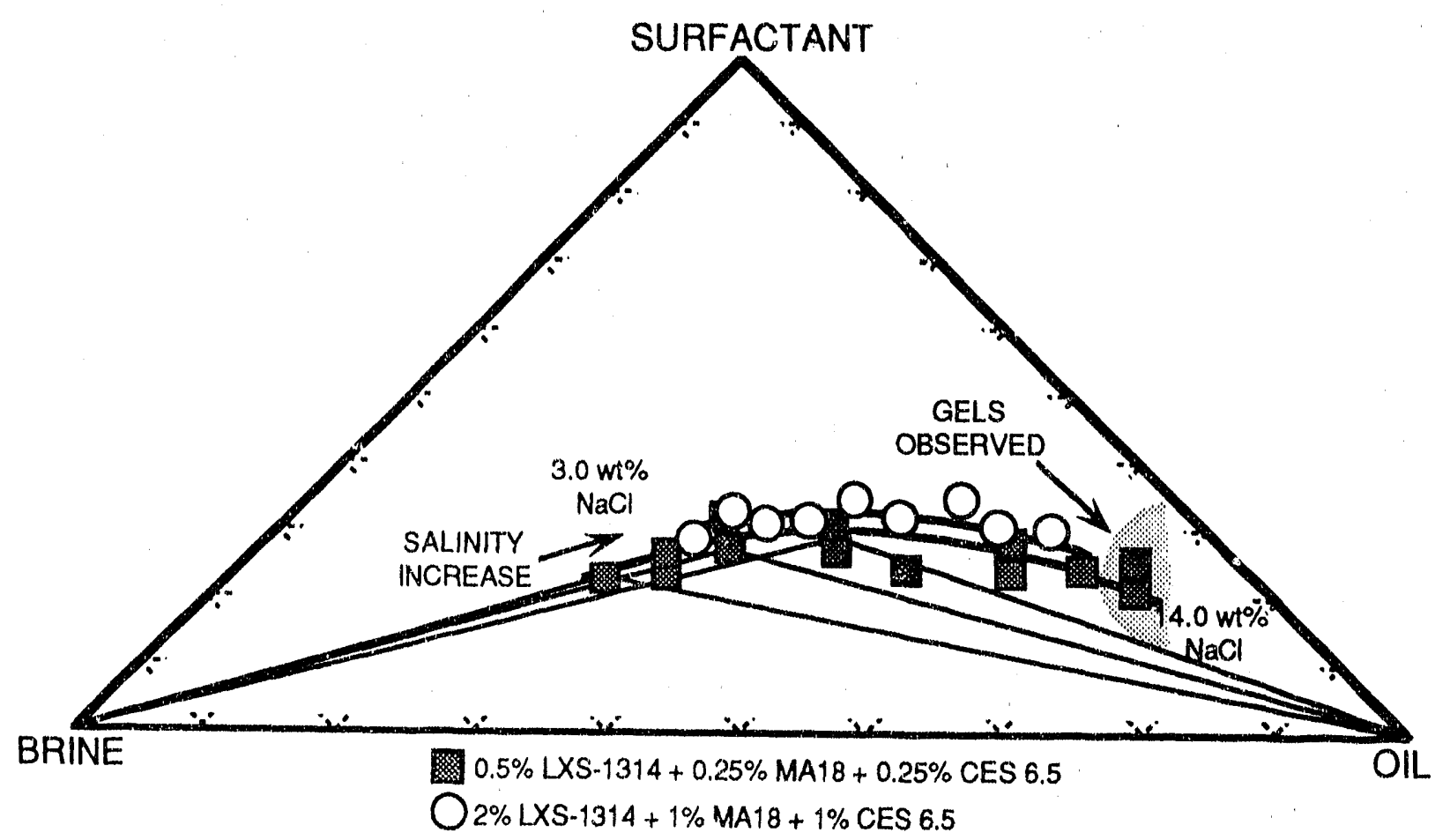

FIGURE 16. - Calculated middle-phase composition as a function of salinity. 


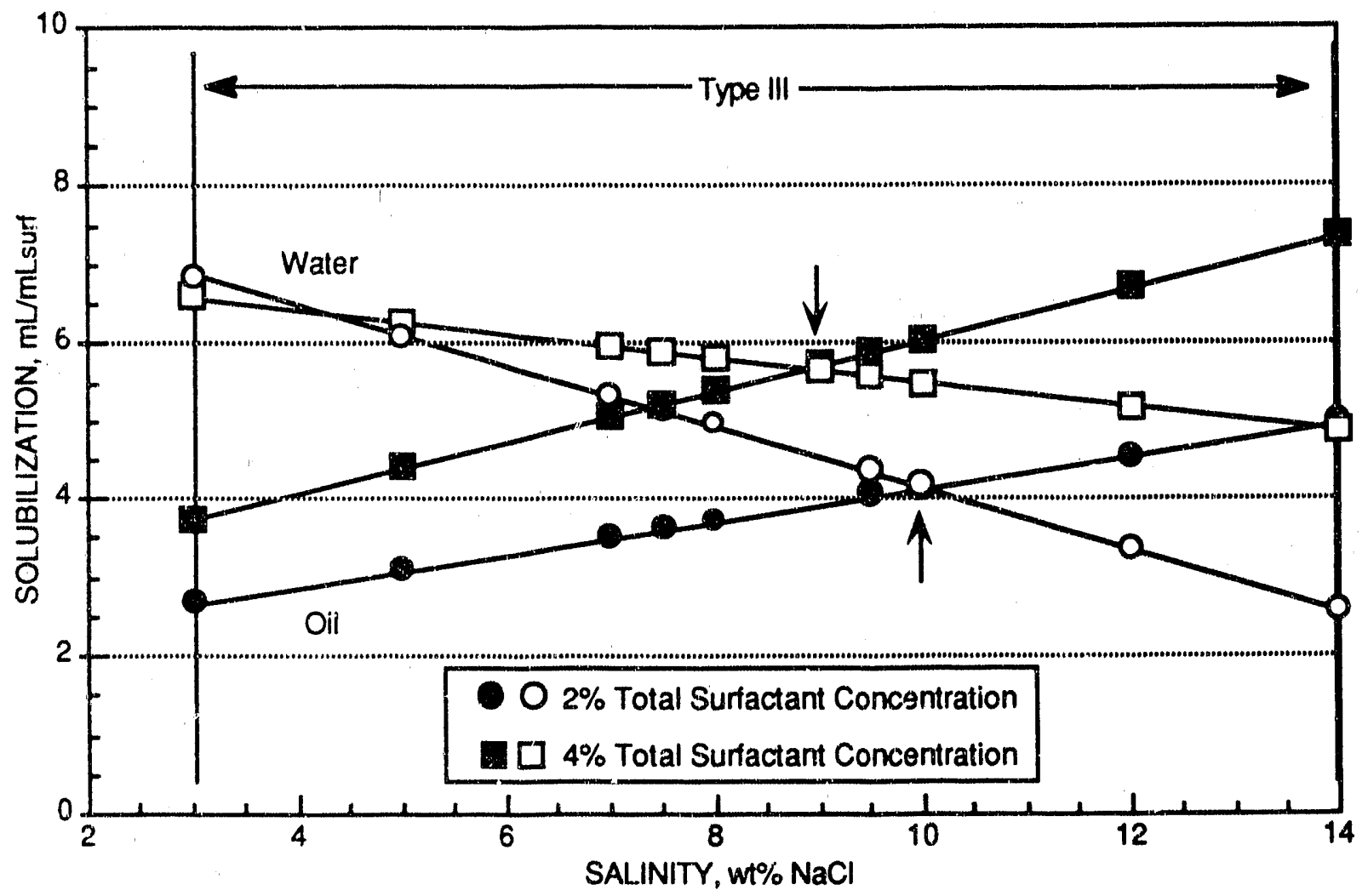

FIGURE 17. - Solubilization parameters as a function of salinity for system of LXS-1314, MA-18, and CES 6.5 with $n$-decane at $50^{\circ} \mathrm{C}$.

The Shell Enordet LXS-series of surfactants were tested in combination with several CME surfactants, using the crude oil from the North Burbank Unit (NBU), Osage County, Oklahoma. The LXS-series of alkyl aryl sulfoliate surfactants (without the addition of CME surfactants) have been previously studied. ${ }^{38-39}$ For the system containing LXS-1314 and RS-16 with the NBU crude oil, the results are presented in figure 18 . The plot of measured IFT versus salinity is shown for the different surfactant mixtures tested. The salinity in these experiments is represented as percent $(\%)$ of total simulated NBU brine strength. This approach introduces the effect of divalent ions in the brine solution used in the study. Results show that the combination of the twe surfactants yielded low to moderate IFT values (> $8 \times 10-2 \mathrm{mN} / \mathrm{m}$ ) even at high salinities (\% NBU strength). The results indicate a broad salt tolerance range, while maintaining relatively even, moderate-to-low IFT values $\left(8 \times 10^{-2}-10^{-1} \mathrm{mN} / \mathrm{m}\right)$. This range of IFT values was ingher than the values of the measurements determined when using the same surfactant system with n-decane, under similar conditions. Under the conditions tested, using this surfactant system for the NBU oil will not result in favorable conditions for oil recovery. 


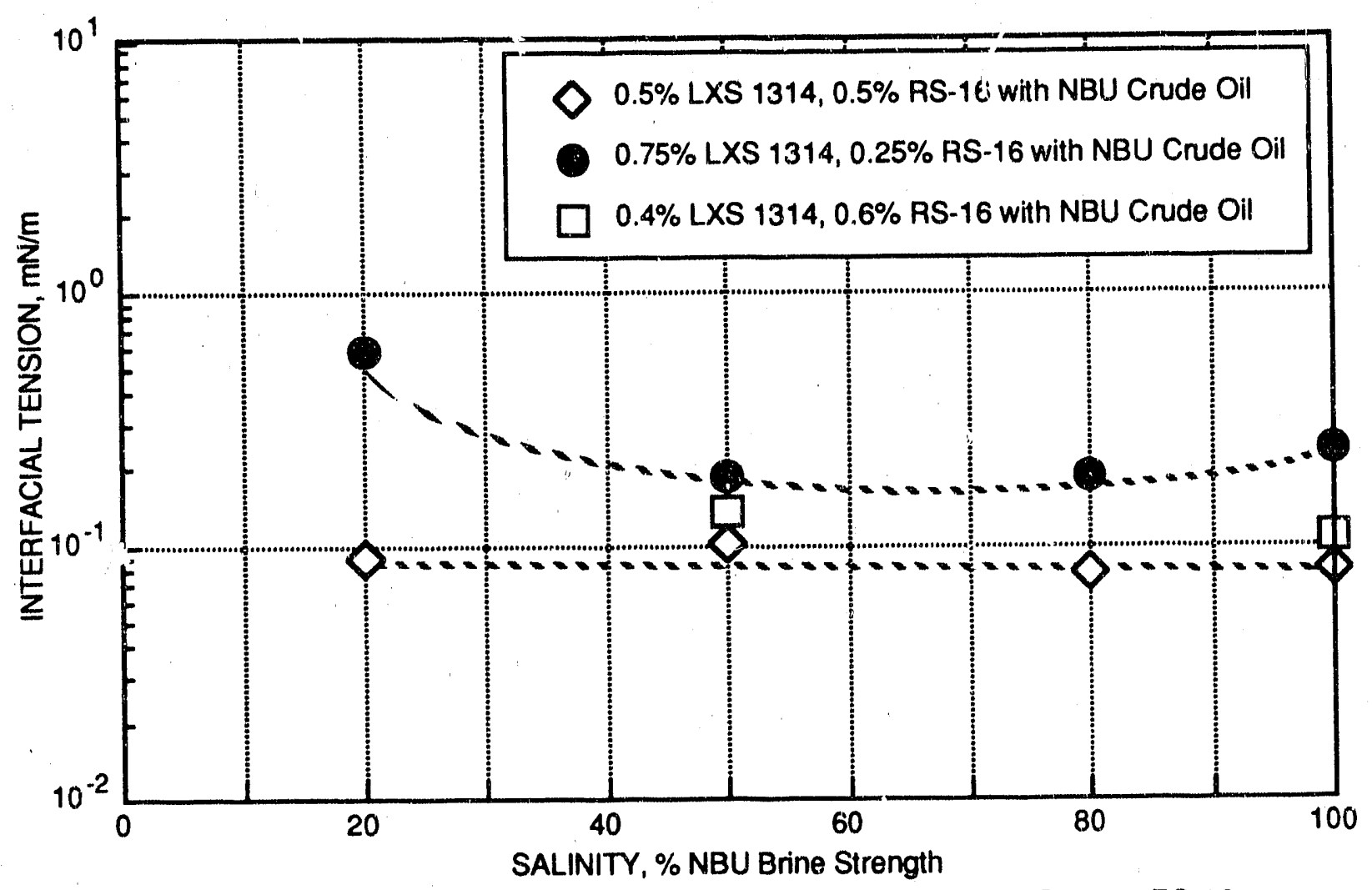

FIGURE 18. - Interfacial tensions measured for system containing LXS-1314, RS-16, and NBU crude oil at $50^{\circ} \mathrm{C}$.

For the system containing LXS-1112 and RS-16 with the NBU crude oil, the results are presented in figure 19. The plot of measured IFT versus salinity, represented as percent (\%) of total simulated NBU brine strength, is shown for the different surfactant mixtures tested. Results show that the combination of the two surfactants yielded low IFT values $(>1 \times 10-2 \mathrm{mN} / \mathrm{m}$ ) even at high salinities of $130 \%$ NBU strength. The results indicate a broad salt tolerance range, while maintaining relatively even, moderate-to-low IFT values $\left(8 \times 10^{-2} \cdot 10^{-1} \mathrm{mN} / \mathrm{m}\right)$. The results also indicate that the effect of changing the proportion of the two surfactants on the overall salinity tolerance of the system. As the amount of CME surfactant component in the system increased at a fixed total surfactant concentration, the low IFT values shifted to higher salinity ranges. Phase behavior measurements have also been conducted using this surfactant system combination. Solubilization parameters calculated for this system reflect the low-to-moderate values of IFT obtained in the previous measurements. Overall, using this surfactant system for the NBU oil will not result in significant oil recovery. 


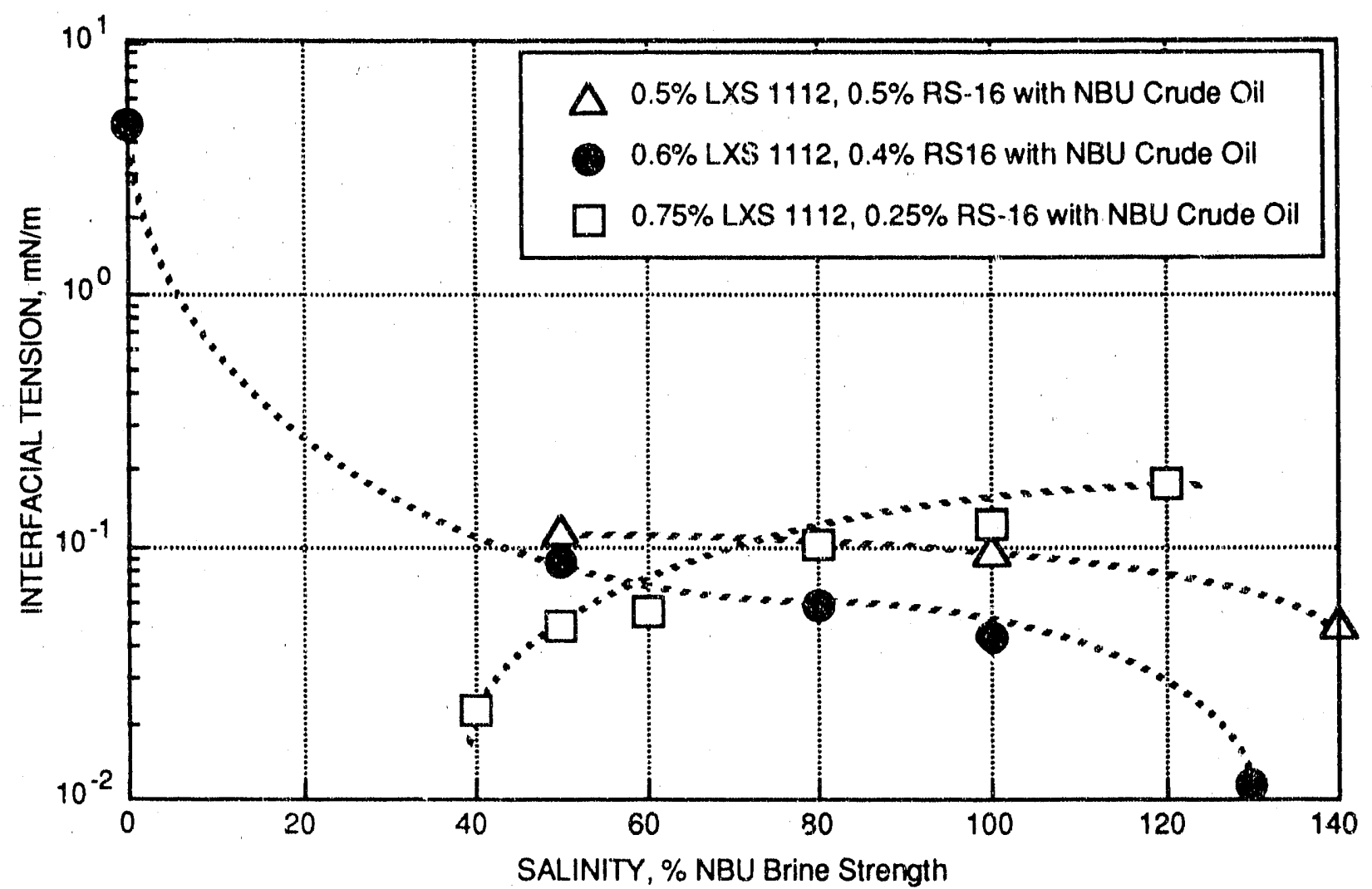

FIGURE 19. - Interfacial tensions measured for system containing LXS-1112, RS-16, and NBU crude oil at $50^{\circ} \mathrm{C}$.

The surfactant system containing LXS-810 and RS-16 with the NBU crude oil was also tested. The results of the IFT measurements are presented in figure 20 . The plot of measured IFT versus salinity shows that the mixtures of the two surfactants yielded fairly low IFT values $\left(>1 \times 10^{-2} \mathrm{mN} / \mathrm{m}\right.$ ) even at high salinities of $160 \%$ NBU strength. The higher salinity tolerance is reflected by the improved solubility of the shorter chain length $L \times s$-surfactant. The results show a fairly broad salt tolerance range, while maintaining relatively iist IFT values $\left(10^{-2}-10^{-1} \mathrm{mN} / \mathrm{m}\right)$. This range of IFT values was better than the values of the measurements when using the other two LXS surfactants in the series, under similar conditions. The results also indicate the same effect of changing the proportion of the two surfactants on the overall salinity tolerance of the system, as was observed for the LXS-1112 containing system. Phase behavior measurements have been conducted using this surfactant system. The low values of the solubilization parameters calculated for this system reflect the moderate values of IFT obtained from the measurements. A coreflood experiment using this system was conducted, based on the results of the initial IFT measurements. The results from the displacement experiment are presented in a later section. If 


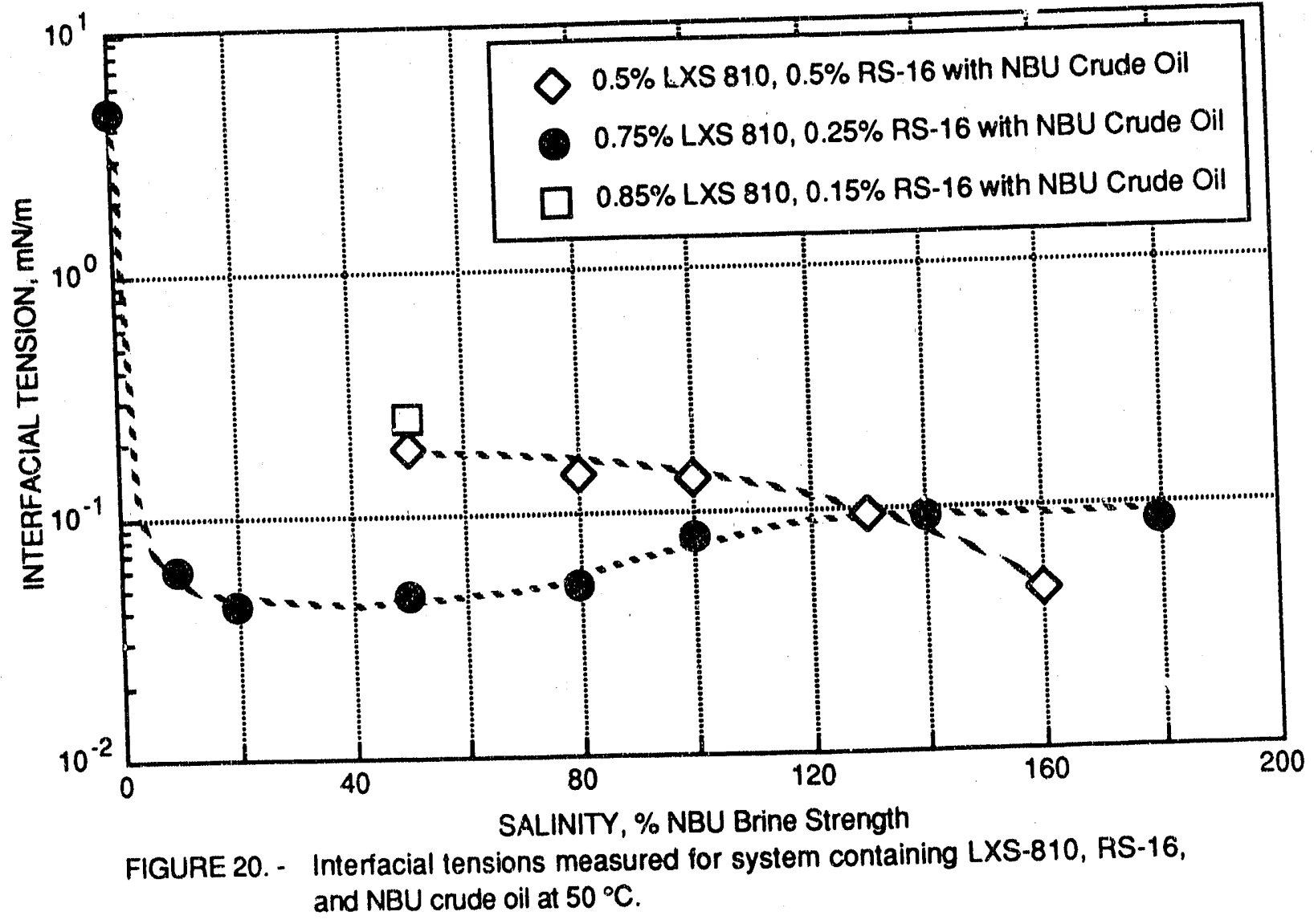

both the IFT and phase behavior measurements were taken into consideration, this surfactant system was not expected to achieve favorable conditions for oil recovery using the NBU crude oil.

IFT measurements were also conducted for the mixture of Stepan's B-120 surfactant (mixed, low-average-molecular weight AAS) and the CME surfactants, MA-18 and CES 6.5 with NBU crude oil. The results of the IFT measurements are presented in figure 21. Relatively low IFT values have been measured, less than $10^{-2} \mathrm{mN} / \mathrm{m}$, over a broad range of percent NBU brine sirength. These measurements were conducted using surlactant formulations containing a fixed proportion $(1: 1)$ of the CME surfactants in the total surfactant concentration. Phase tube observations conducted during the study showed one major drawbick: the B-120 precipitated when the amount of CME surfactant in the system was less than $40 \%$ of the total surfactant concentration. No unfavorable phase behavior was observed at conditions greater than $40 \%$ CME surfactant. Results of the solubilization parameter calculations from the phase tube measurements are presented in figure 22. Based on the IFT measurement results, this surfactant system was used in one of the coreflood displacement experiments. 


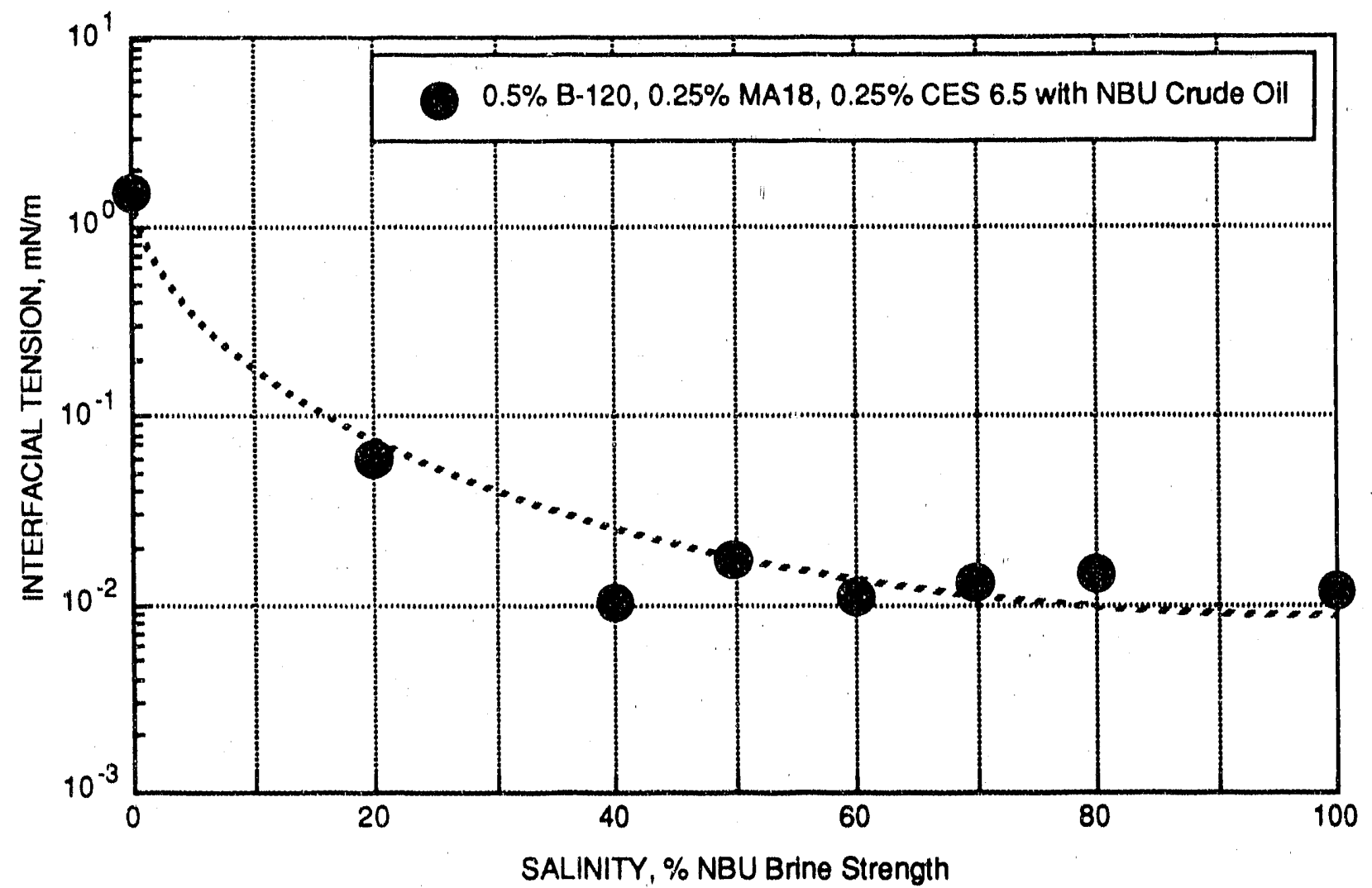

FIGURE 21. - Interfacial tensions measured for system containing B-120, MA-18, CES 6.5, and NBU crude oll at $50^{\circ} \mathrm{C}$.

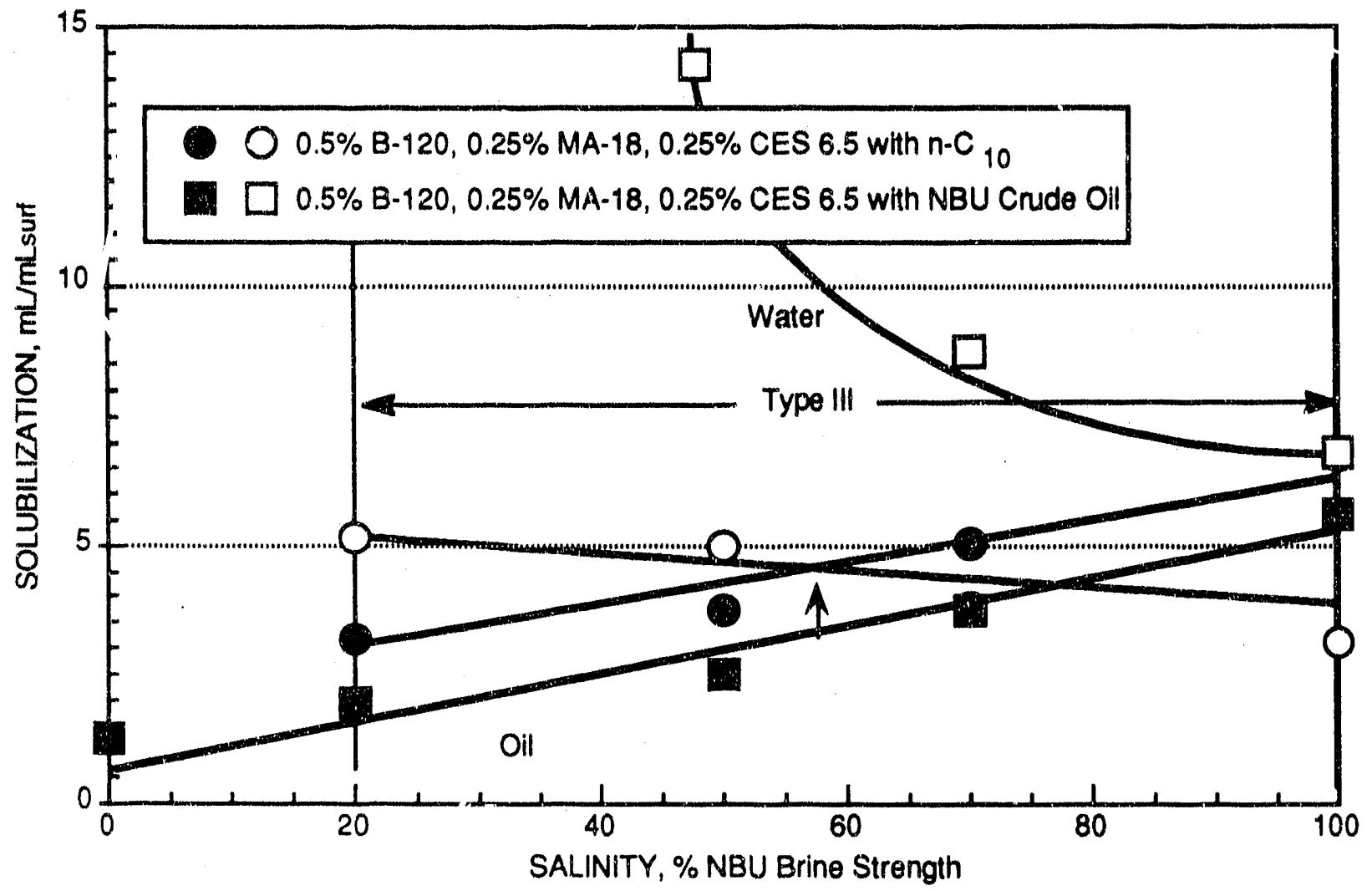

FIGURE 22. - Solubilization parameters as a function of salinity for system of B-120, MA-18, CES 6.5 , and n-decane and NBU crude oil at $50^{\circ} \mathrm{C}$. 


\section{Alpha Olefin and CME Surfactants}

Screening IFT measurements were also conducted for several mixtures of AOS and CME surfactants with n-decane and NBU crude oil as the hydrocarbon component. The AOS surfactants tested included Shell's AOS-1416, Shell's AOS-1618, and Siponate A-168. The CME surfactants tested included RS-16, MA-18, and CES 6.5. In most cases, particularly for the AOS-1416 and AOS-1618 containing systems, alcohol was added to the mixtures as a cosurfactant, primarily to improve solubility. Severe gel formation or precipitation were observed in most of the mixtures at the different salinities tested. The addition of the CME surfactant did not alleviate the formation of gels or precipitates in the test mixtures. Reliable IFT measurements were not possible under most of these conditions, such that the tests conducted for these systems were fairly limited. Figure 23 shows a plot of the results from limited IFT measurements conducied for the system containing A-168, MA-18, and CES 6.5 with NBU crude oil. The IFT values measured for this system were greater than $10^{-1} \mathrm{mN} / \mathrm{m}$, under the conditions tested.

\section{Alkyl Aryl Sulfonates and ES Surfactants}

IFT measurements were also conducted for a mixture containing the LXS-1314 surfactant and a different secondary surfactant. In this mixture, an alkylbenzene ethoxylated sulfate surfactant, GAF's CO-436 surfactant, was used to improve solubility. Based on the results of adsorption measurements conducted on this system, screening IFT arid phase behavior measurements were also conducted with NBU crude oil at $50^{\circ} \mathrm{C}$. The results of the IFT measurements are presented in figure 24. Low-to-mocierate IFT values have been measured $\left(10^{-2}-10^{-1} \mathrm{mN} / \mathrm{m}\right.$ ), over a brc ad range of salinity ( $w$ t $\% \mathrm{NaCl}$ ). Figure 24 also shows a comparison of the IFT measurements when using both NBU crude oil and $n$-decane as the hydrocarbon component. The results of the phase behavior measurements are presented in figure 25. The values of the calculated solubilization parameter are fairly low, corresponding to the low-10-moderate values of IFT measured. This surfactant system was used in one of the coreflood displacement experiments. 


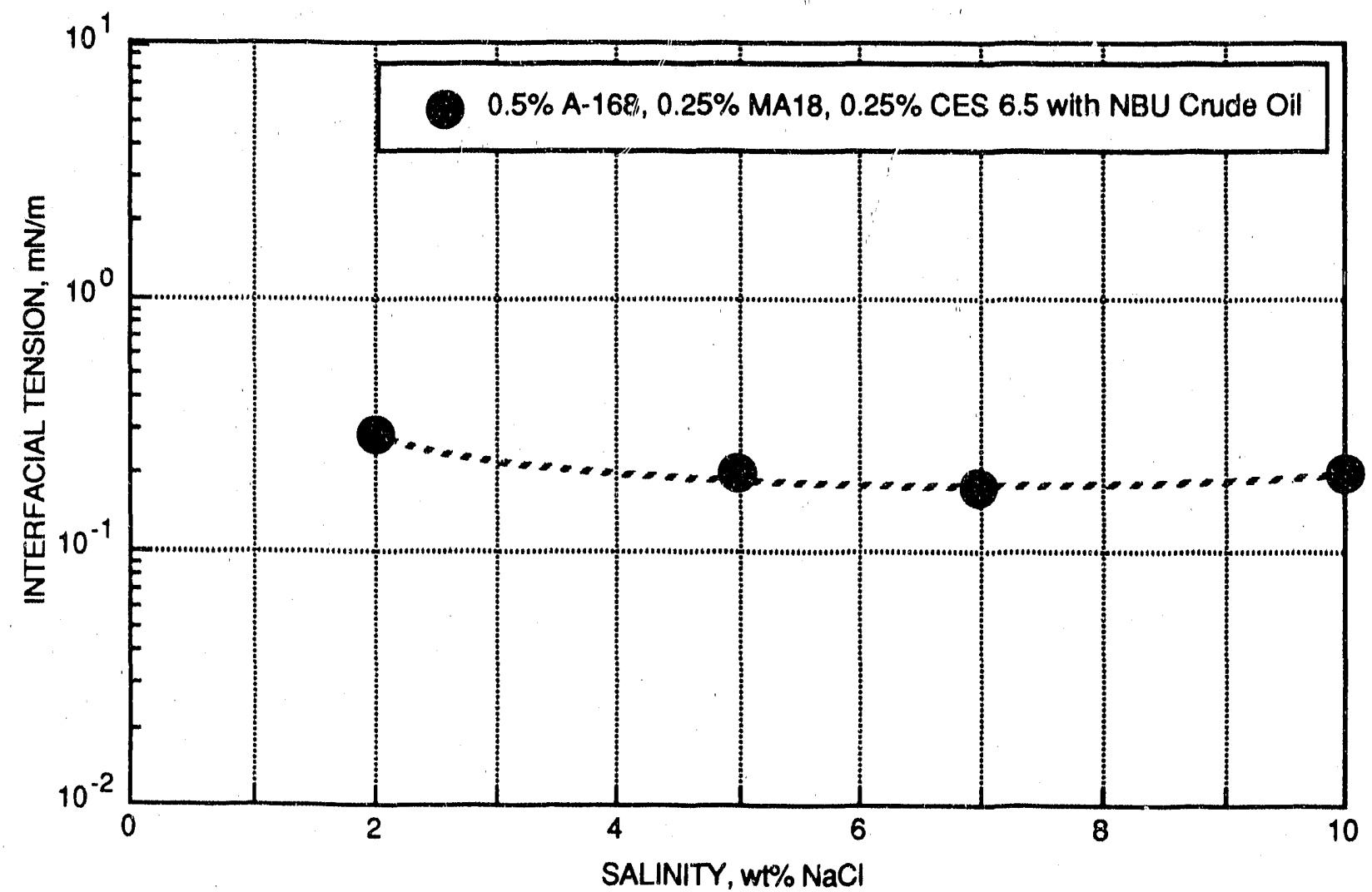

FIGURE 23. - Interfacial tensions measured for system containing A-168, MA-18, CES 6.5 , and NBU crude oil at $50^{\circ} \mathrm{C}$.

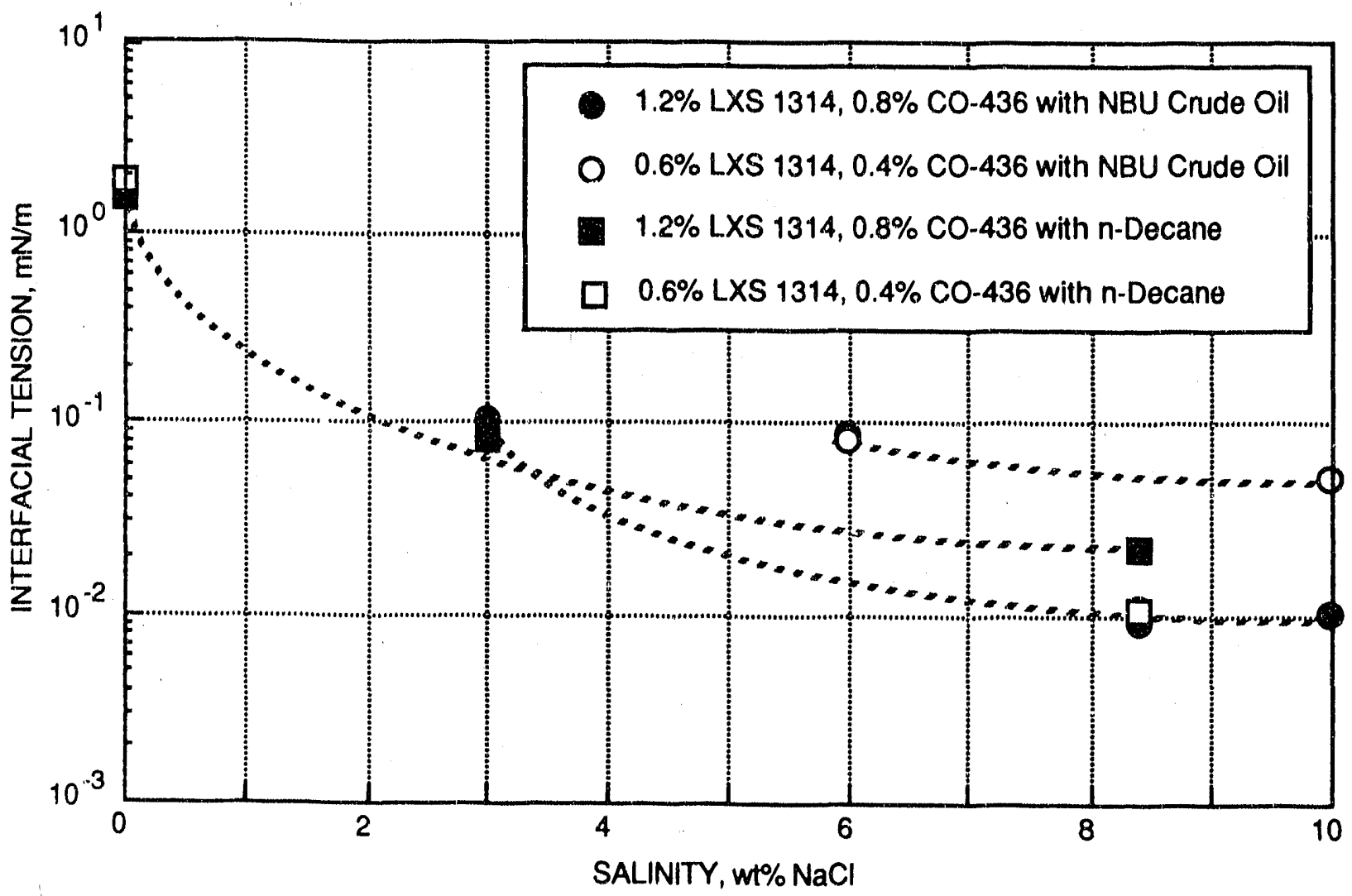

FIGURE 24. - Interfacial tensions measured for system containing LXS-1314, CO-436, and $\mathrm{n}$-decane and NBU crude oil at $50^{\circ} \mathrm{C}$. 


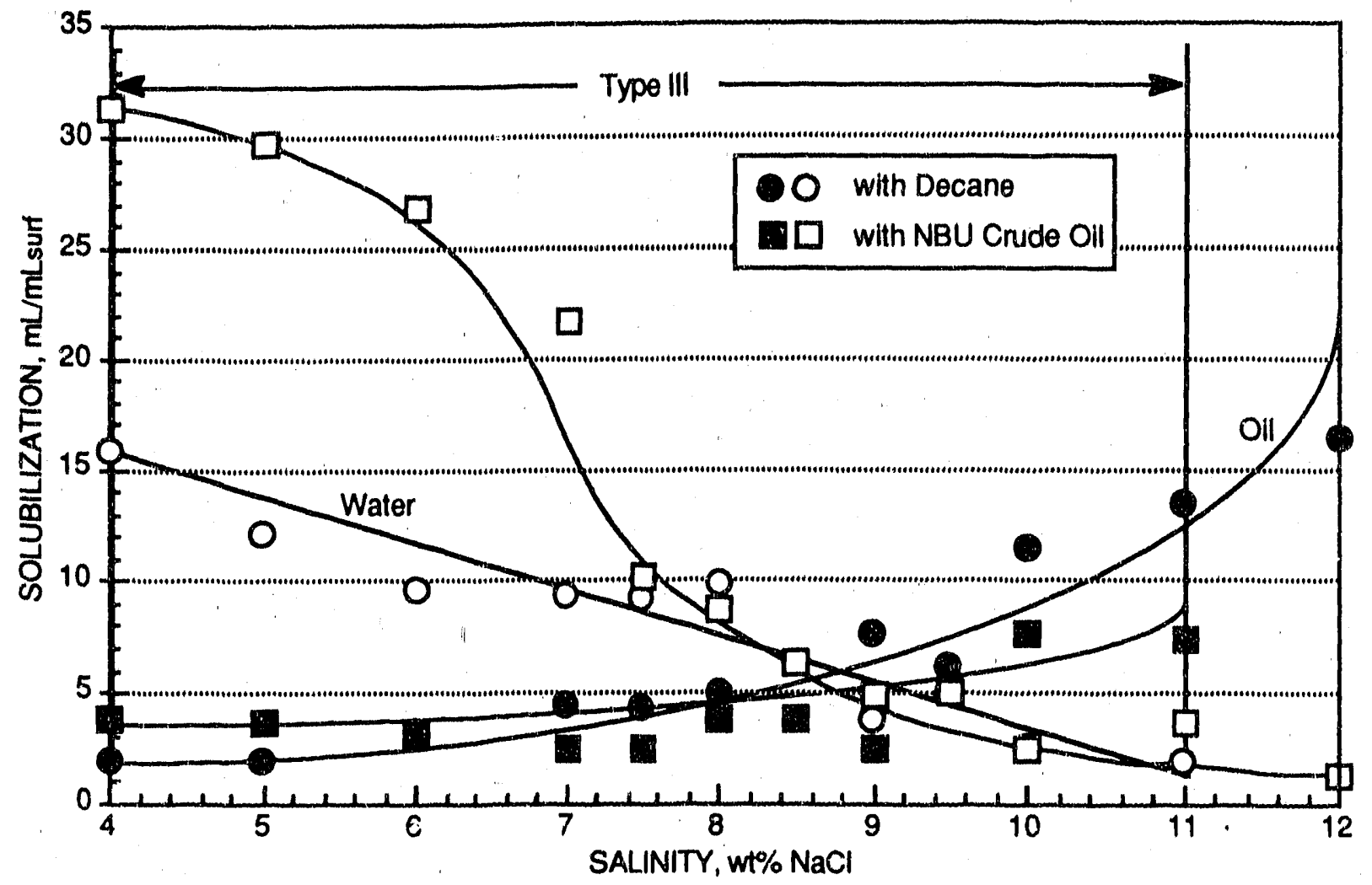

FIGURE 25. - Interfacial tensions measured for system containing LXS-1314, CO-436, and $\mathrm{n}$-decane and NBU crude oil at $50^{\circ} \mathrm{C}$.

\section{Phase Inversion Temperature Measurements}

Phase inversion temperature (PIT) measurements were conducted to confirm any relationship between the PIT and the occurrence of minimal IFT. The PIT measurements were only conducted on a few of the surfactant systems that have been studied in this work. The PIT measurement is routinely associated with observation of the phase inversion for nonionic surfactants, and the technique has been used extensively by Shinoda et al. to investigate surfactant-oil interaction. ${ }^{17-18}$ They have found that for nonionic surfactants, the PIT was closely associated with the temperature at which three-phase behavior occurs. The PIT in emulsions corresponds to the temperature at which the hydrophilic-lipophilic property (HLB) of the surfactant is balanced for a given surfactant-hydrocarbon-brine system, a balance of the affinity of the surfactant toward the brine and oil phases. The ionic surfactant becomes more hydrophilic as the operating temperature increases, while the nonionic surfactant becomes more lipophilic as a function of the temperature rise. For CME surfactants, Balzer 40 suggests that the phase transformation results from the breakdown of the hydrates associated with the EO units as the temperature increases. Under this condition, the surfactant becomes more hydrophobic and oll soluble. This provides the surfactant the capability of stabilizing a water-in-oil emulsion. 40 In this case, the CME behavior is similar to that of a nonionic surfactant. 
The surfactant systems used for PIT measurements were combinations of several alkyl aryl sulfonate and CME surfactants. As an example, the system containing NBU crude oil, LXS-810, and RS16 was used for the PIT measurements. These experiments were conducted in various salinities, expressed as percent (\%) total synthetic NBU brine strength. Figure 26 shows a plot of the solution electrical conductivity of the surfactant system tested as a function of sallinity. The results show that only the $100 \%$ NBU strength solution inverted to oil external at less than $30^{\circ} \mathrm{C}$. The rest of the solutions inverted at a higher temperature, and the slope of the transition from high-conducting to low-conducting was not very abrupt. In this system, no definitive IFT minima was observed that corresponded with the estimated PIT for the different solutions tested.

Similar observations were made for the B-120, CES 6.5, MA-18 system with NBU oll. No IFT minimum was observed and the transition of the solution from high conducting to low conducting conditions was not very complete. For the solutions tested, PIT measurements did not seem to be a suitable screening technique.

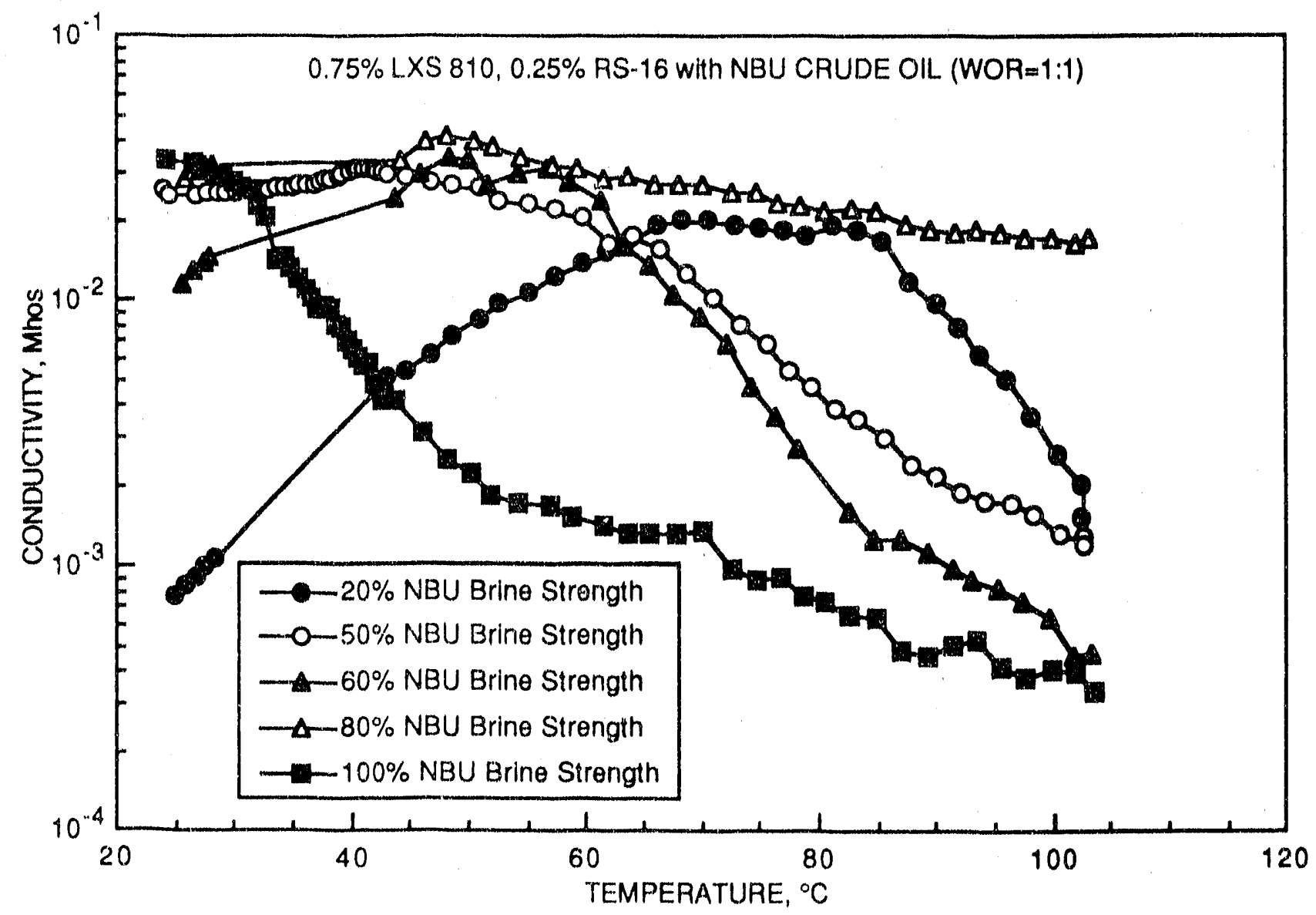

FIGURE 26. - Electrical conductivity measured for systern containing LXS-810 and RS-16 with NBU crude oll. 


\section{Summary}

Surfactant mixtures that include at least one nonethoxlyated and at least one othoxylated anionic surfactant were tested to determine phase behavior and IFT behavior in the presence of oll. These studies were initiated to determine methods to increase the salinity tolerance of surfactant solutions and to improve oll production. Ethoxylated anionio surfactants can be used to provide greater salt tolerance for nonethoxylated surfactant such alkyl aryl sulfonates. Incorporation of ethoxylated surfactants in mixed surfactant systems was used to adjust optimal salinity conditions to match those of a selected reservolr.

The results of IFT measurements using a serles of alkyl aryl sulfonate (AAS) surfactants and several CME surfactants indicated that this surfactant-type combination ylelded relatively low IFT values $\left(<10^{-2} \mathrm{mN} / \mathrm{m}\right.$ ) over a broad range of conditions, even at high salinitles (wt $\% \mathrm{NaCl}$ or \% NBU strength). A broadening of the salt tolerance range of the surfactant solution was observed as a function of an increase In the ethoxylated surfactant proportion in the mixture, while maintaining relatively low IFT values $\left(10^{-3}-10^{-1} \mathrm{mN} / \mathrm{m}\right)$. The CME surfactarit improved the solubility of the AAS surfactants in brine. The range of IFT values measured was considerably lower than the values of the measurements when using the AAS or the CME surfactant alone, under similar conditions. However, no broad ultralow IFT values $\left(<10^{-3}\right.$ $\mathrm{mN} / \mathrm{m}$ ) were determined for the tested surfactant mixtures. The solubllization parameters measured for these systems were generally moderate to low.

PIT measurements of mixtures of AAS and CME surfactants falled to show any abrupt changes from sil-external to water-external emulsions with change in temperature. This correlates with the observations of broad, relatively low IFT values without a distinct low minimum or optimum IFT for the mixtures of surfactants used in this study. This also suggests that the PIT lechnique is not an informative screening tool for mixed surfactant systems containing anionic surfactants.

\section{Adsorption Results}

\section{Alkyl Aryl Sulfonates and CME Surfactants}

Experiments were condlicted to determine static and dynamic adsorption of the surfactant mixture LXS-1314, MA-18, and CES 6.5 on crushed Berea sandstone. The objectives of these experiments were to determine total surfactant loss at ambient conditions and to determine if chromatographic separation of the components could be observed.

Adsorption results for the LXS/MA/CES mixture under static and dynamic conditions are summarized in table 3. For these surfactant-loss experimerits, simulated NBU brine was used $(6.65 \%$ $\mathrm{NaCl}, 1.53 \% \mathrm{CaCl}_{2}$, and $0.24 \% \mathrm{MgCl}_{2}$ ). At this salinity, the LXS surfactant would phase separate and 
TABLE 3. - Total surfactant loss for a mixed surfactant system

\begin{tabular}{|c|c|c|c|}
\hline $\begin{array}{c}\text { inttlal } \\
\text { [LXS-1314] } \\
\text { wt \% } \\
\end{array}$ & $\begin{array}{c}\text { Initial } \\
\text { [MA-18] } \\
\text { Wt \% }\end{array}$ & $\begin{array}{c}\text { initial } \\
\text { [CES 6.5] } \\
\text { wt \% }\end{array}$ & $\begin{array}{c}\text { Surfactant loss, } \\
\mathrm{mg} / \mathrm{g}\end{array}$ \\
\hline \multicolumn{4}{|c|}{ STATIC TESTS } \\
\hline 1.0 & 0.5 & 0.5 & $3.8 \pm 0.2$ \\
\hline 0.1 & 0.05 & 0.05 & $3.5 \pm 0.2$ \\
\hline 0.6 & 0.2 & 0.2 & $4.6 \pm 0.5$ \\
\hline \multicolumn{4}{|c|}{ DYNAMIC TESTS } \\
\hline 0.6 & 0.2 & 0.2 & $5.3 \pm 0.9$ \\
\hline
\end{tabular}

show $100 \%$ surfactant loss without the presence of CME surfactants in solution. With the addition of CME surfactants, the solutlons were cloudy but did not phase separate.

Total surfactant loss was reduced slightly when the ratio of CME surfactants to LXS-1314 was increased from 40 to $50 \%$. A 10 -fold increase in total surfactant concentration from 0.2 to $2.0 \%$ showed little effect on total surfactant loss. Since adsorption appears to remain constant for surfactant concentrations above the critical micelle concentration (CMC), this suggests that for these mixtures surfactant association occurs at concentrations less than $0.2 \%$. In addition, agreement was good between surfactant loss values measured in static and in dynamic tests.

An HPLC analysis of surfactant concentration for the mixed system indicated two main components of the mixture eluted separately from the reverse-phase HPLC column. All three surfactants were present in peak 1 , which was approximately 5 times greater in area than peak 2 . Only components of the CME surfactants appeared to be present in peak 2 which had previously been associated with the nonionic (noncarboxylated) components of these commercial CME surfactants. The presence of LXS-1314, an anionic surfactant, did not appear to change the peak area of peak 2. Two dynamic tests were performed. For test 1 (1-ft sandpack), components of peaks 1 and 2 appeared to travel through the sandpack together, as shown in flgure 27. Some indication of the begining of separation of the anionic and nonionic surfactants can be observed in test 2 (2-ft sandpack), as shown in figure 28. The nonionic surfactant slightly precedes the anionic surfactant in this test. Over longer travel distances in the reservoir, nonionic and anionic surfactants may chromatographically separate in the same way that surfactant and alcohol can separate. 


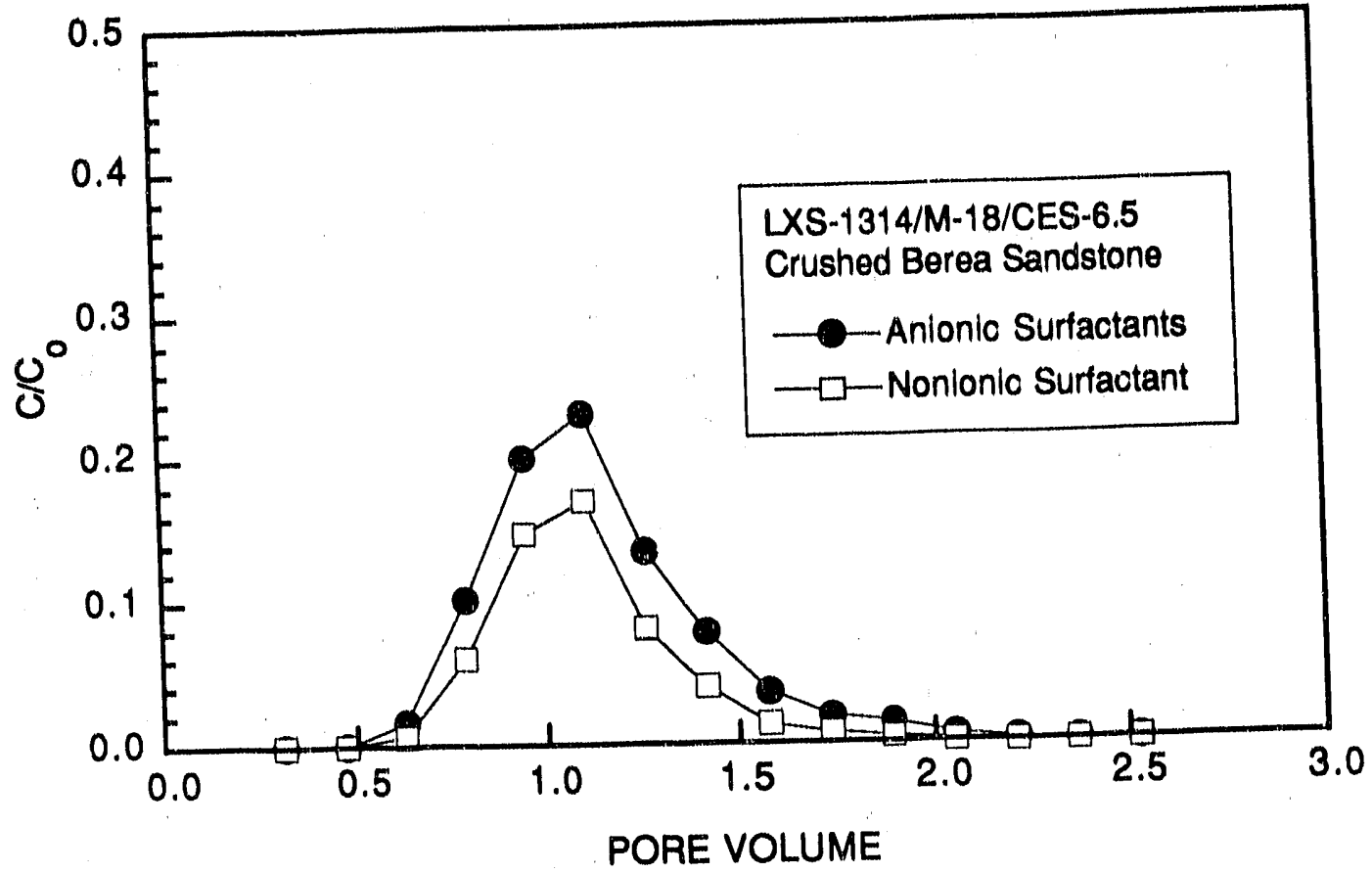

FIGURE 27.- Relative surfactant concentration as a function of volume through a crushed Berea sandstone column for the surfactant system, LXS-1314/MA-18/CES 6.5, in NBU brine.

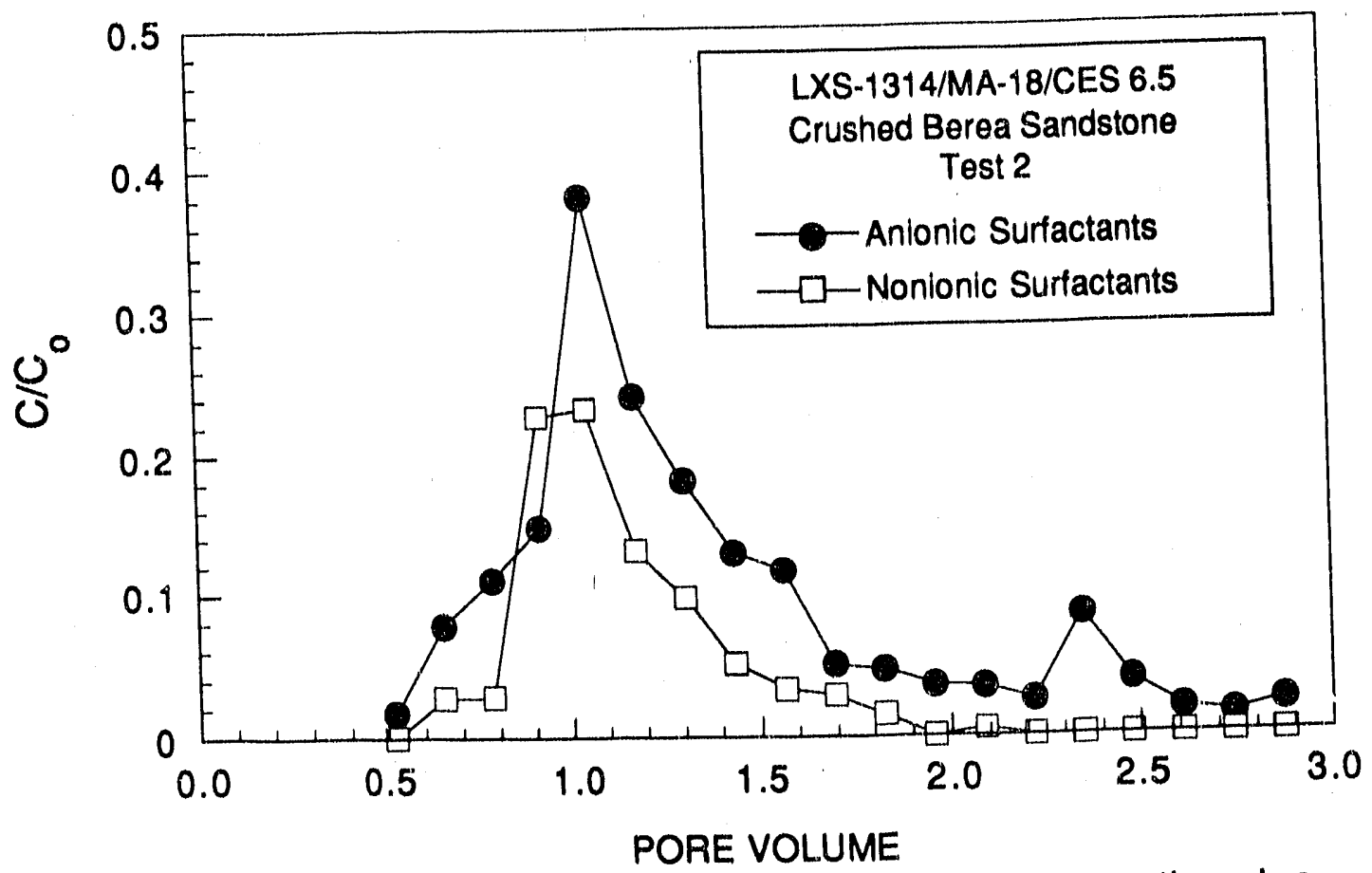

FIGURE 28. - Relative surfactant concentration as a function of volume through a crushed Berea sandstone column for the surfactant system, LXS-1314/MA-18/CES 6.5, in NBU brine. 
For test $1,92 \%$ of the components in peak 2 were retained in the column. A slightly smaller amount of the components in peak 1 (87\%) was retained in the column. The surfactant-loss values for the dynamic test were calculated using these relative retention vallues. These differences are not significant enough to conclude that the nonionic surfactant adsorbs more than the anionic surfactants, but it suggests this difference in adsorption may eventually lead to complete separation of nonionic and anionic surfactant types in the reservolr.

Separate detection of the nonionic and anionic surfactant components of the mixture by HPLC. analysis suggests that mixtures with different hydrophilic structures are more likely to separate because of different solvent affinities. In the HPLC the anionic/nonionio surfactant mixtures can be separated more easily than the anionic/anionic mixtures. Variation in composition of the mobile phase solvent, which consists of a mixture of water and polar organic solvents methanol and acetonitrile, changes the time of elution of the surfactants from the chromatographic column. It does not separate the anionic components from each other, however.

\section{Alkyl Aryl Sulfonate and ES Surfactants}

Static adsorption tests were conducted using a binary mixture of LXS-1314 and an ethoxylated sulfate, $\mathrm{CO}-436$, in $3 \% \mathrm{NaCl}$ at ambient temperature. Solutions containing only LXS.1314 separated into two phases at this brine concentration. The ethoxylated sulfate was added to Improve the solubility of the alkylaryl sulfonate. Solutions containing both surfactants in $3 \%$ brine were cloudy but did not phase separate. Significant reduction of surfactant loss was observed for the binary mixtures as compared to the solution containing only LXS-1314. Results are shown in table 4.

Table 4. - Surtactant loss of a mixed surfactant system on crushed Berea sandstone at ambient temperature

\begin{tabular}{ccc}
\hline $\begin{array}{c}\text { LXS-1314 Concentration, } \\
\%\end{array}$ & $\begin{array}{c}\text { Co-436 Concentration, } \\
\%\end{array}$ & $\begin{array}{c}\text { Surfactant loss, } \\
\mathrm{mg} / \mathrm{g}\end{array}$ \\
\hline 0.991 & 0.000 & $46.8 \pm 1.4$ \\
0.891 & 0.113 & $1.59 \pm 0.14$ \\
0.794 & 0.209 & $2.36 \pm 0.37$ \\
0.708 & 0.336 & $1.03 \pm 0.27$ \\
0.000 & 0.331 & $0.59 \pm 0.02$ \\
\hline
\end{tabular}


Addition of the ethoxylated anionic surfactarit was effective in extending the useful salinity range for an alkylaryl sulfonate. Surfactant loss may still be excessive for economical oil recovery, and additional methods to reduce surfactant loss such as the use of sacrificial agents may be desirable.

Surfactant loss for the surfactant mixture LXS-1314 and CO-436 in 3\% NaCl brine for the dynainic test using a crushed Berea sandstone column was $2.2 \mathrm{mg} / \mathrm{g}$. This value falls within the range of values determined in the static surfactant-loss tests of 1.0 to $2.3 \mathrm{mg} / \mathrm{g}$. Surfactant loss may be lower for this surfactant mixture than for the LXS/MACES mixture because of lower solution brine concentration.

\section{Summary}

Carboxylated and sulfated ethoxylated surfactants reduce the amount of surfactant loss of alkyl aryl sulfonates by Improving surfactant solubility. For sallnity conditions at which the alkly aryl sulfunate will completely phase separate, total surfactant loss using crushed Berea sandstone was in the rango of 1 to 5 $\mathrm{mg} / \mathrm{g}$. This amount of adsorption loss is still significant and may adversely affect the application of these mixtures for oll recovery processes.

\section{Oll Recovery From Corefleod Experiments}

\section{Alkyl Aryl Sulfonato and CME Surfactants}

Coreflood experiments were conducted at $50^{\circ} \mathrm{C}$ using the surfactant mixture LXS-1314/MA-18/CES 6.5 and decane or NBU oil in Berea sandstone cores as summarized in the experimental section. The objectives of these experiments were to determine oil recovery efficiency of the surfactant mixture and to test several injection strategles to increase oil recovery efficiency. Table 5 describes the core paramaters for th. jse tests. Results of the corefloods are summarized in table 6.

TABLE 5.- Berea sandstone core parameters for oil recovery experiments using the surfactant mixture LXS-1314/MA-18/CES 6.5 at $50^{\circ} \mathrm{C}$

\begin{tabular}{ccccc}
\hline $\begin{array}{c}\text { Coreflood } \\
\text { identification }\end{array}$ & $\begin{array}{c}\text { Core dimensions } \\
\text { length/diameter, } c \text { cm }\end{array}$ & $\begin{array}{c}\text { Permeability, } \\
\text { md }\end{array}$ & $\begin{array}{c}\text { Porosity, } \\
\%\end{array}$ & $\begin{array}{c}\text { Residual oll } \\
\text { saturation before } \\
\text { chemical flood, \% }\end{array}$ \\
\hline LMC/CF-1 & $28.6 / 3.8$ & 497 & 22.2 & 37.6 \\
LMC/CF-2 & $29.0 / 3.8$ & 116 & 17.8 & 37.9 \\
LMC/CF-3 & $29.2 / 3.8$ & 605 & 23.9 & 38.7 \\
LMC/CF-4 & $28.4 / 3.8$ & 528 & 22.1 & 37.1 \\
LMC/CF-5 & $29.6 / 3.8$ & 528 & 21.7 & 38.4 \\
\hline
\end{tabular}


TABLE 6.- Injection parameters for oil recovery experiments using the surfactant mixture LXS-1314/MA-18/CES 6.5 at $50^{\circ} \mathrm{C}$

\begin{tabular}{|c|c|c|c|c|c|c|}
\hline $\begin{array}{c}\text { Coreflood } \\
\text { identification }\end{array}$ & $\begin{array}{l}\text { Surfactant } \\
\text { type }\end{array}$ & $\begin{array}{c}\text { Surfactant } \\
\text { concentration, } \\
\%\end{array}$ & $\begin{array}{c}\text { Surfactant } \\
\text { slug size, } \\
\text { PV }\end{array}$ & Brine & Oil & $\begin{array}{c}\text { Recovery } \\
\text { efficiency, } \\
\% S_{o r}\end{array}$ \\
\hline \multicolumn{7}{|c|}{ STANDARD COREFLOODS } \\
\hline & LXS-1314 & 1.5 & 0.19 & NBU & Decane & 4.4 \\
\hline \multirow[t]{3}{*}{ LMC/CF-1 } & MA-18 & 0.75 & & ; & & \\
\hline & CES 6.5 & 0.75 & & & & \\
\hline & LXS-1314 & 1.5 & 0.31 & NBU & NBU & 11.9 \\
\hline \multirow[t]{2}{*}{ LMC/CF-2 } & MA-18 & 0.75 & & & & \\
\hline & CES 6.5 & 0.75 & & & & \\
\hline \multicolumn{7}{|c|}{ BICARBONATE PREFLUSH AND SALINITY REDUCTION } \\
\hline $\mathrm{LMC} / \mathrm{CF}-3$ & LXS-1314 & 1.5 & 0.18 & $9.7 \% \mathrm{NaCl}$ & NBU & 10.9 \\
\hline \multirow[t]{2}{*}{ part 1} & MA-18 & 0.75 & & $1 \% \mathrm{Na}_{2} \mathrm{CO}_{3}$ & & \\
\hline & CES 6.5 & 0.75 & & $0.8 \% \mathrm{NaHCO}_{3}$ & & \\
\hline LMC/CF-3 & & & & $10 \% \mathrm{NaCl}$ & NBU & 4.6 \\
\hline part 2 & & & & $5 \% \mathrm{NaCl}$ & & \\
\hline \multicolumn{7}{|c|}{ SALINITY GRADIENT } \\
\hline \multirow[t]{3}{*}{$\mathrm{LMC} / \mathrm{CF}-4$} & LXS-1314 & 1.8 & 0.2 & $8 \% \mathrm{NaCl}$ & NBU & 10.2 \\
\hline & $M A-18$ & 0.6 & & gradient from & & \\
\hline & CEES 6.5 & 0.6 & & 8 to $5 \% \mathrm{NaCl}$ & & \\
\hline \multicolumn{7}{|c|}{ CONTINUOUS INJECTION } \\
\hline \multirow[t]{3}{*}{$L M C / C F-5$} & LXS-1314 & 0.6 & 3.5 & $8 \% \mathrm{NaCl}$ & NBU & 23.5 \\
\hline & MA-18 & 0.2 & & & & \\
\hline & CES 6.5 & 0.2 & & & & \\
\hline
\end{tabular}

The base case corefloods, LMC/CF-1 and LMC/CF-2, were conducted using $3 \%$ total surfactant of which $50 \%$ was the alkyl aryl sulfonate and $50 \%$ was the CME surfactants. This mixture showed slightly less surfactant loss in the adsorption studies than the mixture with a lower percentage of CME surfactants. IFT measurements and phase behavior studies, reported above, indicated that the surfactant mixture showed a broad salinity tolerance and moderately low IFT values between surfactant solution and oil. For the LMC surfactant mixture in NBU brine and decane, the IFT value was approximately $0.04 \mathrm{mN} / \mathrm{m}$. For the mixture and NBU oil, ths IFT value was $0.007 \mathrm{mN} / \mathrm{m}$. The oil recovery efficiencies for these two tests were 
low, 4.4 and $11.9 \%$ of the residual oil in place after waterilood. No surfactant was observed in the effluent of either coreflood. The surfactant was either adsorbed, trapped in the oll, or bypassed by the brine pusher solution. Subsequent injection of an isopropanol-brine solution in LMC/CF-1 recovered surfactant and additional oil. The alcohol asted either to mobilize the surfactant, bringing it into contact with additional oil, or to improve the phase behavior of the surfactant-oil interaction and mobilize additional oil.

To improve oil production using this surfactant mixture, the next coreflood experimelits were designed either to reduce surfactant loss by using a sacrificial agent (sodium bicarbonate) as a preflush and ir the surfactant solution (LMC/CF-3) or to improve phase behavior through the use of a salinity gradient to keep the surfactant within the optimum three phase region (LMC/CF-4).

For LMC/CF-3, the surfactant mixture was prepared in a brine containing $\mathrm{NaCl}, \mathrm{NaHCO}_{3}$, and $\mathrm{Na}_{2} \mathrm{CO}_{3}$. The ionic strength of this solution was adjusted to be equivalent to that for NBU brine. Approximately 0.9 PV of bicarbonate brine was used to preflush the core before injection of surfactant. The same brine was injected after the surfactant slug. No surfactant was observed in the effluent samples. The ionic strength of the pusher brine was then reduced in two steps. First, a small slug of $10 \% \mathrm{NaCl}$ brine was injected (0.15-PV), followed by $0.9 \mathrm{PV}$ of $5 \% \mathrm{NaCl}$. The salinity reduction resulte t in the production of a second small slug of oil. In addition, some surfactant could be observed in core effluent samples. The reduced salinity mobilized at least part of the surfactant that had been trapped in the core. Figure 29 shows the production of NBU oil as a function of throughput for LMC/CF-3. Also shown in the graph is the oil production for LMC/CF-2. The use of bicartonate did not improve initial oil production $(11 \%$ versus $12 \%)$. However, combined with a reduction in salinily, oil production was improved (15.5\%), although total production was still low. In addition, surfactant propagation has been improved using these combined techniques. 


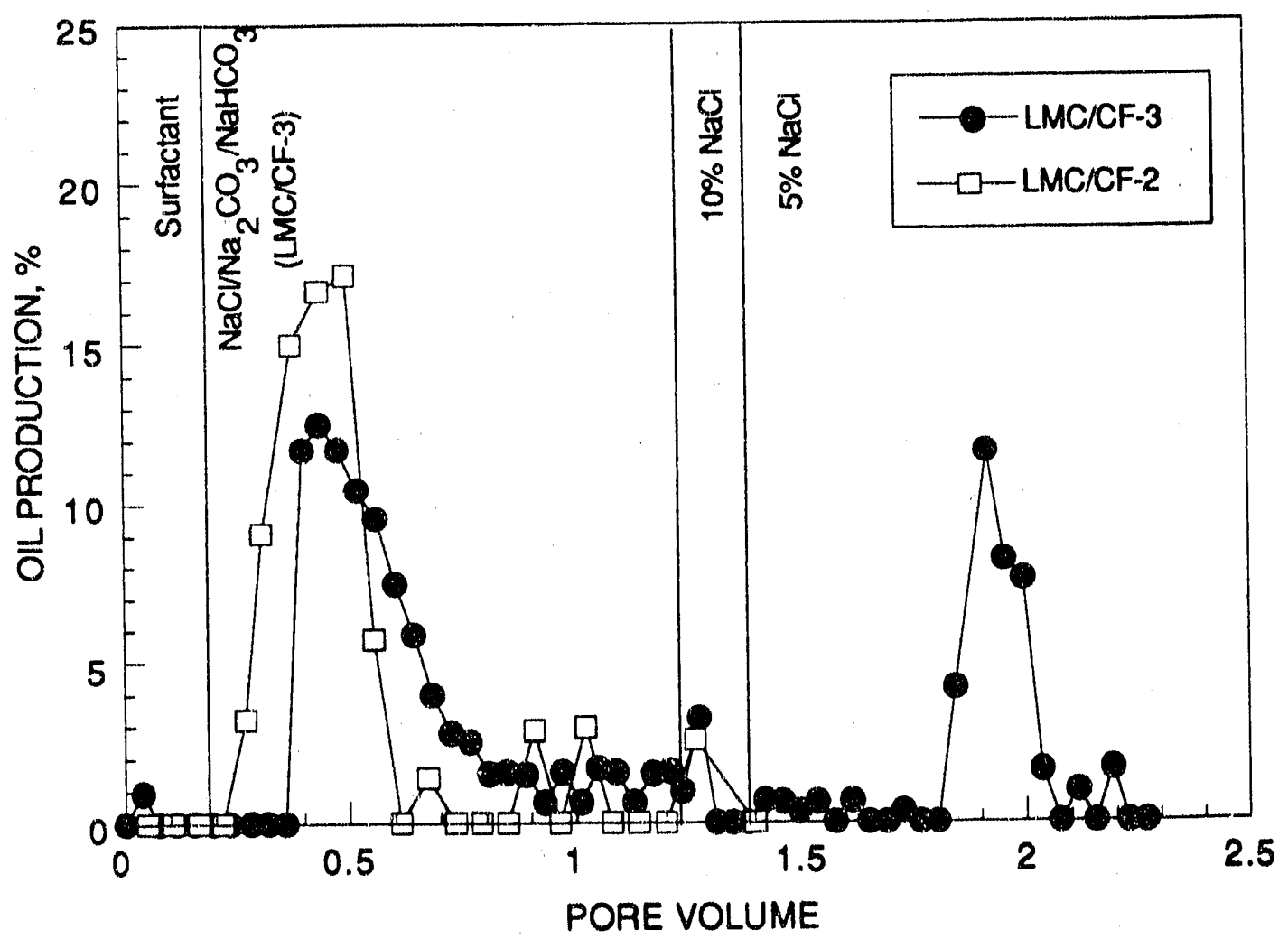

FIGURE 29. - Oil production for corefloods LMC/CF-2 and LMC/CF-3 using the surfactant mixture $1.5 \%$ LXS-1314/0.75\% MA-18/0.75\% CES 6.5 in Berea sandstone cores.

LIMC/CF-4 was designed to test the use of a salinity gradient technique to produce NBU oil with this surfactant mixture. For this ratio of LXS to CME surfactants, the lowest IFT values were obtained in 7 to $8 \%$ $\mathrm{NaCl}$ brine solutions. After injection of the surfactant mixture prepared in $8 \% \mathrm{NaCl}$, the salinity was gradually reduced to $5 \% \mathrm{NaCl}$. Oil was produced in small amounts throughout the production cycie. No significant oil bank was created by this injection method. Oil production appeared to decline when the salinity was reduced to $5 \%$. Oil production as a function of pore volumes through the core is shown in figure 30. Failure to produce an oil bank may imply that optimum conditions for oil production were missed. Total oil production for this coreflood $\left(10.2 \%\right.$ of $\left.S_{\text {or }}\right)$ compares with the results from corefloods LMC/CF-2 and LMC/CF-3 pant 1. 


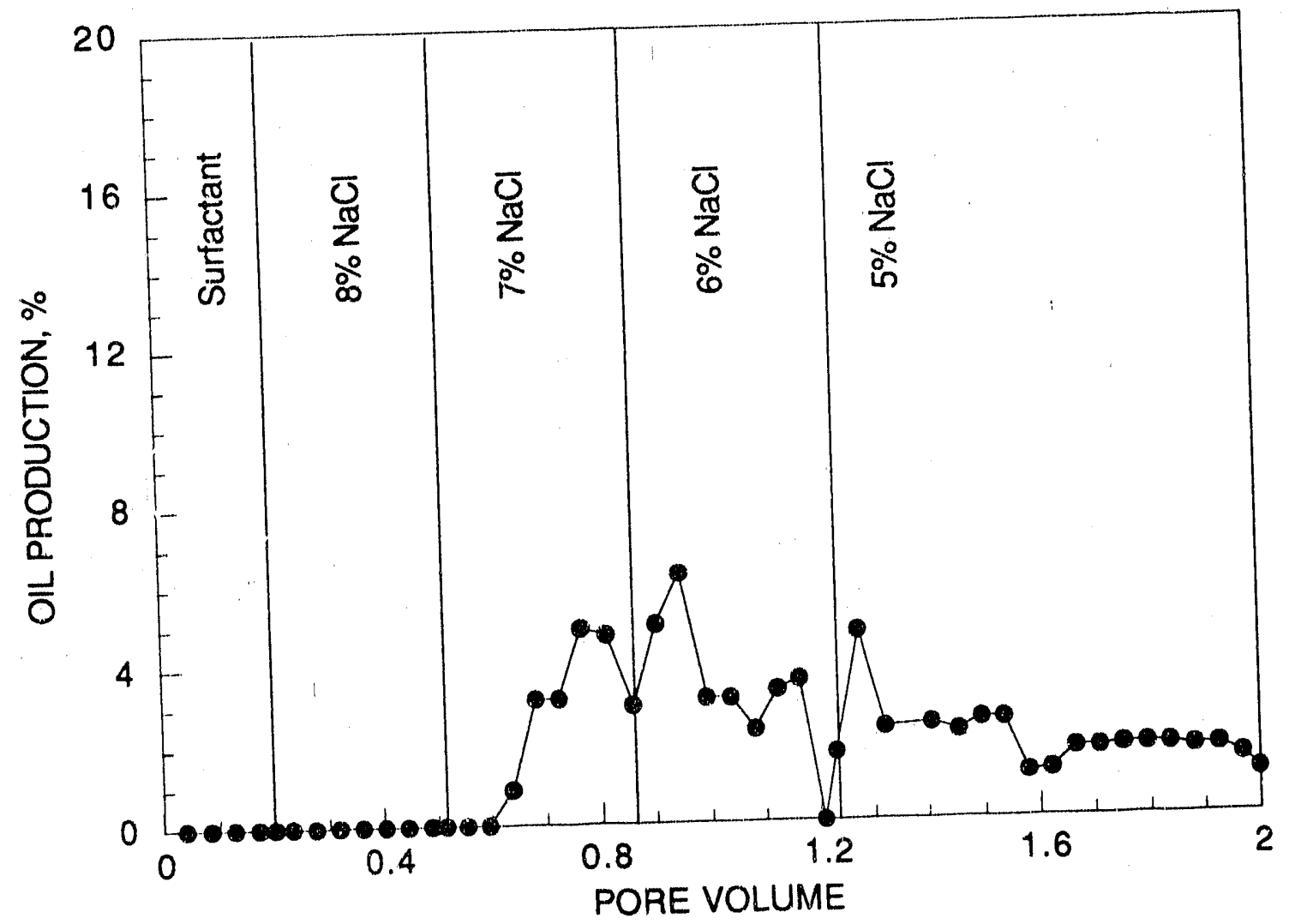

FIGURE 30. - Effect of salinity gradient on production of NBU oil from Berea sandstone cores using the surfactant mixture LXS-1314/MA-18/CES 6.5.

The final coreflood in this series, LMC/CF-5, was conducted using a continuous injection of surfactant mixture to determine surfactant breakthrough and loss in the core. A total of $1 \%$ surfactant concentration rather than $3 \%$ was used for more detalled observation of the surfactant front. The surfactant was injected in $8 \% \mathrm{NlaCl}$ brine without the use of a salinity gradient. Figure 31 shows the oll cut as a function of pore volumes of solution through the core and the surfactant front. Surfactant breakthrough was delayed by over 1.5 pore volumes. Once again, an oil bank was not formed. Rather, small amounts of oll were produced continuously until surfactant breakthrough occurred. Surfactant loss during this test was approximately $1.6 \mathrm{mg} / \mathrm{g}$ of rock. This is a very high value for a coreflood test and indicates that this mixture would be very uneconomical even if increased oil production could be achieved. 


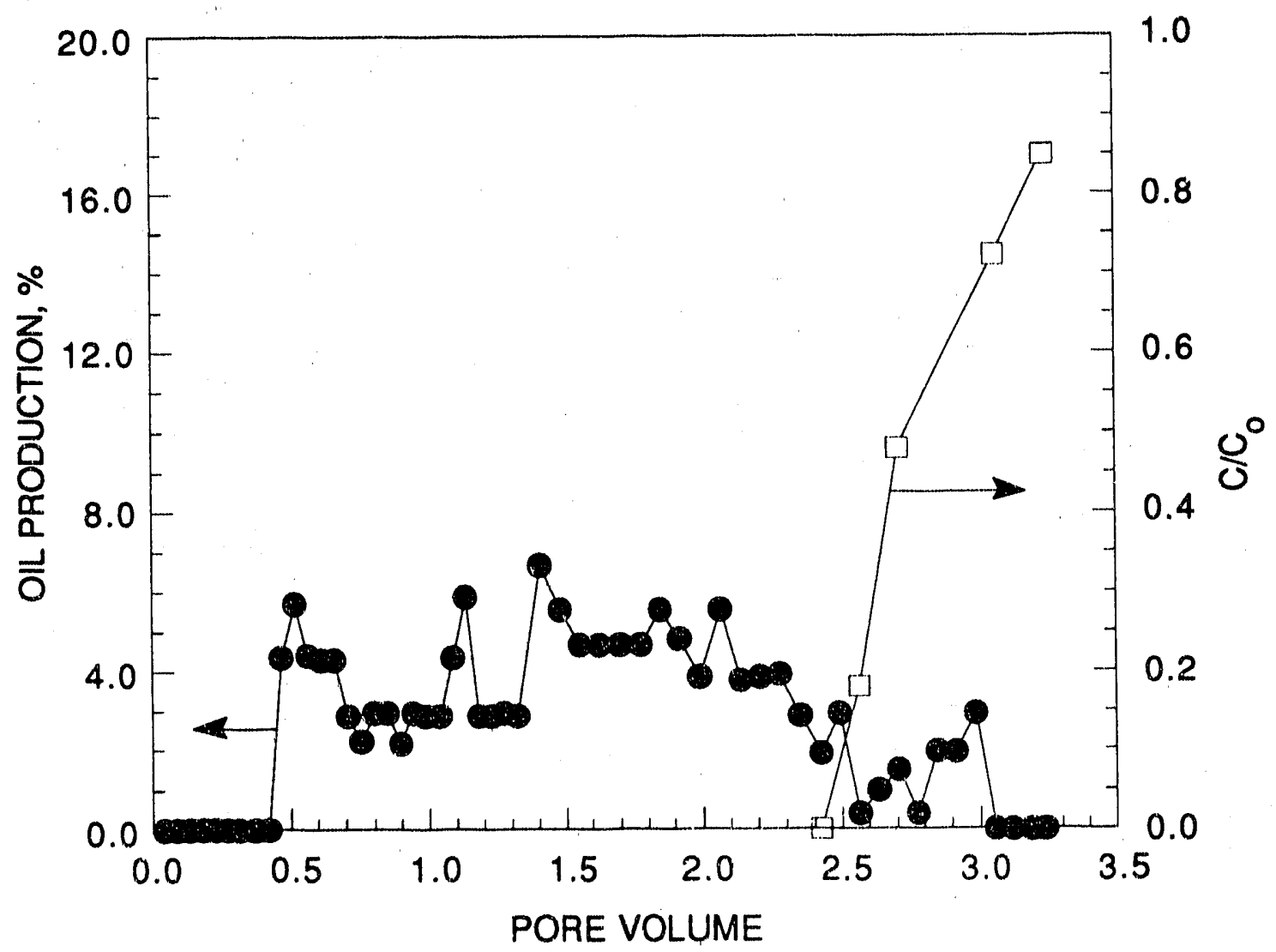

FIGURE 31. - Oil production during coreflood LMC/CF-5 during continuous injection of surfactant mixture, LXS-1314/MA-18/CES 6.5

Figure 32 summarizes cumulative oil production for the five tests using the surfactant mixture containing LXS-1314, MA-18, and CES 6.5. These results indicate that this mixture, in medium salinity brines (NBU brine or $5-10 \% \mathrm{NaCl}$ ), does not efficiently mobilize NBU oil. This may be attributed to the relatively poor solubilization parameters of this mixture. One study in the literature ${ }^{3}$ demonstrated that mixtures of alkylxylene sulfonates and ethoxylated sulfonates did not produce large solubilization parameters. Another study of phase behavior of mixed surfactant systems ${ }^{4}$ determined that addition of alcohol was still required, in many cases, for the mixtures to form microemulsions and prevent the formation of liquid crystals and/or precipitates. Neither of these studies included results of coreflood experiments. Within the core, effects of ion exchange or dilution may shift conditions enough to encourage partitioning of the surfactant into the oil phase and loss of surfactant slug effectiveness for oil recovery. For the corefloods discussed in this report, only the reduction of salinity in LMC/CF-3 part 2 and the use of a postflush brine coniaining alcohol in LMC/CF-1 resulted in surfactant mobilization through the core. Therefore, this mixture may only be effective at mobilizing oil when cornbined with an alcohol cosolvent. 


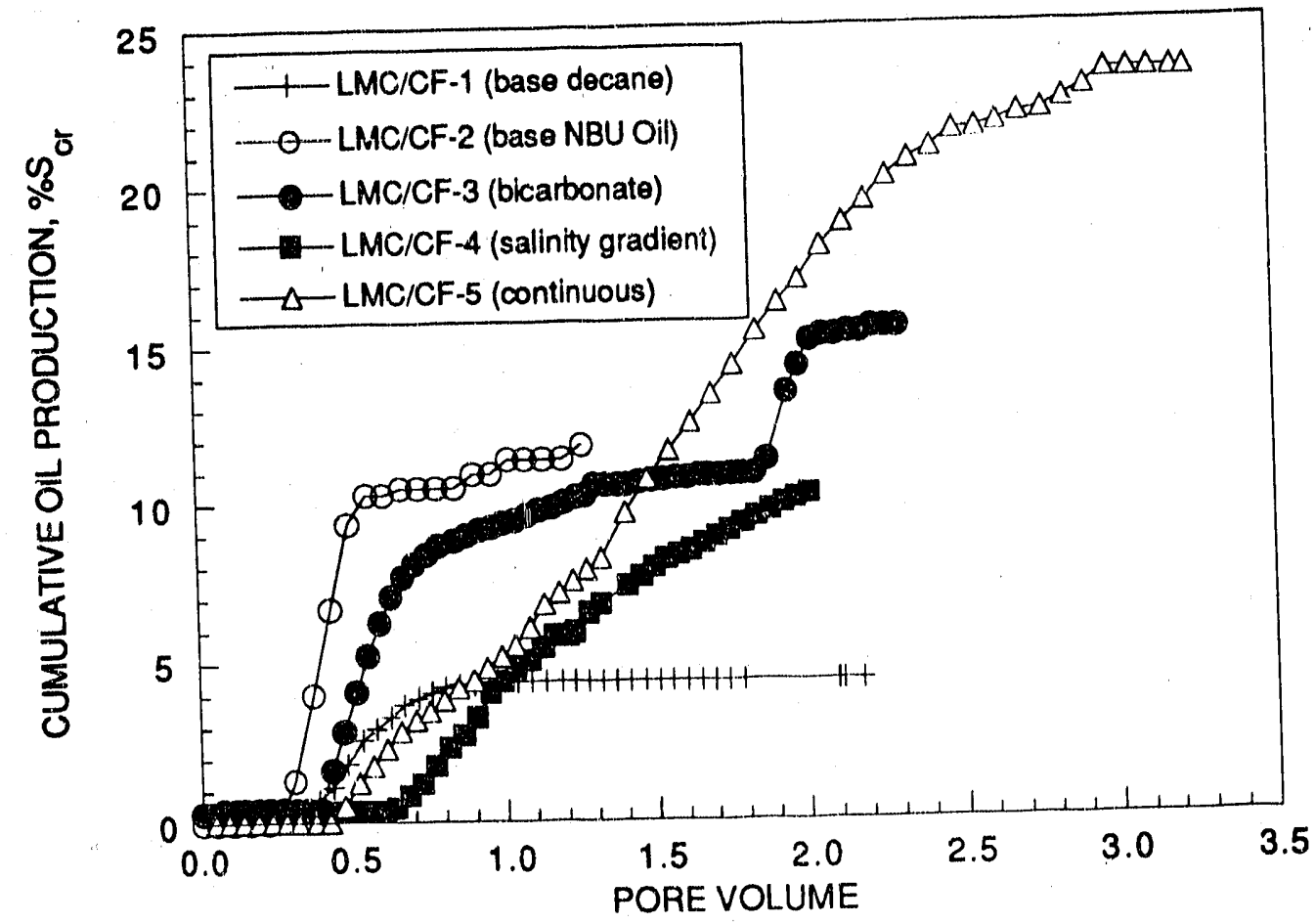

FIGURE 32. - Cumulative oil production for all corefloods using the sirfactant mixture LXS-1314/MA-18/CES 6.5.

\section{Other Mixed Surfactant Systems}

One coreflood was performed using an alkylxylene sulfonate and alkylbenzene ethoxylated sulfate mixtur , LXS-1314 and C0-436. In addition, two other surfactant mixtures, discussed in the phase behavior and IFT sections were tested in coreflood experiments. Table 7 describes the core parameters of these corefloods, and table 8 summarizes fluids used and results of the tests.

TABLE 7.- Eerea sandstone core parameters for oil recovery experiments at $50^{\circ} \mathrm{C}$ using several different surfactant mixtures

\begin{tabular}{ccccc}
\hline $\begin{array}{c}\text { Coreflood } \\
\text { identification }\end{array}$ & $\begin{array}{c}\text { Core dimensions } \\
\text { length/diameter, cm }\end{array}$ & $\begin{array}{c}\text { Permeability, } \\
\text { md }\end{array}$ & $\begin{array}{c}\text { Porosity, } \\
\%\end{array}$ & $\begin{array}{c}\text { Residual oil } \\
\text { saturation before } \\
\text { chemical flood, \% }\end{array}$ \\
\hline LC/CF-1 & $29.2 / 3.8$ & 127 & 18.0 & 41.5 \\
BMC/CF-1 & $29.9 / 3.8$ & 220 & 19.4 & 41.8 \\
LR/CF-1 & $27.7 / 3.8$ & 734 & 22.5 & 36.7 \\
\hline
\end{tabular}


TABLE 8.- Injection parameters for oil recovery experiments at $50^{\circ} \mathrm{C}$ using several different surfactant mixtures

\begin{tabular}{|c|c|c|c|c|c|c|}
\hline $\begin{array}{l}\text { Coreflood } \\
\text { identification }\end{array}$ & $\begin{array}{c}\text { Surtactant } \\
\text { type }\end{array}$ & $\begin{array}{c}\text { Surfactant } \\
\text { concentration, } \\
\% \\
\end{array}$ & $\begin{array}{l}\text { Surfactant } \\
\text { slug size, } \\
\text { PV }\end{array}$ & Brine & Oil & $\begin{array}{c}\text { Recovery } \\
\text { efficiency, } \\
\% S_{\text {or }}\end{array}$ \\
\hline LC/CF-1 & $\begin{array}{c}\text { LXS-1314 } \\
\text { C. } 0-436\end{array}$ & $\begin{array}{l}1.2 \\
0.8\end{array}$ & 0.25 & NBU & NBU & 19.4 \\
\hline $\mathrm{BMC} / \mathrm{CF}-1$ & $\begin{array}{l}\text { B-120 } \\
\text { MA-18 } \\
\text { CES } 6.5\end{array}$ & $\begin{array}{c}0.5 \\
0.25 \\
0.25\end{array}$ & 0.2 & $\begin{array}{l}80 \% \text { NBU } \\
60 \% \text { NBU }\end{array}$ & NBU & 2.2 \\
\hline$L R / C F-1$ & $\begin{array}{c}\text { LXS.810 } \\
\text { RS.16 }\end{array}$ & $\begin{array}{l}1.5 \\
0.5\end{array}$ & 0.2 & $\begin{array}{c}80 \% \text { NBU } \\
\text { gradient of } \\
70 \% \rightarrow 60 \% \rightarrow \\
50 \% \rightarrow 35 \% \\
\text { NBU }\end{array}$ & NBU & 0 \\
\hline
\end{tabular}

The LXS-1314/CO-436 mixture in NBU brine had the highest oil recovery of any coreflood conducted in this study, $19.4 \%$ of residual oil in place. Figure 33 shows cumulative oil production for this coreflood compared to the base case coreflood using the previous surfactant mixture. Both these corefloods produced at least a small oil bank. The LXS/CO system sustained oil production slightly longer, however. No surfactant emerged from the core, however, indicating surfactant losses may be high.

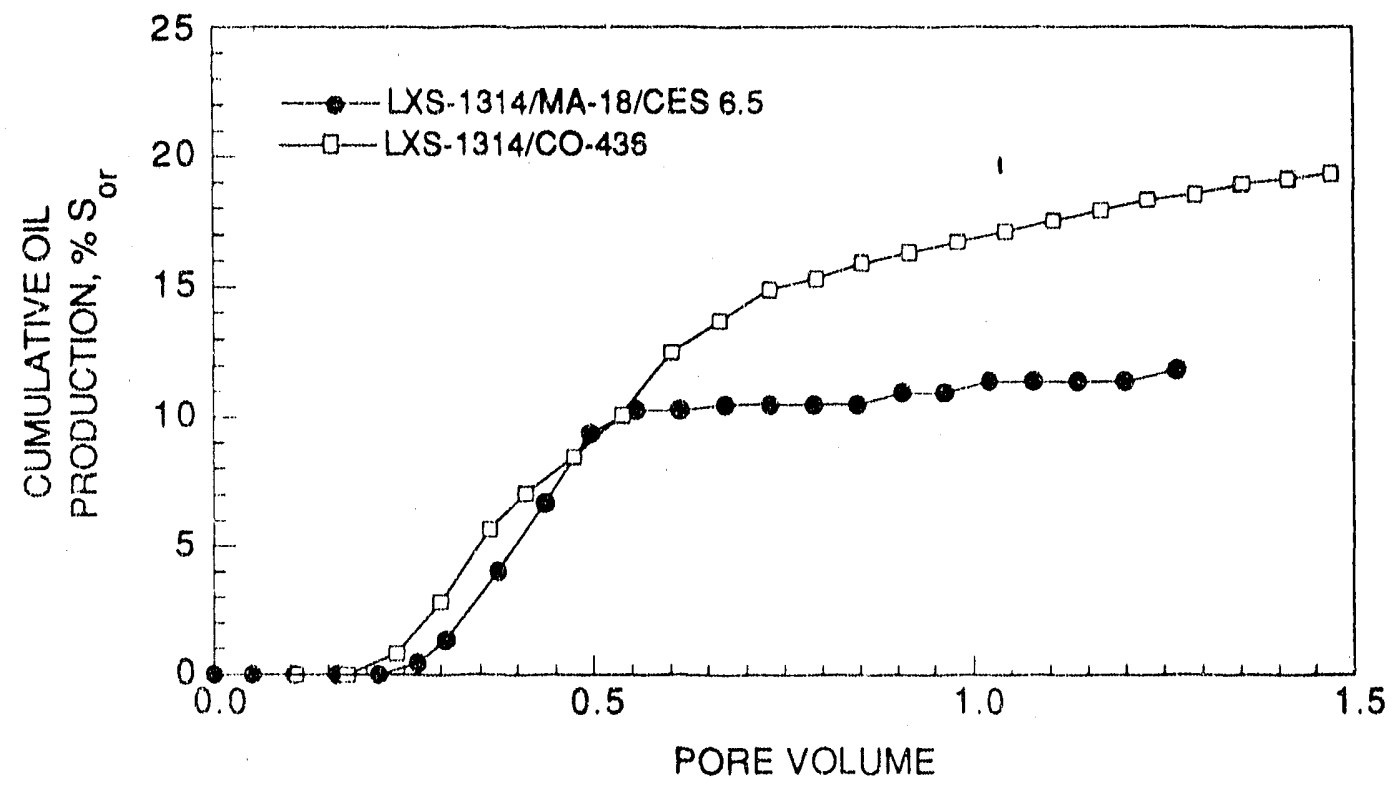

FIGURE 33. - Comparison of cumulatic e oil production for two mixed surfactant systems. 
The other surfactant mixtures listed in table 7 were not successful in mobilizing NBU oll in the coreflood studies. In these tests, CME surfactants were used with different alkyl aryl sulfonates than LXS-1314. (B120 is a commercial mixture of alkyl aryl sulfonates having a distribution of carbon chain lengths in the hydrophobic structure of the surfactant.) Phase behavior and IFT measurement studies were used to select coreflood parameters to test these mixtures. It appeared that severe trapping of the surfactant systems in the core occurred, however. A salinity gradient failed to affect surfactant/oll interaction to achieve oil mobilization for either test BMC/CF-1 or test $L R / C F-1$. Alcohol solution was required to remobilize the surfactant and improve oll production. Fur test LR/CF-1, approximately $9 \%$ of the residual oll in place was produced by using a slug of isopropanol and brine.

\section{Summary}

In surnmary, surfactant mixtures that contain ethoxylated sulfates show slightly more promise for production of crude oil thar those that contain carboxymethylated ethoxylated surfactants. Oll production has not been optimized, however, and further studies are required before the evaluation of mixed surfactant systems for oil recovery can be generalized.

\section{Solution Propertles of Mixed Surfactant Systems as Function of Temperature}

Dilution calorimetry has been used to study the solution behavior as a function of temperature of several commercial surfactants and their mixtures which have been described in prevlous sections of this report. The density and apparent molar volumes, $v_{\phi}$ of each aqueous surfactant solution were determined as explained in the experimental section. The graph of the apparent molar volumes of surfactant in each solution is shown in figure 34.

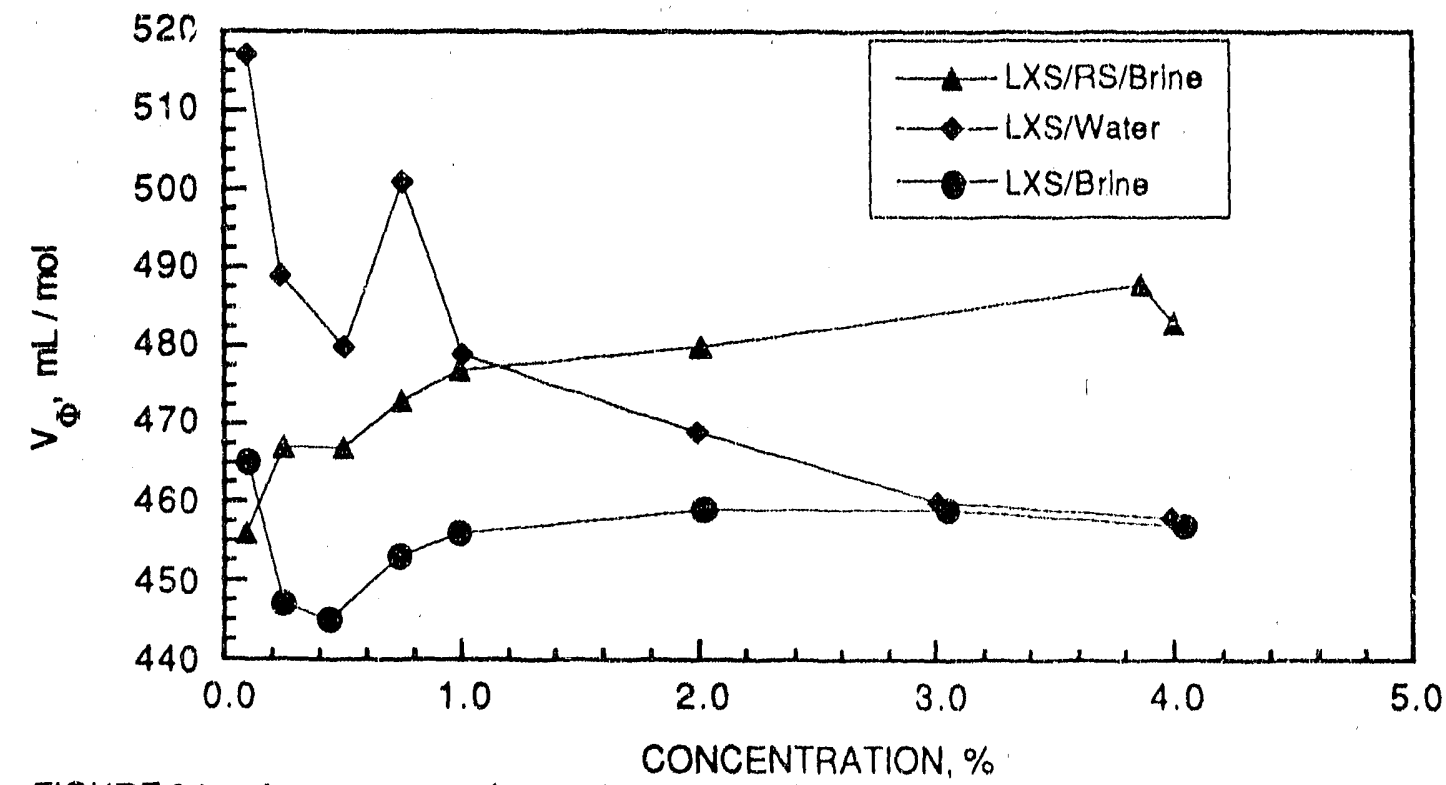

FIGURE 34. - Apparent molar volumes of LXS-1314 in water, in brine, and LXS-1314/RS-16 mixture in brine at $25^{\circ} \mathrm{C}$. 
The apparent molar volume $\left(V_{\phi}\right)$ for LXS-1314 in brine is only slightly dependent on concentration, while that of the LXS-1314 in water decreases as the concentration increases, at higher concentrations reaching a value close to that of LXS-1314 in brine. Thus, it seems that as lonic strength increases, whether from added brine or from the presence of lonio surfactant, the molar volume approaches a constant value. This behavior of $v_{\phi}$ suggests that the surfactant molecules are more compact in the presence of electrolyte. It may be noted that the molal concentration of surfactant in the $4 \%$ solution containing no brine is approximately 0.09 , and the molal concentration of electrolyte, the brine, is about the same.

The variation of $V_{\phi}$ as a function of surfactant concentration for the 4 to 1 mixture of LXS-1314 and MA-18 is different from that of the other two, increasing with increasing concentration. The presence of the CME in the mixture seems to enable the LXS-1314 molecules to resist the effect of brine and to enjoy a less restrictive environment.

The normal behavior of $V_{\phi}$ versus concentration for pure surfactants is to remain at a relatively constant value up to the $\mathrm{CMC}$, where it increases rapidly to an upper, relatively constant plateau value. None of the LXS solutions showed this break in their molar volume versus conisentration curve. This suggests that at all concentrations used in this study, the surfactant solutions are above their CMC's.

Enthalpies of dilution of these solutions were measured at $25^{\circ}, 50^{\circ}$, and $90^{\circ} \mathrm{C}$. The experimental values are given in tables $A 1$ through $A 9$, while the least squares fit to the experimental values are found in tables $A 13$ through $A 15$. Results are shown in figures 35 through 37 where the points are experimental data and the lines are the least squares it to the data.

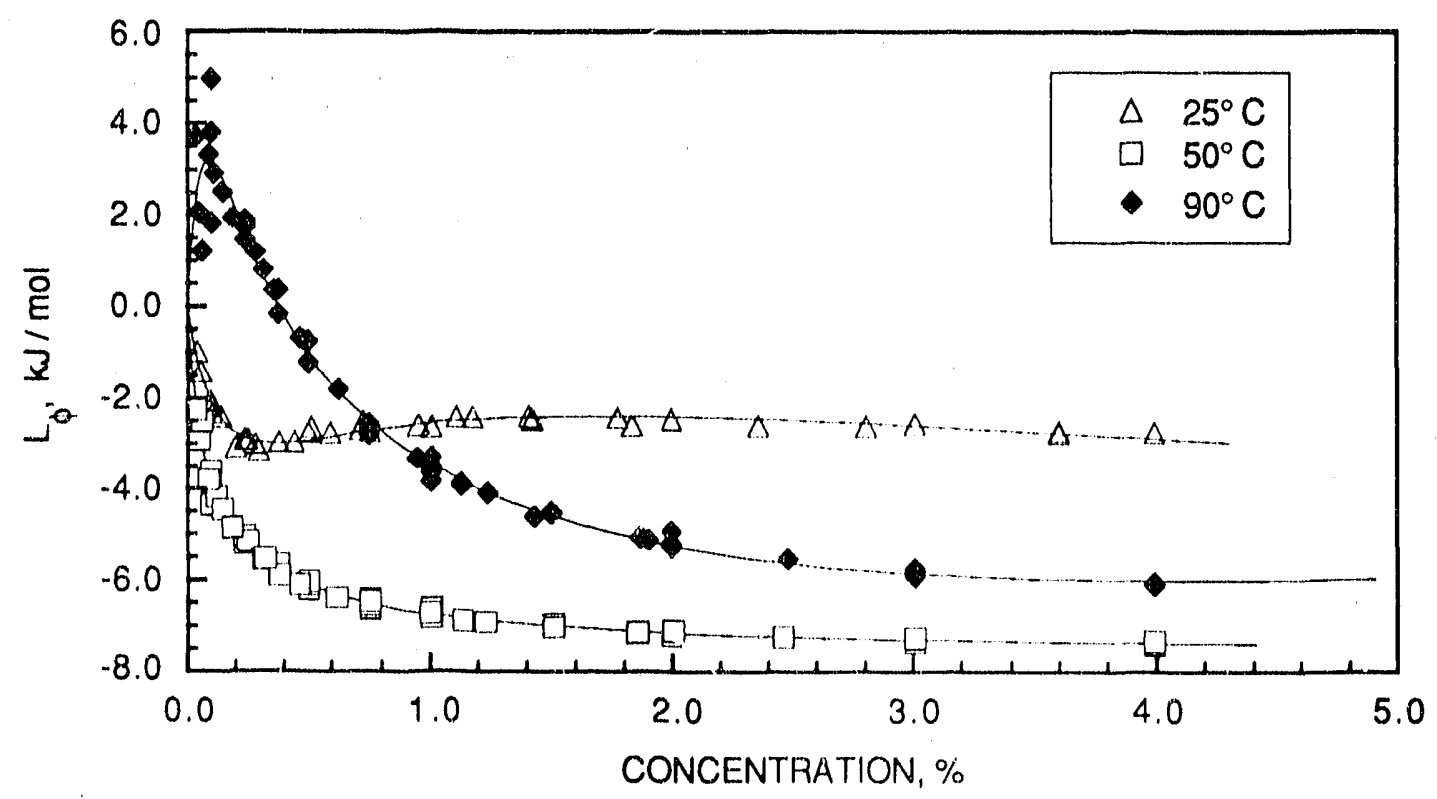

FIGURE 35 - Relative apparent molar enthalpies of LXS-1314 in water at $25^{\circ}, 50^{\circ}$, and $90^{\circ} \mathrm{C}$. 


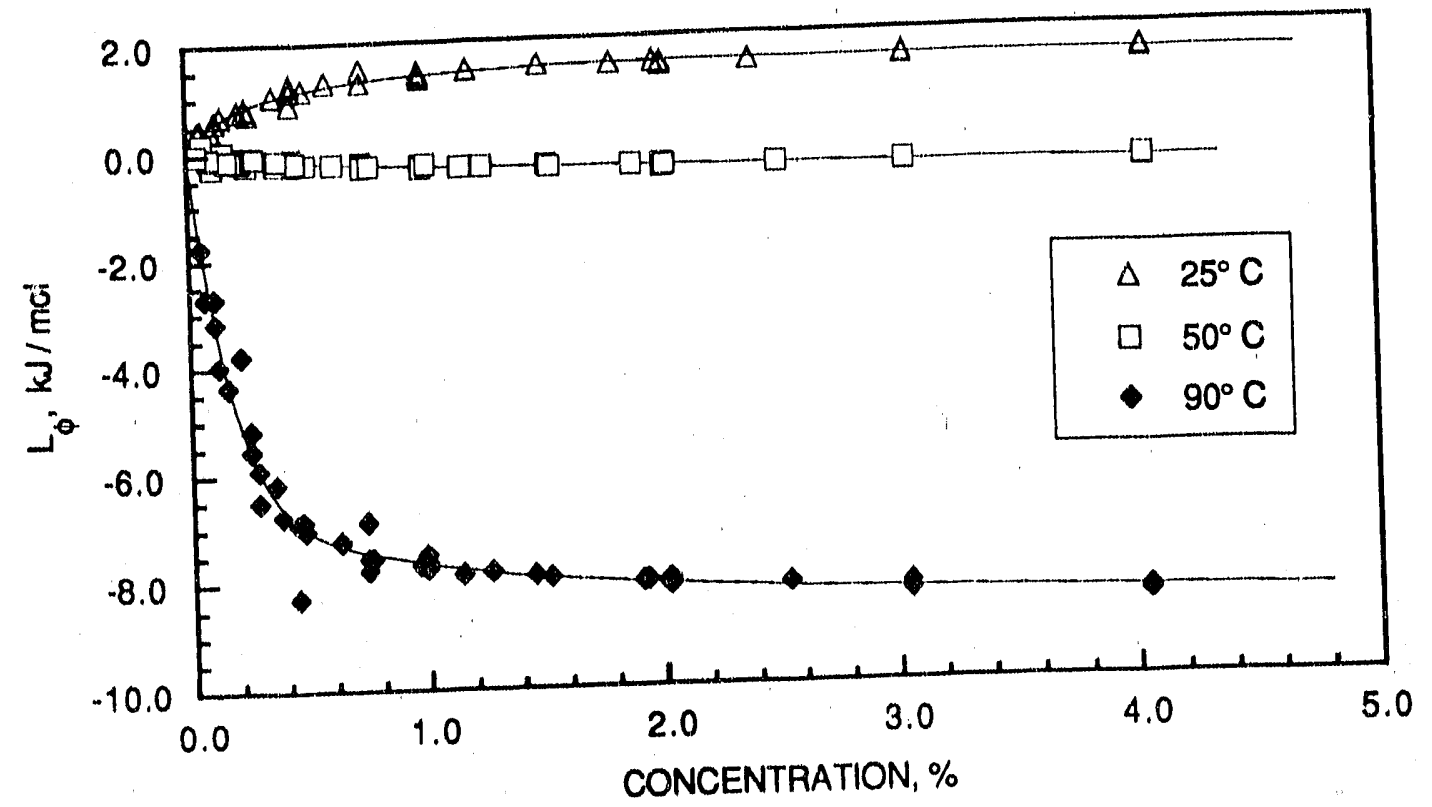

Figure 36. - Relative apparent molar enthalpies of LXS-1314 in brine at $25^{\circ}, 50^{\circ}$, and $90^{\circ} \mathrm{C}$.

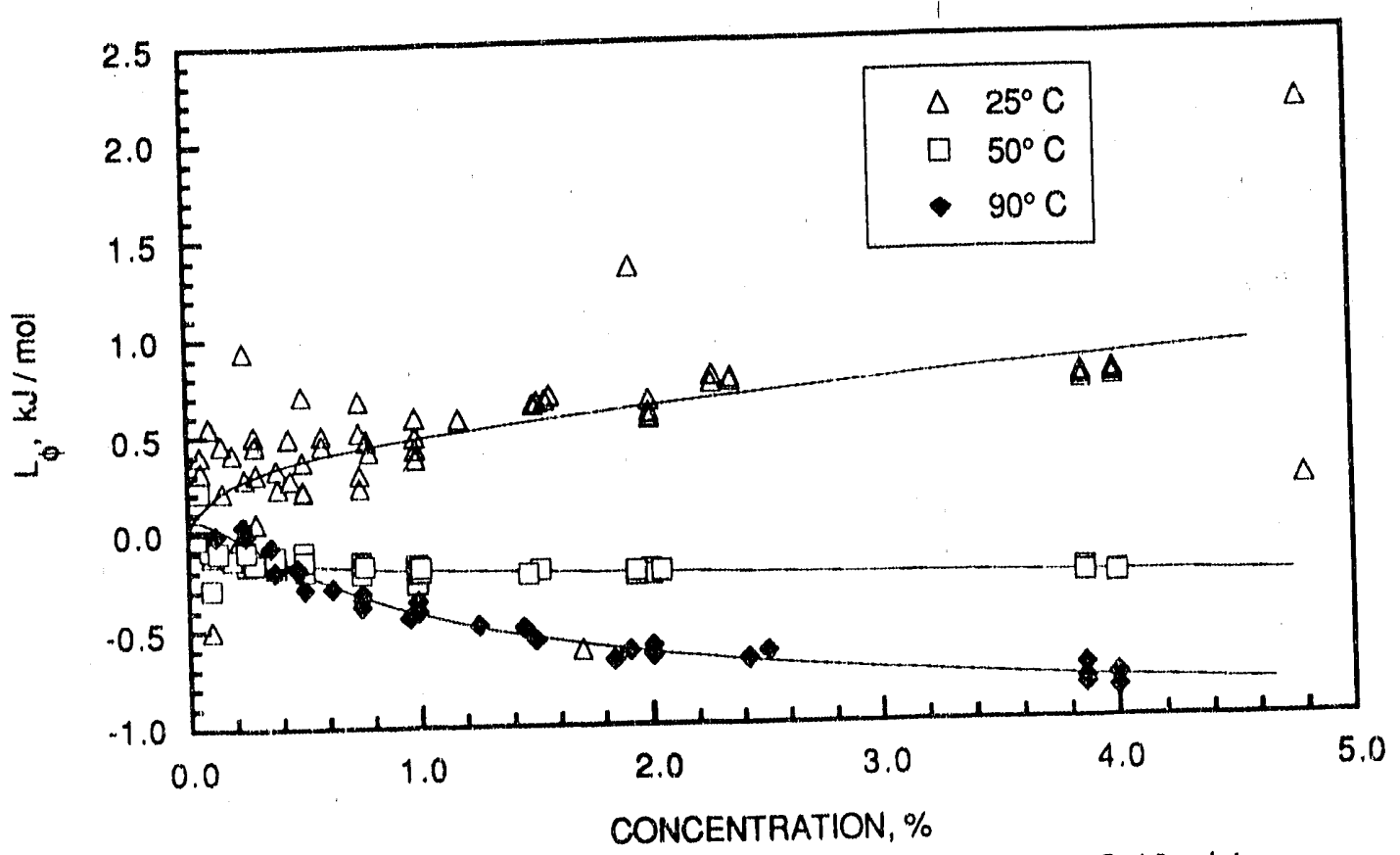

FIGURE 37. - Relative apparent molar enthalpies of the LXS-1314/RS-16 mixture in brine at $25^{\circ}, 50^{\circ}$, and $90^{\circ} \mathrm{C}$. 
Figure 35 shows the results for $L X S-1314$ in water. All values of $L_{\phi}$ are quite small in comparison with those for pure and other commercial surfactants that have been studled previously, ${ }^{20-28} \mathrm{~A}$ break in the curve has previously been interpreted as an indication of change from premicellar to micellar association (CMC) as surfactant concentration increases. Only for LXS-1314 in water and only at $90^{\circ} \mathrm{C}$ is the CMC within the experimentally accessible region, occurring at $0.1 \%$. At $25^{\circ}$ and $50^{\circ} \mathrm{C}$, the $\mathrm{L}_{\phi}$ curve simply drops to negative values indicating that at these temperatures the CMC occurs at a surfactant concentration lower than $0.1 \%$.

Figure 36 shows the results for LXS-1314 in brine. The presence of brine drastically changes the dilution behavior. As mentioned above, LXS-1314 in brine produces a cloudy solution, which remains cloudy even up to the bolling point. At all temperatures, the surfactant in solution has a constant concentration. As more solvent is added, undissolved surfactant can then go into solution. The shape of the dilution curves is consistent with this interpretation. From the slope of the curve, the heat of solution is exothermal at $25^{\circ} \mathrm{C}$, athermal at $50^{\circ} \mathrm{C}$, and exothermal at $90^{\circ} \mathrm{C}$. Since the curve for $90^{\circ} \mathrm{C}$ is becoming like that for water at $50^{\circ} \mathrm{C}$, one would expect that if dilution experiments were continued at higher lemperatures, all surfactant would initially be in solution, and that the behavior of LXS-1314 in brine would start to show the presence of a CMC within the range of dilution experiments.

Figure 37 shows the results for mixed surfactant in brine. The mixture is clear and transparent at all concentrations used which suggests that association between the two surfactants has occurred. All dilution enthalpies are quite small. This is consistent with a surfactant system in which the CMC is at very low concentration, so that the only region experimentally avallable is the "tail" which is almost flat. Clearly, this system does not pass through any critical aggregation region within the range of experimentally accessible concentrations at any temperature. The $25^{\circ}$ and $50^{\circ} \mathrm{C}$ curves are similar to those of the LXS-1314 in brine at the same temperatures, but the magnitude is smaller. The curve at $90^{\circ} \mathrm{C}$ is not like elther of the LXS-1314 in water or in brine. Thus the effect of mixing the CME with the LXS-1314 is to promote solubility of the L.XS-1314 even in brine and to reduce its CMC to a very low level, even at $90^{\circ} \mathrm{C}$. However, additional experiments must be periormed either at higher brine concentration or with solutions containing less CME surfactant to determine if trends in these observations can be correlated with the oll recovery features of these surfactant systems.

\section{Summary}

From these dilution calorimetry results, it would appear that ethoxylated surfactants improve solution properties of alkyl aryl sulfonates by improving solubility and encouraging micellar associations oven at very low surfactant concentrations. This should affect properties that are detrimental to oil recovery such as adsorption. This agrees with results from the adsorption experiments reported in previous sections of 
this report which indicate that improvement in solution properties greatly reduces surfactant loss caused by precipitation or phase separation. However, even from clear solutions, adsorption or partition losses may be very high and detrimental to oil recovery precesses. Minimum IFT values and favorable phase behavior, however, may often be assoclated with "cloudy" surfactant solutions. A cloudy solution may still indicate sufficient affinity for both oll and brine phases to result in oil mobilization. Additional dilution experiments are required before correlation of these solution property measurements and phase behavior can be made.

\section{SUMMARY and CONCLUSIONS}

- Ethoxylated anionic surfactants can be used to provide greater salt tolerance for nonethoxylated surfactant such alkyl aryl sulfonates. Incorporation of ethoxylated surfactants in mixed surfactant systems can be used to adjust optimal sailinity conditions to match those of the reservoir. Results from this study suggest that, in order to eliminate alcohol from the surfactant slug, ethoxylated sulfates or sulfonates are better candidates for use in mixed surfactant systems than ethoxylated carboxylates.

- The results of the IFT measurements using a series of alkyl aryl sulfonate (AAS) surfactants and several CME surfactants indicated that this surfactant-type combination yielded relatively low IFT values $\left(<10^{-2} \mathrm{mN} / \mathrm{m}\right.$ ) over a broad range of conditions, even at high salinities ( $W t \% \mathrm{NaCl}$ or $\% \mathrm{NBU}$ strength). A broadening of the salt tolerance range of the surfactant solution was observed as a function of an increase in the ethoxylated surfactant proportion in the mixture, while maintaining relatively low IFT values $\left(10^{-3}-10^{-1} \mathrm{mN} / \mathrm{m}\right)$. The CME surfactant improved the solubility of the AAS surfactants in brine. The range of IFT values measured was considerably lower than the values of the measurements when using the AAS or the CME surfactant alone, under similar conditions. However, no broad ultralow IFT values $\left(<10^{-3} \mathrm{mN} / \mathrm{m}\right)$ were determined for the tested surfactant mixtures. The solubilization parameters measured for these systems were generally moderate to low. As a result, oil production frorn Berea sandstone cores using these mixtures were only approximately 10 to $25 \%$ of residual oil after waterflood. The combination of the AAS and the CME surfactants did not appear to be a promising chemical flooding system, based on the results of surfactant systems tested.

- Chromatographic separation of the components of the mixed surfactant systems described in this report did nor appear to be a problem provided all surfactants were anionic in nature. Over extended distances, anionic and nonionic surfactants may separate. A.ll components of the mixed surfactant system appeared to suffer severe loss in oll rocovery experiments. For these mixed systems, the use of ethoxylated surfactants probably did not eliminate the requirement of at least some alcohol in the surfactant slug to alter surfactant solution properties and aid surfactant slug propagation. 
- In both static and dynamic adsorption experiments, CME surfactants greatly reduced surfactant loss of surfactant types such as alkyl aryl sulfonates at salinities where the sulfonates would precipitate or phase separate without the CME surfactant present in solution. Losses during oil recovery experiments were still great enough to jeopardize economical application of the mixed surfactant systems tested in this study.

- An injection strategy which used sodium bicarbonate/sodium carbonate solution as a preflush and in the surfactant slug followed by a salinity gradient was effective in increasing oll production and propagating the mixed surfactant system through a core. If a surfactant system can be developed that produces significant oll in coreflood experiments, methods to reduce surfactant loss may improve the economics of the process.

- Dilution calorimetry results indicate that only for LXS in water at $90^{\circ} \mathrm{C}$ is the $\mathrm{CMC}$ within the experimentally accessible region, occurring at $0.1 \%$. For lower temperatures and in brine and in the mixture, the $C M C$ is at concentrations lower than $0.1 \%$. The dilution curves for $L X S$ in brine at $25^{\circ}$ and $50^{\circ} \mathrm{C}$ are consistent with a system in which solution of a second phase is occurring.

- The results for the mixture of $80 \%$ LXS and $20 \%$ CME in brine indicate that at all temperatures the $C M C$ is very low, so that the only region experimentally available is the "tail" of the $L_{\phi}$ curve which is almost flat. The low CMC value for this mixture should help the surfactants stay together and move through the reservoir. Additional studies are required, however, to determine if changes in salinity or surfactant mixture composition provide conditions within which dilution calorimetry results may be correlated with the oll recovery potential of these mixtures.

\section{REFERENCES}

1. Lowry, P. H., H. H. Ferrell, and D. L. Dauben. A review and Statistical Analysis of Micellar-Polymer Field Test Data. Dept. of Energy Report DOE/BC/10830-4, November 1986, 27 pp.

2. Verkruyse, L. A. and S. J. Salter. Potential Use of Nonionic Surfactants in Micellar Flooding. Pres. at the Soc. Pet. Eng. International Symp. on Oilfield and Geothermal Energy, Phoenix, Apr. 9-11, 1985. SPE paper 13574.

3. Lewis, S. J., L. A. Verkruyse, and S. J. Salter. Selection of Nonionic Surfactants for Minimized Adsorption and Maximized Solubilization. Pres. at the SPE/DOE Fitth Symposium on Enhanced Oil Recovery, Tulsa, OK, Apr. 20-23, 1985. SPE/DOE paper 14910.

4. Sauge, A. and O. Palmgren. Phase Behavior ond Solution Properties of Ethoxylated Anionic Surfactants. Pres. at the Soc. Pet. Eng. International Symp. on Ollfield Chemistry, Houston, Feb. 8-10, 1989. SPE paper 18499. 
5. Baradat, Y., L. N. Fortney, C.LaLanne-Cassou, R. S. Schechter, W. H. Wade, and S YlV. The Phase Behavior of Simple Salt Tolerant Surtonates. Pres. at the DOE/SPE Symposium on Enhanced Oll Recovery, Tulsa, April 4-7, 1982. DOE/SPE paper 10679.

6. Lelanne-Cassou, C., I. Carmona, L. Fortney, A. Samil, R. S. Schecter, W. H. Wade, U. Werrasooriya, V. Weerasooriya, and S. Yiv. Binary Surfactant Mixtures for Minimizing Alcohol Cosolvent Requirements. Pres, at the Soc. Pet Eng. 58th Annual Technical Conference and Exhibition, San Francisco, CA, Oct. 5-8, 1983. SPE paper 12035.

7. Balzer, D. D. Carboxymethylated Ethoxylates, Tallor-Made Surfactants for Enhanced Oil Recovery. Pres. at the Oll Recovery By Chemcial Flooding Symposium, Essen, Nov. 24, 1981.

8. Balzer, D. D. Carboxylated Ethoxylates as EOR Surfactants. Pres, at 2nd European Symp. Conference on EOR, Paris, Nov. 8-10, 1982 .

9. Chiu, Y. C. and H. J. Hwang. The Use of Carboxymethyl Ethoxylates in Enhanced Oil Recovery. Colloids \& Surfaces, v. 28, 1987, pp.53.65.

10. Lysenko, V. I., V. G. Germashev, and V. D. Gusev. Effect of Amyl Alcohol on the Phase Behavior of Carboxymethylated Ethoxylates of Isononyphenol in a Surfactant-Water-Hydrocarbon System. Kolloidnyi Zhurnal, v. 49, No. 5, Sept.-Oct., 1987, pp. 1012-1015.

11. Abe, M., R. S. Shechter, R. D. Selliah, B. Sheikh, and W. H. Wade. Phase Behavior of Branched Tail Ethoxylated Carboxylate Surfactant/Electrolyte/Alkane Systems. J. Dispersion Sci. \& Tech., v. 8, No. 2, 1987, pp 157-172.

12. Olsen, D. K. and C. B. Josephson. Carboxylmethylated Ethoxylated Surfactants. Deptartment of Energy Report No. NIPER-228, August 1987, 54 pp. NTIS reorder No. DE87001258.

13. Stryker, Arden. Selection and Design of Ethoxylated Carboxylates for Chemcial Flooding. Department of Energy Report No. NIPER-449, Jan. 1990, 61 pp. NTIS reorder No. DE90000213.

14. Gall, Bonnie. The Use of Sacrificial Agents to Reduce Carboxymethylatted Ethoxylated Surfactant Loss During Chemical Flooding. Department of Energy Report No. NIPER-447, Dec. 1989, 27 pp. NTIS reorder No. DE90000203.

15. Lorenz, P.B., and S. Brock. Surfactant and Cosurfactant Properties of Mixed and Polysulfonated Surfactant by Phas Volume Measurements. Department of Energy Report No. NIPER-256, October 1987. NTIS reorder No. DE87001259.

16. Llave, F.M. and D.K. OIsen Development of an Aufomated System for Phase Inversion Temperature Measurements. Department of Energy Report No. NIPER-318, June 1988.

17. Shinoda, K. and $H$. Arai. The Correlation Between Phase Inversion Temperature in Emulsion and Cloud Point in Solution of Nonionic Emulsifier. J. Phys. Chem., v. 68, 1964, pp. 3485-3490.

18. Shinoda, K. and M. Kuneida. Conditions to Produce So-called Microemulsions: Factors to Increase the Mufual Solubility of Oil and Water by Solubilizer. J. Coll. and Interface Sci., v. 42, 1973, p. 381. 
20. Archer, D. G. Enthalpies of Dilution from $50^{\circ}$ to $225^{\circ} \mathrm{C}$ of Aqueous Decyltrimethylammonium Bromide. J. Solution Chem., v. 7, 1986, p. 581.

21. . Enthalpy of Dilution of Aqueous Sodium Chloride from $76^{\circ}$ to $225^{\circ} \mathrm{C}$ and Aqueous Dodec, ftrimethylammonium Bromide from $50^{\circ}$ to $225^{\circ} \mathrm{C}$. J. Solution Chem. v. 15, 1986, p. 727.

22. Enthalpies of Dilution of Aqueous Dodecyl- and Tetradecyl- Trimethylammonium Bromides from 323 to $448 \mathrm{~K}$ and of Aqueous Sodium Chloride from 349 to $448 \mathrm{~K}$. Department of Energy Report No. NIPER-217, 1987. NTIS reorder No. DE87001221

23. Enthalpies of Dilution of Aqueous Tetradecyltrimethylammonium Bromide from $50^{\circ}$ to $175^{\circ} \mathrm{C}$. J. Solution Chem., v. 16, 1987, p. 347.

24. Heat Capacities of Aqueous Decyl- and Dodecyl- Trimethylammonium Bromides from 324.6 to 374.6 K. J. Chern. Thermo., v. 19, 1987, p. 407.

25. Lam, A. C. and D. G. Archer. Enthalples of Dilution of Dodecyl- and Tetradecyl- Trimethylammonium Bromides in Aqueous Solutions of Sodium Bromide at Elevated Temperatures. Department of Energy Report No. NIPER-304, 1987. NTIS reorder No. DE88001219.

26. Noll, L. A. and A. C. Lam. Effects of 1-Butanol on the Micellization of Dodecyltrimethylammonium Bromide at Elevated Temperatures. Department of Energy Report No. NIPER-368, 1988. NTIS reorder No. DE89000723.

27. Noll, L. A. Ambient and High Temperature Calorimetry of Commercial Surfactants. Department of Energy Report No. NIPER-438, 1989.

28. Berg, R. L. Thermodynamics of Aqueous Sodium Dociecyl Sulfate. Department of Energy Report No. BERC/TPR-77/3. 1977. (Available from NIPER.)

29. Bolsman, T.A.B.M. Phase Behavior of Alkylxylenesulfonate/Oil/Brine Systems. Pres. ar the 2nd European Symposium on Enhanced Oll Recovery, Paris, Nov. 8-10, 1982.

30. Foulser, R. W. S., S. G. Goodyear, C. D. Lee-Tufinell, V. Potts and A. Read. Optimal Phase Diagrams and the Effect of Salt Anion Composition in a Model Surfactant System for Improved Oil Recovery. J. Chem. Soc. Chem. Commun., 1989, p. 365.

31. Weast, Robert C. ed. Handbook of Chemistry and Physics, 49th edition. The Chemical Rubber Co., 1968.

32. De Lisi, R. and S. Milioto. Mass Aciion Model for Solute Distribution Between Water and Micelles. Partial Molar Volumes of Butanol and Pentanol in Dodecyl Surfactant Solutions. J. Solution Chem., v. 15, 1986, p. 23.

33. Sharma, M.K. ar,d D.O. Shah. Macro- and Microemulsions in Enhanced Oil Recovery. Macro- and Microemulsions, Theory and Applications; ACS Symp. Series 272, Ed. D. O. Shah, publ. ACS, 1985 , Ch. 11. Symp. of Div. of Ind. and Eng. Chem, 1983 ACS meeting, Aug. 28-Sept. 2.

34. Bansal, V.K., and D.O. Shah. The Effect of Ethoxylated Sulfonates on Salt Tolerance and Optimal Salinity of Surfactant Formulations for Tertiary Oil Recovery. SPE J, June 1978, pp. 167-172. 
35. Winsor, P.A. Solvent Properties of Ampiriphillic Compounds, Butterworth's Scientific Publication, London (1954).

36. Nelson, R.C. and G.A. Pope. Phase Relationships in Chemical Flooding. SPEJ, Oct. 1978, pp. 325 338.

37. Healy, R.N., R.L. Reed, and D.G.Stenmark. Multiphase Microemulsion Systems. SPEJ, June 1976, pp. $147-160$.

38. Bolsman, T.A.B.M. Phase Behaviour of Alkylxylenesurfonate/Oil/Brine Systems. Pres. at the 2nd European Symposium on Enhanced Oil Recovery, Paris, Nov. 8-10, 1982.

39. Boisman, T.A.B.M. and G.J. Daane. Relationship Between Structure and Performance of Alkylxylenesulphonate Blends in Surfactant-Brine-Crude Oil Systems, Pres. at the World Surfactant Congress, Munich, Germany, May, 1984.

40. Balzer, D. Carboxymethylated Ethoxylates, Tailor-Made Surfactants for Enhanced Oil Recovery. Oil Gas - European Magazine, v. 1, No. 50, 1983. 
APPENDIX 1

DATA TABLES FOR DILUTION CALORIMETRY RESULTS

TABLE A1. - Enthalpies of dilution of Enordet LXS-1314 in water at $25^{\circ} \mathrm{C}$

\begin{tabular}{|c|c|c|c|}
\hline \multicolumn{4}{|c|}{$P=0.10 \mathrm{MPa} \quad \sigma=0.077$} \\
\hline$m_{i}$ & $m_{i}$ & $\Delta \mathrm{L}_{\phi}$ & Residual \\
\hline $\mathrm{mol} \cdot \mathrm{kg}^{-1}$ & $\mathrm{~mol} \cdot \mathrm{kg}^{-1}$ & $\mathrm{~kJ} \cdot \mathrm{mol}^{-1}$ & $\mathrm{~kJ} \cdot \mathrm{mol}^{-1}$ \\
\hline 0.0888 & 0.0516 & 0.161 & 0.274 \\
\hline 0.0798 & 0.0308 & 0.264 & 0.090 \\
\hline 0.0798 & 0.0305 & 0.375 & -0.023 \\
\hline 0.0662 & 0.0386 & 0.125 & 0.083 \\
\hline 0.0617 & 0.0239 & 0.187 & -0.137 \\
\hline 0.0435 & 0.0254 & 0.032 & -0.101 \\
\hline 0.0399 & 0.0156 & 0.080 & -0.428 \\
\hline 0.0217 & 0.0127 & -0.139 & -0.183 \\
\hline 0.0206 & 0.0081 & -0.369 & -0.064 \\
\hline 0.0162 & 0.0095 & -0.240 & -0.028 \\
\hline 0.0154 & 0.0060 & -0.311 & 0.109 \\
\hline 0.0111 & 0.0044 & -0.447 & 0.609 \\
\hline 0.0108 & 0.0063 & -0.390 & 0.367 \\
\hline 0.0054 & 0.0021 & 0.846 & -0.027 \\
\hline 0.0051 & 0.0030 & 0.473 & -0.054 \\
\hline 0.0023 & 0.0009 & 1.339 & -0.343 \\
\hline 0.0021 & 0.0013 & 0.741 & -0.146 \\
\hline
\end{tabular}


TABLE A2. - Enthalpies of dilution of Enordet LXS-1314 in water at $50^{\circ} \mathrm{C}$

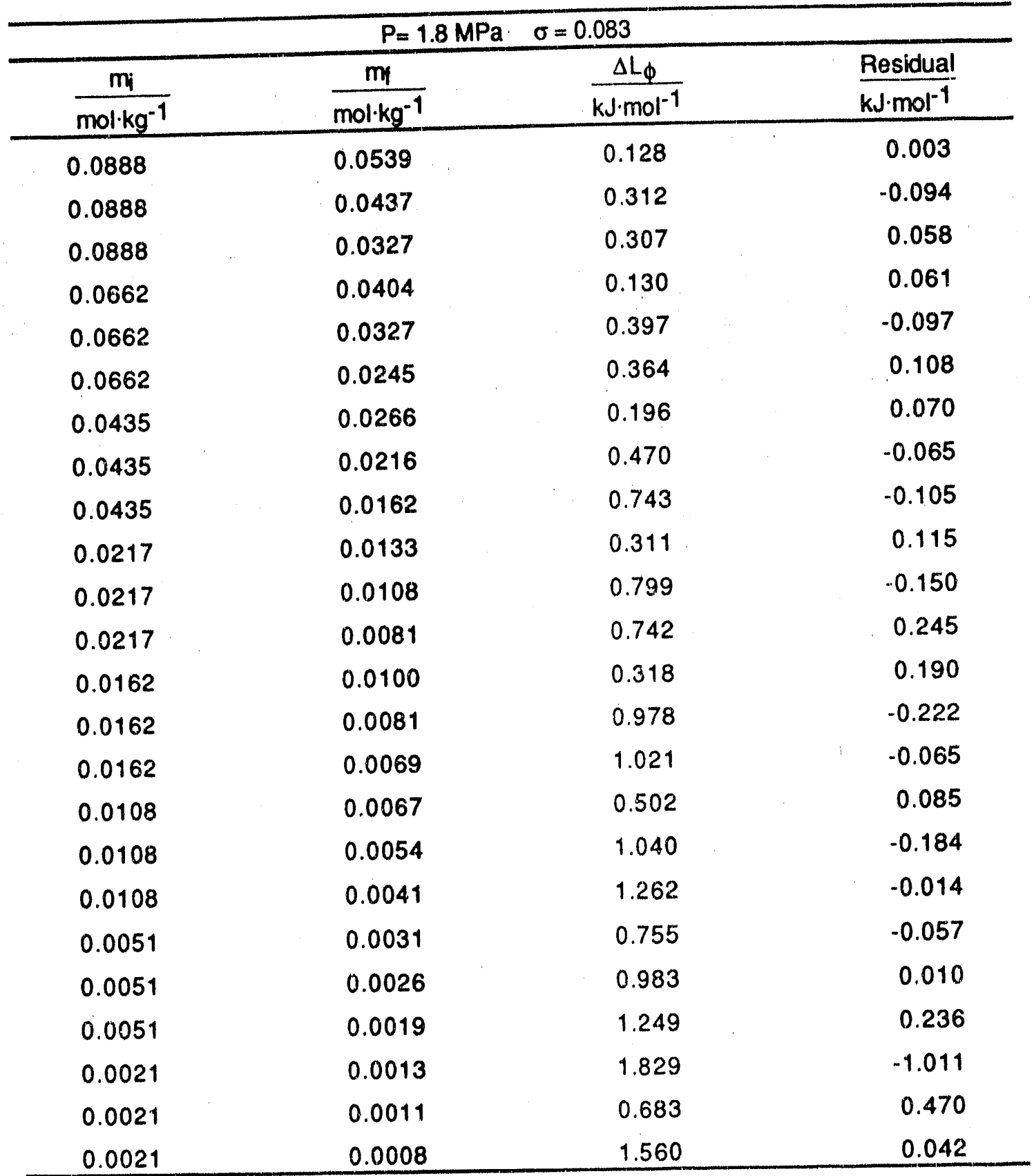


TABLLE A3. - Enthaipies of dilution of Enordet LXS-1314 in water at $90^{\circ} \mathrm{C}$

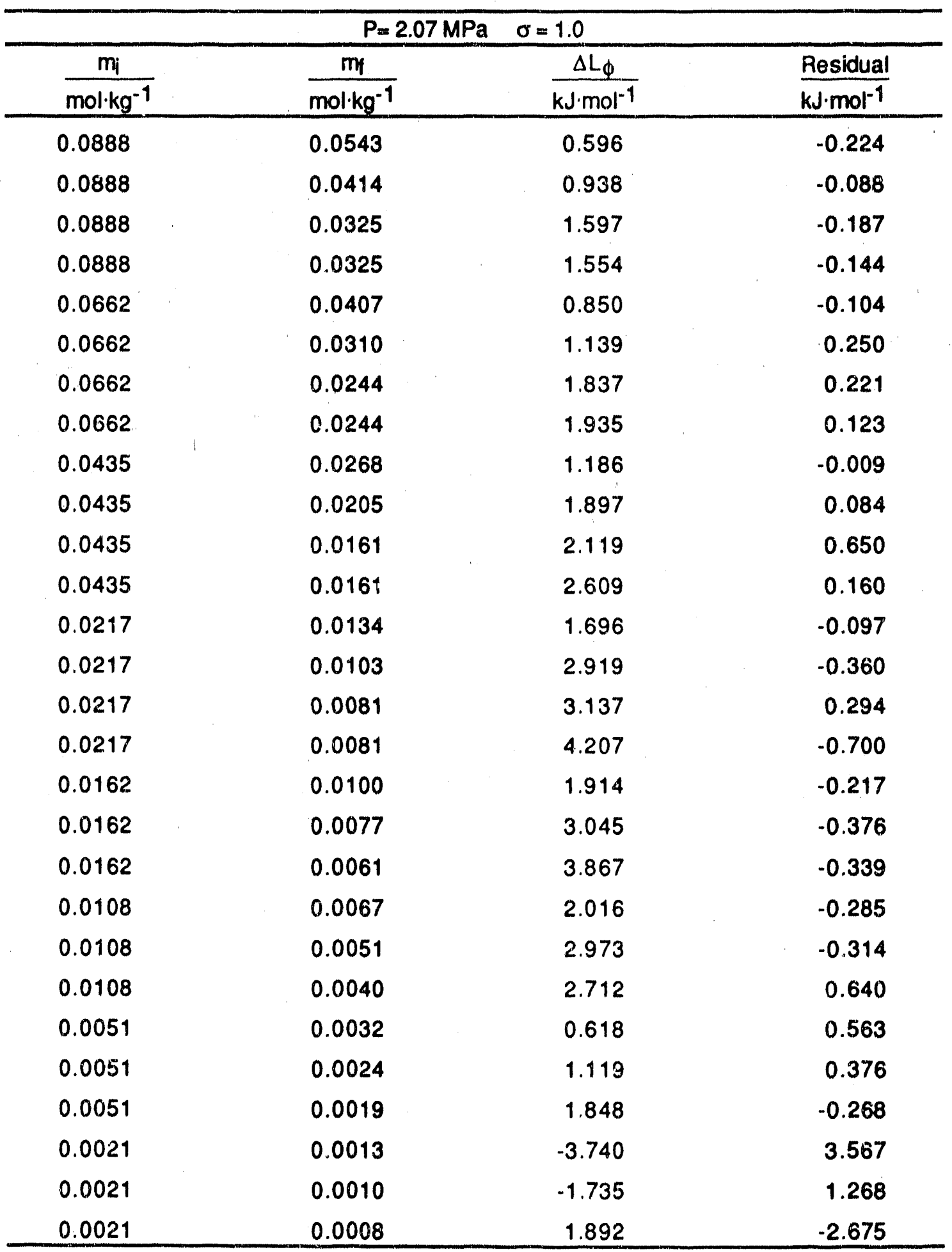


TABLE A4. - Enthalpies of dilution of Enordet LXS-1314 in brine at $25^{\circ} \mathrm{C}$

\begin{tabular}{cccc}
\hline & \multicolumn{2}{c}{$\mathrm{P}=0.10 \mathrm{MPa}$} & $\sigma=0.032$ \\
\hline $\mathrm{mo}$ & $\frac{\mathrm{mf}}{\mathrm{mol} \cdot \mathrm{kg}^{-1}}$ & $\frac{\Delta \mathrm{L}_{\phi}}{\mathrm{kJ} \cdot \mathrm{mol}^{-1}}$ & $\frac{\text { Residual }}{\mathrm{kJ} \cdot \mathrm{mol}^{-1}}$ \\
\hline 0.0901 & 0.0524 & -0.074 & 0.069 \\
0.0901 & 0.0434 & -0.019 & 0.001 \\
0.0672 & 0.0393 & -0.053 & 0.022 \\
0.0672 & 0.0326 & -0.003 & -0.054 \\
0.0441 & 0.0259 & -0.031 & -0.052 \\
0.0441 & 0.0214 & -0.039 & -0.093 \\
0.0215 & 0.0126 & -0.051 & -0.129 \\
0.0215 & 0.0105 & -0.244 & -0.008 \\
0.0159 & 0.0094 & -0.619 & 0.416 \\
0.0159 & 0.0078 & -0.223 & -0.057 \\
0.0095 & 0.0056 & -0.515 & 0.295 \\
0.0095 & 0.0047 & -0.351 & 0.054 \\
0.0053 & 0.0031 & -0.121 & -0.090 \\
0.0053 & 0.0026 & -0.228 & -0.051 \\
0.0022 & 0.0013 & 0.000 & -0.166 \\
0.0022 & 0.0011 & 0.000 & -0.213 \\
\hline
\end{tabular}


TABLE A5. - Enthalpies of dilution of Enordet LXS-1314 in brine at $50^{\circ} \mathrm{C}$

\begin{tabular}{|c|c|c|c|}
\hline \multicolumn{4}{|c|}{$P=1.8 \mathrm{MPa} \quad \sigma=0.014$} \\
\hline$m_{i}$ & $m y$ & $\Delta \mathrm{L}_{\phi}$ & Residual \\
\hline $\mathrm{mol} \cdot \mathrm{kg}^{-1}$ & $\mathrm{~mol} \cdot \mathrm{kg}^{-1}$ & $\mathrm{~kJ} \cdot \mathrm{mol}^{-1}$ & $\mathrm{~kJ} \cdot \mathrm{mol}^{-1}$ \\
\hline 0.0901 & 0.0549 & 0.054 & -0.012 \\
\hline 0.0901 & 0.0443 & 0.047 & 0.018 \\
\hline 0.0901 & 0.0334 & 0.075 & 0.023 \\
\hline 0.0672 & 0.0411 & 0.061 & -0.011 \\
\hline 0.0672 & 0.0332 & 0.111 & -0.036 \\
\hline 0.0672 & 0.0251 & 0.099 & 0.013 \\
\hline 0.0441 & 0.0271 & 0.061 & -0.001 \\
\hline 0.0441 & 0.0219 & 0.164 & -0.076 \\
\hline 0.0441 & 0.0166 & 0.090 & 0.036 \\
\hline 0.0215 & 0.0132 & 0.062 & 0.004 \\
\hline 0.0215 & 0.0107 & 0.057 & 0.037 \\
\hline 0.0215 & 0.0081 & 0.183 & -0.053 \\
\hline 0.0159 & 0.0098 & 0.084 & -0.019 \\
\hline 0.0159 & 0.0080 & 0.000 & 0.091 \\
\hline 0.0159 & 0.0060 & 0.205 & -0.081 \\
\hline 0.0095 & 0.0059 & 0.140 & -0.081 \\
\hline 0.0095 & 0.0047 & 0.000 & 0.082 \\
\hline 0.0095 & 0.0036 & 0.000 & 0.110 \\
\hline 0.0053 & 0.0033 & 0.251 & -0.202 \\
\hline 0.0053 & 0.0027 & 0.000 & 0.066 \\
\hline 0.0053 & 0.0020 & 0.000 & 0.085 \\
\hline 0.0022 & 0.0014 & 0.440 & -0.415 \\
\hline 0.0022 & 0.0011 & 0.000 & 0.033 \\
\hline 0.0022 & 0.0009 & 0.000 & 0.040 \\
\hline
\end{tabular}


TABLE A6. - Enthalpies of dilution of Enordet LXS-1314 in brine at $90^{\circ} \mathrm{C}$

\begin{tabular}{cccc}
\hline & \multicolumn{2}{c}{$\mathrm{P}=2.07 \mathrm{MPa}$} & $\sigma=0.68$ \\
\hline $\mathrm{m}_{\mathrm{m}}$ & $\frac{\mathrm{m} \mathrm{f}}{\mathrm{mol} \cdot \mathrm{kg}^{-1}}$ & $\frac{\Delta \mathrm{L}_{\phi}}{\mathrm{kJ} \cdot \mathrm{mol}^{-1}}$ & $\frac{\text { Residual }}{\mathrm{kJ} \cdot \mathrm{mol}^{-1}}$ \\
\hline 0.0901 & 0.0555 & 0.307 & -0.162 \\
0.0901 & 0.0420 & 0.380 & -0.101 \\
0.0901 & 0.0329 & 0.423 & -0.004 \\
0.0672 & 0.0416 & 0.281 & -0.072 \\
0.0672 & 0.0315 & 0.421 & -0.050 \\
0.0672 & 0.0247 & 0.340 & 0.189 \\
0.0441 & 0.0274 & 0.309 & -0.026 \\
0.0441 & 0.0208 & 0.390 & 0.082 \\
0.0441 & 0.0163 & 0.483 & 0.160 \\
0.0215 & 0.0134 & 0.519 & -0.166 \\
0.0215 & 0.0102 & 0.596 & 0.079 \\
0.0215 & 0.0080 & 0.739 & 0.344 \\
0.0159 & 0.0099 & 0.699 & -0.202 \\
0.0159 & 0.0075 & 1.602 & -0.613 \\
0.0159 & 0.0059 & 0.391 & 1.146 \\
0.0095 & 0.0059 & 1.005 & -0.032 \\
0.0095 & 0.0045 & 4.488 & -2.766 \\
0.0053 & 0.0033 & 1.196 & 0.149 \\
0.0053 & 0.0025 & 1.196 & 0.900 \\
0.0022 & 0.0014 & 0.000 & 1.010 \\
0.0022 & 0.0011 & 1.417 & 0.064 \\
\hline
\end{tabular}


TABLE A7. - Enthalpies of dilution of LXS-1314/RS - 16 mixture in brine at $25^{\circ} \mathrm{C}$

\begin{tabular}{|c|c|c|c|}
\hline & $P=0.1$ & $\sigma=0.449$ & \\
\hline$m_{i}$ & $m i$ & $\Delta \mathrm{L}_{\phi}$ & Residual \\
\hline $\mathrm{mol} \cdot \mathrm{kg}^{-1}$ & $\mathrm{~mol} \cdot \mathrm{kg}^{-1}$ & $\mathrm{~kJ} \cdot \mathrm{mol}^{-1}$ & $\mathrm{~kJ} \cdot \mathrm{mol}^{-1}$ \\
\hline 0.0985 & 0.0385 & 1.131 & -1.448 \\
\hline 0.0985 & 0.0338 & -2.760 & 2.411 \\
\hline 0.0814 & 0.0473 & 0.003 & -0.186 \\
\hline 0.0814 & 0.0472 & -0.030 & -0.153 \\
\hline 0.0814 & 0.0313 & -0.051 & -0.238 \\
\hline 0.0814 & 0.0309 & -0.088 & -0.203 \\
\hline 0.0785 & 0.0456 & 0.052 & -0.231 \\
\hline 0.0785 & 0.0455 & -0.031 & -0.149 \\
\hline 0.0785 & 0.0302 & -0.087 & -0.196 \\
\hline 0.0785 & 0.0299 & -0.115 & -0.171 \\
\hline 0.0400 & 0.0234 & 0.008 & -0.129 \\
\hline 0.0400 & 0.0234 & 0.001 & -0.123 \\
\hline 0.0400 & 0.0156 & -0.247 & 0.055 \\
\hline 0.0400 & 0.0154 & -0.125 & -0.069 \\
\hline 0.0196 & 0.0115 & 0.031 & -0.113 \\
\hline 0.0196 & 0.0115 & 0.129 & -0.211 \\
\hline 0.0196 & 0.0077 & -0.353 & 0.215 \\
\hline 0.0196 & 0.0076 & -0.158 & 0.019 \\
\hline 0.0147 & 0.0088 & -0.240 & 0.167 \\
\hline 0.0147 & 0.0087 & 0.198 & -0.273 \\
\hline 0.0147 & 0.0058 & -0.620 & 0.491 \\
\hline 0.0147 & 0.0057 & 0.279 & -0.410 \\
\hline 0.0098 & 0.0059 & -0.060 & -0.009 \\
\hline 0.0098 & 0.0058 & 0.238 & -0.309 \\
\hline 0.0098 & 0.0039 & .0 .796 & 0.673 \\
\hline 0.0098 & 0.0038 & 0.205 & -0.329 \\
\hline 0.0049 & 0.0029 & -0.069 & 0.004 \\
\hline 0.0049 & 0.0029 & 0.428 & -0.494 \\
\hline 0.0049 & 0.0019 & -1.437 & 1.325 \\
\hline 0.0049 & 0.0019 & 0.655 & -0.769 \\
\hline 0.0019 & 0.0012 & 0.347 & -0.395 \\
\hline 0.0019 & 0.0011 & 0.517 & -0.566 \\
\hline
\end{tabular}


TABLE A8. - Enthalpies of dilution of LXS-1314/RS-16 mixture in brine at $50^{\circ} \mathrm{C}$

\begin{tabular}{|c|c|c|c|}
\hline & $P=1.8$ & $\sigma=0.014$ & \\
\hline$\frac{\mathrm{mi}}{\mathrm{mol} \cdot \mathrm{kg}^{-1}}$ & $\frac{m_{f}}{m o l \cdot k^{-1}}$ & $\frac{\Delta \mathrm{L}_{\phi}}{\mathrm{kJ} \cdot \mathrm{mol}^{-1}}$ & $\frac{\text { Residual }}{\mathrm{kJ} \cdot \mathrm{mol}^{-1}}$ \\
\hline 0.0814 & 0.0409 & 0.040 & -0.007 \\
\hline 0.0814 & 0.0409 & 0.049 & -0.016 \\
\hline 0.0814 & 0.0303 & 0.061 & -0.016 \\
\hline 0.0785 & 0.0386 & 0.000 & 0.033 \\
\hline 0.0785 & 0.0386 & 0.039 & -0.006 \\
\hline 0.0785 & 0.0292 & 0.014 & 0.031 \\
\hline 0.0400 & 0.0199 & 0.000 & 0.026 \\
\hline 0.0400 & 0.0199 & 0.051 & -0.025 \\
\hline 0.0400 & 0.0151 & 0.066 & -0.029 \\
\hline 0.0196 & 0.0098 & 0.168 & -0.137 \\
\hline 0.0196 & 0.0098 & 0.068 & -0.037 \\
\hline 0.0196 & 0.0074 & 0.000 & 0.047 \\
\hline 0.0147 & 0.0074 & 0.000 & 0.037 \\
\hline 0.0147 & 0.0074 & 0.091 & -0.054 \\
\hline 0.0147 & 0.0056 & 0.000 & 0.055 \\
\hline 0.0098 & 0.0049 & -0.032 & 0.077 \\
\hline 0.0098 & 0.0049 & 0.100 & -0.055 \\
\hline 0.0098 & 0.0037 & 0.000 & 0.065 \\
\hline 0.0049 & 0.0025 & 0.000 & 0.050 \\
\hline 0.0049 & 0.0025 & 0.000 & 0.050 \\
\hline 0.0049 & 0.0019 & 0.000 & 0.070 \\
\hline 0.0019 & 0.0010 & 0.000 & 0.037 \\
\hline 0.0019 & 0.0010 & 0.500 & -0.463 \\
\hline 0.0019 & 0.0007 & 0.000 & 0.048 \\
\hline
\end{tabular}


TABLE A9. - Enthalpies of dilution of LXS-1314/RS-16 mixture in brine at $90^{\circ} \mathrm{C}$

\begin{tabular}{|c|c|c|c|}
\hline & $P=0$. & $\sigma=0.008$ & \\
\hline$\frac{\mathrm{mi}_{\mathrm{i}}}{\mathrm{mol}^{\mathrm{kg}} \mathrm{g}^{-1}}$ & $\frac{m_{f}}{m_{0} / k^{-1}}$ & $\frac{\Delta L_{\phi}}{\mathrm{kJ} \cdot \mathrm{mol}^{-1}}$ & $\frac{\text { Residual }}{\mathrm{kJ} \cdot \mathrm{mol}^{-1}}$ \\
\hline 0.0814 & 0.0502 & 0.212 & -0.109 \\
\hline 0.0814 & 0.0380 & 0.161 & 0.014 \\
\hline 0.0814 & 0.0298 & 0.217 & 0.028 \\
\hline 0.0785 & 0.0485 & 0.125 & -0.020 \\
\hline 0.0785 & 0.0366 & 0.056 & 0.123 \\
\hline 0.0785 & 0.0288 & 0.328 & -0.079 \\
\hline 0.0400 & 0.0249 & 0.161 & $-0,022$ \\
\hline 0.0400 & 0.0189 & 0.161 & 0.064 \\
\hline 0.0400 & 0.0148 & 0.333 & -0.032 \\
\hline 0.0196 & 0.0122 & 0.121 & 0.027 \\
\hline 0.0196 & 0.0093 & 0.218 & 0.010 \\
\hline 0.0196 & 0.0073 & 0.159 & 0.129 \\
\hline 0.0147 & 0.0092 & 0.162 & -0.022 \\
\hline 0.0147 & 0.0070 & 0.312 & -0.104 \\
\hline 0.0098 & 0.0047 & 0.323 & -0.161 \\
\hline 0.0049 & 0.0023 & 0.000 & 0.084 \\
\hline
\end{tabular}

TABLE A10. - Knot positions from the isothermal fits of Enordet LXS-1314 in water

\begin{tabular}{cccc}
\hline$T^{\prime} C$ & 25 & 50 & 90 \\
\hline$m^{0.5}$ & 10 & 10 & 10 \\
$L_{\phi}$ & 10 & 10 & 10 \\
$m^{0.5}$ & 0.045 & 0.03 & 0.035 \\
$L_{\phi}$ & -2.0 & -2.0 & 2.9 \\
$m^{0.5}$ & 0.13 & 0.08 & 0.08 \\
$L_{\phi}$ & -2.7 & -5.5 & 0.9 \\
$m^{0.5}$ & 0.33 & 0.17 & 0.17 \\
$L_{\phi}$ & -3.2 & -6.9 & -4.3 \\
$m^{0.5}$ & & 0.33 & 0.35 \\
$L_{\phi}$ & & -7.4 & -5.9 \\
\hline
\end{tabular}

${ }^{1}$ These knots were not allowed to vary in the least -squares minimization procedure. 
TABLE A11. - Knot positions for the isothermal fits of Enordet LXS-1314 in brine

\begin{tabular}{cccc}
\hline$T / C^{\prime}$ & 25 & 50 & 90 \\
\hline$m^{0.5}$ & 10 & 10 & 10 \\
$L_{\phi}$ & 10 & 10 & 10 \\
$m^{0.5}$ & 0.05 & 0.07 & 0.07 \\
$L_{\phi}$ & 0.5 & -0.32 & -5.2 \\
$m^{0.5}$ & 0.22 & 0.15 & 0.13 \\
$L_{\phi}$ & 1.4 & -0.5 & -7.2 \\
$m^{0.5}$ & 0.35 & 0.33 & 0.35 \\
$L_{\phi}$ & 1.4 & -0.66 & -8.3 \\
\hline
\end{tabular}

1These knots were not allowed to vary in the least -squares minimization procedure.

TABLE A12. - Knot positions for the isothermal fits of LXS-1314/RS-16 mixture in brine

\begin{tabular}{clll}
\hline$T / C$ & 25 & 50 & 90 \\
\hline$m^{0.5}$ & 10 & 10 & 10 \\
$L_{\phi}$ & 10 & 10 & 10 \\
$m^{0.5}$ & 0.055 & 0.05 & 0.04 \\
$L_{\phi}$ & 0.02 & -0.04 & -2.0 \\
$m^{0.5}$ & 0.13 & 0.15 & 0.12 \\
$L_{\phi}$ & 0.4 & -0.04 & -3.5 \\
$m^{0.5}$ & 0.35 & 0.33 & 0.33 \\
$L_{\phi}$ & 1.0 & -0.21 & -4.2 \\
\hline
\end{tabular}

1 These knots were not allowed to vary in the least -squares minimization procedure. 
TABLE A13, - Results of ouble spline fit: $L_{\phi}$ data for Enordet LXS-1314 in water

\begin{tabular}{|c|c|c|c|c|c|}
\hline \multicolumn{2}{|c|}{$25^{\circ} \mathrm{C}$} & \multicolumn{2}{|c|}{$50^{\circ} \mathrm{C}$} & \multicolumn{2}{|c|}{$90^{\circ} \mathrm{C}$} \\
\hline$\%$ Active & $L_{\phi}, \mathrm{kJ} / \mathrm{mol}$ & $\%$ Aotive & $\mathrm{L}_{\phi}, \mathrm{kJ} / \mathrm{mol}$ & $\%$ Active & $L_{\phi}, \mathrm{kJ} / \mathrm{mol}$ \\
\hline 0.000 & 0.00 & 0.000 & 0.00 & 0.000 & 0.00 \\
\hline 0.001 & -0.03 & 0.000 & -0.03 & 0.001 & 0.08 \\
\hline 0.004 & -0.13 & 0.002 & -0.14 & 0.002 & 0.26 \\
\hline 0.009 & -0.29 & 0.004 & -0.32 & 0.005 & 0.53 \\
\hline 0.015 & -0.49 & 0.007 & -0.55 & 0.009 & 0.87 \\
\hline 0.024 & -0.72 & 0.011 & -0.82 & 0.014 & 1.24 \\
\hline 0.034 & -0.98 & 0.015 & -1.12 & 0.021 & 1.63 \\
\hline 0.046 & -1.26 & 0.021 & -1.45 & 0.028 & 2.02 \\
\hline 0.061 & -1.53 & 0.027 & -1.78 & 0.037 & 2.39 \\
\hline 0.077 & -1.79 & 0.034 & -2.12 & 0.046 & 2.70 \\
\hline 0.095 & -2.03 & 0.042 & -2.44 & 0.057 & 2.95 \\
\hline 0.134 & -2.41 & 0.057 & -2.94 & 0.073 & 3.14 \\
\hline 0.180 & -2.68 & 0.075 & -3.38 & 0.091 & 3.19 \\
\hline 0.232 & -2.86 & 0.095 & -3.77 & 0.110 & 3.13 \\
\hline 0.291 & -2.96 & 0.117 & -4.11 & 0.131 & 2.97 \\
\hline 0.357 & -3.00 & 0.141 & -4.41 & 0.154 & 2.72 \\
\hline 0.429 & -2.99 & 0.168 & -4.67 & 0.180 & 2.41 \\
\hline 0.508 & -2.94 & 0.197 & -4.91 & 0.207 & 2.05 \\
\hline 0.594 & -2.86 & 0.229 & -5.11 & 0.235 & 1.65 \\
\hline 0.686 & -2.77 & 0.263 & -529 & 0.266 & 1.24 \\
\hline 0.785 & -2.68 & 0.299 & -5.46 & 0.299 & 0.83 \\
\hline 1.042 & -2.52 & 0.369 & -5.73 & 0.369 & 0.06 \\
\hline 1.334 & -2.43 & 0.447 & -5.96 & 0.447 & -0.64 \\
\hline 1.661 & -2.39 & 0.533 & -6.16 & 0.533 & -1.28 \\
\hline 2.022 & -2.40 & 0.626 & -6.33 & 0.626 & -1.85 \\
\hline 2.416 & -2.46 & 0.726 & -6.48 & 0.726 & -2.38 \\
\hline 2.842 & -2.55 & 0.833 & -6.60 & 0.833 & -2.84 \\
\hline 3.299 & -2.68 & 0.948 & -6.71 & 0.948 & -3.26 \\
\hline 3.787 & -2.82 & 1.070 & -6.80 & 1.070 & -3.64 \\
\hline \multirow[t]{2}{*}{4.304} & -2.98 & 1.199 & -6.87 & 1.199 & -3.98 \\
\hline & & 1.334 & -6.94 & 1.334 & -4.28 \\
\hline
\end{tabular}


TABLE A13 cont. - Results of cublc spline fit: $L_{\phi}$ data for Enordet LXS-1314 in water

\begin{tabular}{|c|c|c|c|c|c|}
\hline \multicolumn{2}{|c|}{$25^{\circ} \mathrm{C}$} & \multicolumn{2}{|c|}{$50^{\circ} \mathrm{C}$} & \multicolumn{2}{|c|}{$90^{\circ} \mathrm{C}$} \\
\hline$\%$ Active & $L_{\phi}, \mathrm{kJ} / \mathrm{mol}$ & $\%$ Active & $\mathrm{L}_{0}, \mathrm{~kJ} / \mathrm{mol}$ & $\%$ Active & $L_{\phi}, \mathrm{kJ} / \mathrm{mol}$ \\
\hline & & 1.593 & .7 .04 & 1.627 & -4.80 \\
\hline & & 1.874 & -7.12 & 1.947 & -5.20 \\
\hline & & 2.176 & -7.19 & 2.294 & -5.51 \\
\hline & & 2.499 & -7.25 & 2.668 & -5.73 \\
\hline & & 2.842 & .7 .29 & 3.067 & -5.88 \\
\hline & & 3.205 & -7.33 & 3.491 & -5.96 \\
\hline & & 3.588 & -7.35 & 3.939 & -6.00 \\
\hline & & 3.990 & -7.37 & 4.411 & -6.00 \\
\hline & & 4.411 & -7.39 & 4.905 & -5.98 \\
\hline
\end{tabular}


TABLE A14. - Results of cubic spline fit: $L_{\phi}$ data for Enordet $L X S-1314$ in brine

\begin{tabular}{|c|c|c|c|c|c|}
\hline \multicolumn{2}{|c|}{$25^{\circ} \mathrm{C}$} & \multicolumn{2}{|c|}{$50^{\circ} \mathrm{C}$} & \multicolumn{2}{|c|}{$90^{\circ} \mathrm{C}$} \\
\hline$\%$ Active & $L_{\phi}, \mathrm{kJ} / \mathrm{mol}$ & $\%$ Active & $L_{\phi}, \mathrm{kJ} / \mathrm{mol}$ & $\%$ Active & $L_{0}, \mathrm{~kJ} / \mathrm{mol}$ \\
\hline 0.000 & 0.00 & 0.000 & 0.00 & 0.000 & 0.00 \\
\hline 0.001 & 0.02 & 0.002 & 0.01 & 0.002 & -0.07 \\
\hline 0.005 & 0.05 & 0.009 & 0.02 & 0.009 & -0.34 \\
\hline 0.011 & 0.09 & 0.021 & 0.02 & 0.021 & -0.76 \\
\hline 0.019 & 0.14 & 0.037 & 0.01 & 0.037 & -1.32 \\
\hline 0.029 & 0.21 & 0.057 & 0.00 & 0.057 & -1.96 \\
\hline 0.042 & 0.27 & 0.082 & -0.02 & 0.082 & -2.66 \\
\hline 0.057 & 0.35 & 0.112 & -0.04 & 0.112 & -3.39 \\
\hline 0.075 & 0.42 & 0.147 & -0.06 & 0.147 & -4.12 \\
\hline 0.095 & 0.50 & 0.185 & -0.68 & 0.185 & -4.80 \\
\hline 0.117 & 0.57 & 0.229 & -0.10 & 0.229 & -5.41 \\
\hline 0.210 & 0.80 & 0.284 & -0.13 & 0.270 & -5.85 \\
\hline 0.329 & 0.99 & 0.345 & -0.15 & 0.314 & -6.22 \\
\hline 0.475 & 1.14 & 0.412 & -0.17 & 0.361 & -6.52 \\
\hline 0.647 & 1.26 & 0.485 & -0.19 & 0.412 & -6.77 \\
\hline 0.846 & 1.36 & 0.563 & -0.21 & 0.466 & -6.97 \\
\hline 1.070 & 1.43 & 0.647 & -0.23 & 0.523 & -7.13 \\
\hline 1.319 & 1.48 & 0.738 & -0.25 & 0.584 & -7.25 \\
\hline 1.593 & 1.51 & 0.833 & -0.27 & 0.647 & -7.35 \\
\hline 1.892 & 1.53 & 0.935 & -0.28 & 0.714 & -7.43 \\
\hline 2.215 & 1.55 & 1.042 & -0.30 & 0.785 & -7.50 \\
\hline 2.478 & 1.55 & 1.304 & -0.33 & 1.070 & -7.72 \\
\hline 2.754 & 1.56 & 1.593 & -0.35 & 1.397 & -7.90 \\
\hline 3.044 & 1.56 & 1.910 & -0.37 & 1.766 & -8.04 \\
\hline 3.347 & 1.56 & 2.254 & -0.39 & 2.176 & -8.15 \\
\hline 3.662 & 1.56 & 2.625 & -0.41 & 2.625 & -8.24 \\
\hline 3.990 & 1.55 & 3.021 & -0.42 & 3.113 & -8.30 \\
\hline 4.331 & 1.55 & 3.442 & -0.43 & 3.637 & .8 .35 \\
\hline 4.683 & 1.55 & 3.888 & -0.44 & 4.198 & -8.38 \\
\hline 5.047 & 1.54 & 4.357 & -0.45 & 4.794 & -8.40 \\
\hline
\end{tabular}


TABLE A15. - Results of cubic spline fit: $L_{\phi}$ data for $L X S-1314 / R S-16$ mixture in brine

\begin{tabular}{|c|c|c|c|c|c|}
\hline \multicolumn{2}{|c|}{$25^{\circ} \mathrm{C}$} & \multicolumn{2}{|c|}{$50^{\circ} \mathrm{C}$} & \multicolumn{2}{|c|}{$90^{\circ} \mathrm{C}$} \\
\hline$\%$ Rctive & $L_{\phi}, \mathrm{kJ} / \mathrm{mol}$ & $\%$ Active & $L_{\phi}, \mathrm{kJ} / \mathrm{mol}$ & $\%$ Active & $L_{\phi}, \mathrm{kJ} / \mathrm{mol}$ \\
\hline 0.000 & 0.00 & 0.000 & 0.00 & 0.000 & 0.00 \\
\hline 0.002 & 0.01 & 0.001 & 0.01 & 0.001 & 0.02 \\
\hline 0.006 & 0.03 & 0.005 & 0.01 & 0.003 & 0.03 \\
\hline 0.014 & 0.04 & 0.012 & 0.01 & 0.007 & 0.04 \\
\hline 0.025 & 0.06 & 0.020 & 0.01 & 0.013 & 0.05 \\
\hline 0.039 & 0.09 & 0.032 & 0.00 & 0.020 & 0.06 \\
\hline 0.056 & 0.11 & 0.046 & -0.02 & 0.029 & 0.06 \\
\hline 0.076 & 0.14 & 0.063 & -0.03 & 0.040 & 0.06 \\
\hline 0.099 & 0.17 & 0.082 & -0.04 & 0.052 & 0.06 \\
\hline 0.125 & 0.19 & 0.104 & -0.06 & 0.066 & 0.06 \\
\hline 0.155 & 0.22 & 0.128 & -0.07 & 0.082 & 0.05 \\
\hline 0.200 & 0.25 & 0.184 & -0.10 & 0.118 & 0.03 \\
\hline 0.250 & 0.28 & 0.250 & -0.12 & 0.160 & 0.00 \\
\hline 0.307 & 0.30 & 0.327 & -0.14 & 0.209 & -0.03 \\
\hline 0.369 & 0.33 & 0.413 & -0.16 & 0.265 & -0.06 \\
\hline 0.436 & 0.35 & 0.509 & -0.17 & 0.327 & -0.10 \\
\hline 0.509 & 0.37 & 0.616 & -0.18 & 0.395 & .0 .15 \\
\hline 0.588 & 0.39 & 0.732 & -0.19 & 0.470 & -0.19 \\
\hline 0.673 & 0.41 & 0.858 & -0.19 & 0.551 & -0.24 \\
\hline 0.762 & 0.43 & 0.994 & -0.20 & 0.638 & -0.28 \\
\hline 0.858 & 0.45 & 1.139 & -0.20 & 0.732 & -0.32 \\
\hline 1.169 & 0.51 & 1.424 & -0.21 & 1.008 & -0.43 \\
\hline 1.526 & 0.56 & 1.740 & -0.22 & 1.326 & -0.51 \\
\hline 1.929 & 0.62 & 2.086 & -0.23 & 1.686 & -0.58 \\
\hline 2.375 & 0.68 & 2.461 & -0.24 & 2.086 & -0.65 \\
\hline 2.865 & 0.74 & 2.865 & -0.24 & 2.527 & -0.69 \\
\hline 3.395 & 0.79 & 3.296 & -0.25 & 3.005 & -0.74 \\
\hline 3.966 & 0.85 & 3.754 & -0.26 & 3.521 & -0.77 \\
\hline 4.575 & 0.91 & 4.238 & -0.26 & 4.074 & -0.80 \\
\hline 5.221 & 0.97 & 4.747 & -0.27 & 4.661 & -0.82 \\
\hline
\end{tabular}


TABLE A16. - Density of Shell Enordet LXS-1314 in water at $25^{\circ} \mathrm{C}$

\begin{tabular}{lcc}
\hline$\%$ Active & Density, $\mathrm{g} \mathrm{mL}^{-1}$ & $\mathrm{~V}_{\phi} \mathrm{mL} \mathrm{mol}^{-1}$ \\
\hline 0 & 0.9971 & - \\
0.0992 & 0.9970 & 517 \\
0.2382 & 0.9970 & 489 \\
0.5024 & 0.9972 & 480 \\
0.7520 & 0.9966 & 501 \\
1.0045 & 0.9969 & 479 \\
1.9957 & 0.9971 & 469 \\
3.0063 & 0.9977 & 460 \\
3.9892 & 0.9981 & 458 \\
\hline
\end{tabular}

Least squares fit: $d=0.9969+0.000264 \%$.

TABLE A17. - Density of Shell Enordet LXS-1314 in brine at $25^{\circ} \mathrm{C}$

\begin{tabular}{lcc}
\hline$\%$ Active & Density, g mL-1 & $\mathrm{V}_{\phi}, \mathrm{mL} \mathrm{mol}^{-1}$ \\
\hline 0 & 1.0054 & - \\
0.1041 & 1.0054 & 465 \\
0.2471 & 1.0055 & 447 \\
0.4415 & 1.0056 & 445 \\
0.7386 & 1.0056 & 453 \\
0.9944 & 1.0056 & 456 \\
2.023 & 1.0057 & 459 \\
3.049 & 1.0058 & 459 \\
4.0437 & 1.0061 & 457 \\
\hline
\end{tabular}

Least squares fit: $d=1.0054+0.000146 \%$. 
TABLE A18. - Density of mixture in brine at $25^{\circ} \mathrm{C}$

\begin{tabular}{lcc}
\hline$\%$ Active & Density, g mL-1 & $\mathrm{V}_{\phi}, \mathrm{mL} \mathrm{mol}^{-1}$ \\
\hline 0 & 1.0054 & - \\
0.0985 & 1.0055 & 456 \\
0.2496 & 1.0056 & 467 \\
0.5003 & 1.0058 & 467 \\
0.7483 & 1.0059 & 473 \\
0.9947 & 1.006 & 477 \\
2.0086 & 1.0065 & 480 \\
3.8641 & 1.0069 & 488 \\
4.0000 & 1.0073 & 483 \\
\hline
\end{tabular}

Least squares fit: $d=1.0055+0.000414 \%$. 

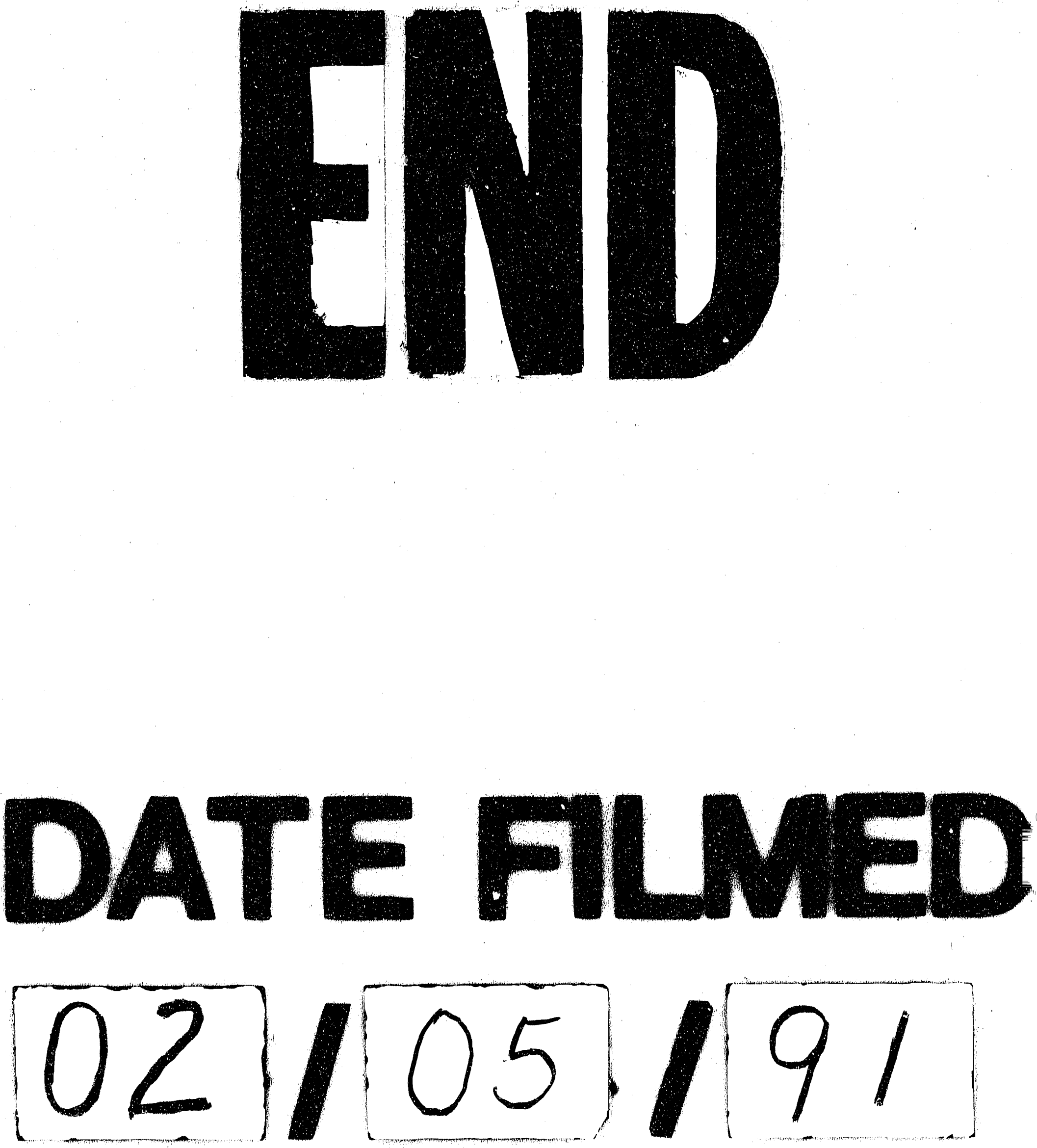
